\title{
A Critical Review of Experimental Investigations about Convective Heat Transfer Characteristics of Nanofluids under Turbulent and Laminar Regimes with a Focus on the Experimental Setup
}

\author{
Gianpiero Colangelo $^{1, *(\mathbb{D}}$, Noemi Francesca Diamante ${ }^{1}$, Marco Milanese $^{1}$ (D), Giuseppe Starace ${ }^{2}$ (D) \\ and Arturo de Risi ${ }^{1}$ (D) \\ 1 Department of Engineering for Innovation, University of Salento, 73100 Lecce, LE, Italy; \\ noemifrancesca.diamante@studenti.unisalento.it (N.F.D.); marco.milanese@unisalento.it (M.M.); \\ arturo.derisi@unisalento.it (A.d.R.) \\ 2 Department of Management, Finance and Technology, University LUM, 70010 Casamassima, BA, Italy; \\ starace@lum.it \\ * Correspondence: gianpiero.colangelo@unisalento.it
}

Citation: Colangelo, G.; Diamante, N.F.; Milanese, M.; Starace, G.; de Risi A. A Critical Review of Experimental Investigations about Convective Heat Transfer Characteristics of Nanofluids under Turbulent and Laminar Regimes with a Focus on the Experimental Setup. Energies 2021, 14, 6004. https://doi.org/10.3390/ en14186004

Academic Editors: Arash Karimipour and Annunziata D'Orazio

Received: 15 June 2021

Accepted: 16 September 2021

Published: 21 September 2021

Publisher's Note: MDPI stays neutral with regard to jurisdictional claims in published maps and institutional affiliations.

Copyright: (c) 2021 by the authors. Licensee MDPI, Basel, Switzerland. This article is an open access article distributed under the terms and conditions of the Creative Commons Attribution (CC BY) license (https:/ / creativecommons.org/licenses/by/ $4.0 /)$.

\begin{abstract}
In this study, several experimental investigations on the effects of nanofluids on the convective heat transfer coefficient in laminar and turbulent conditions were analyzed. The aim of this work is to provide an overview of the thermal performance achieved with the use of nanofluids in various experimental systems. This review covers both forced and natural convection phenomena, with a focus on the different experimental setups used to carry out the experimental campaigns. When possible, a comparison was performed between different experimental campaigns to provide an analysis of the possible common points and differences. A significant increase in the convective heat transfer coefficient was found by using nanofluids instead of traditional heat transfer fluids, in general, even with big data dispersion from one case to another that depended on boundary conditions and the particular experimental setup. In particular, a general trend shows that once a critic value of the Reynolds number or nanoparticle concentrations is reached, the heat transfer performance of the nanofluid decreases or has no appreciable improvement. As a research field still under development, nanofluids are expected to achieve even higher performance and their use will be crucial in many industrial and civil sectors to increase energy efficiency and, thus, mitigate the environmental impact.
\end{abstract}

Keywords: nanofluids; convective heat transfer; experimental investigation

\section{Introduction}

In recent years, it has been necessary to develop new techniques to improve the thermal performance of cooling and heating systems used in the industrial, civil, electronics, and transport sectors, in order to meet growing energy needs. Initially, to increase the convective heat transfer coefficient, the properties of the fluid were improved by changing the characteristics of the heat exchange surfaces and turbulence of the fluids involved. Due to the low thermal conductivity of conventional fluids, this method is good, but not enough to meet the actual needs. The most used heat transfer fluids, such as water, ethylene glycol, or diathermic oil, have low thermal conductivity compared to metals or metal oxides. Therefore, fluids with suspended solid metal particles are expected to have higher thermal conductivity and heat transfer properties compared to that of base fluids. The first attempts with millimeter and micrometer particles were unsuccessful, mainly because of poor suspension stability and viscosity problems. These problems were partially fixed by using a diluted suspension of nanoparticles with a diameter smaller than $100 \mathrm{~nm}$ as working fluid. This innovative fluid, nanofluid, showed improved thermal properties and exhibited good 
heat transfer capabilities, even at low nanoparticle concentrations. Experimental studies showed that experimental conditions and some parameters, such as the volume/solid weight fraction, shape, size, and material characteristics of the nanoparticles, play a very important role in convective heat transfer. The behaviors of different types of nanofluids, such as $\mathrm{Al}_{2} \mathrm{O}_{3}, \mathrm{SiO}_{2}$, or $\mathrm{CuO}$ /water nanofluids, inside circular tubes, were investigated in numerous studies [1-53], and the interest in convective heat transfer performance of nanofluids is growing, as it can been observed in the graph presented in Figure 1. The number of published works about the experimental studies using nanofluids is of high interest and the application of these heat transfer fluids in real cases is no more a far hypothesis. Starting from these experimental campaigns, it has already been observed how the presence of nanofluids significantly affects the thermal efficiency compared to that of traditional fluids. Several experimental campaigns showed that nanofluids could be used efficiently in solar systems applications $[17,49]$, in heating and cooling systems for buildings [21], automobiles [14,42], and in electronics [11,18,31].

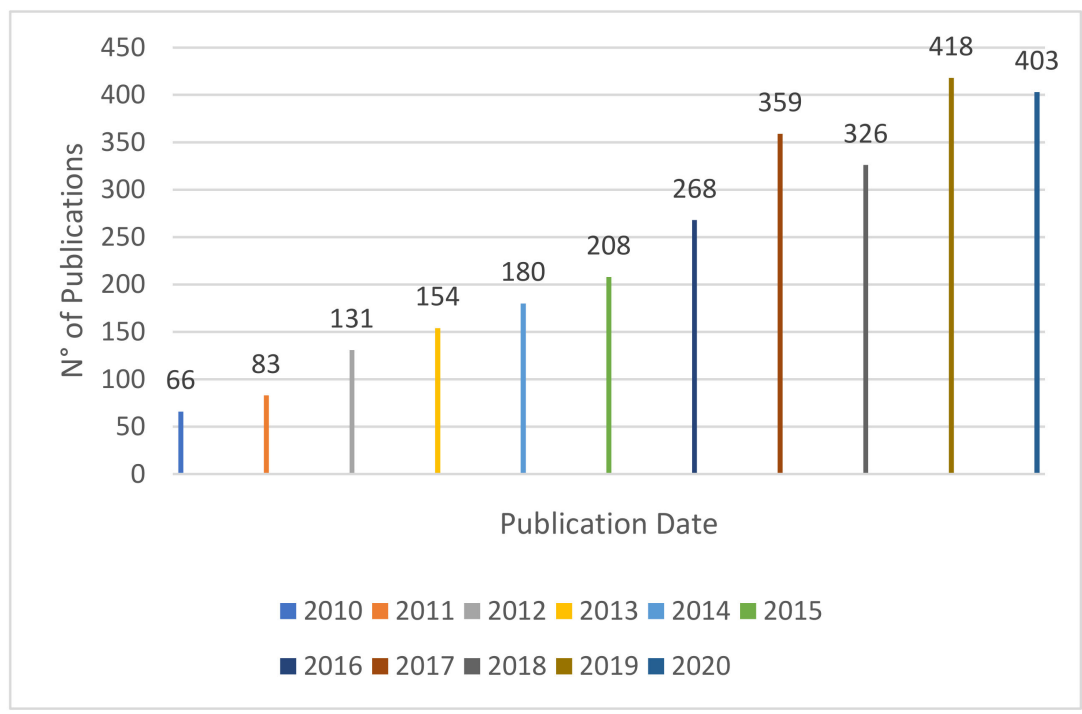

Figure 1. Number of studies published over last 10 years concerning the investigation of convective heat transfer using nanofluids. The data refer to the Scopus-indexed journals.

The intent of this study is to provide an overview of the results and progress achieved using nanofluids in various experimental systems under turbulent and laminar regimes. It also provides a comparison between the thermal performance of different studies with the same Reynolds number and experimental system. Particular attention is paid to the increase in convective heat transfer coefficient and its dependence on the Reynolds number, nanoparticle concentrations, and experimental boundary conditions. Even if there are many literature surveys on nanofluids, this work was born, bearing in mind the need to focus on the different experimental setups used by different scientists to obtain their results. Its scope is to provide the reader with the opportunity to understand which configuration could be optimal for a specific experimental campaign. Each experimental setup or layout has its pros and cons and, in a certain measure, influences the obtained results, as this work explores.

\section{Experimental Measurements and Setups for Natural and Forced Convection under the Laminar Regime}

Zeinali Heris et al. [1] focused their work on convective heat transfer properties of $\mathrm{Al}_{2} \mathrm{O}_{3}$ /water nanofluid flowing in laminar conditions in a circular tube, keeping constant the inner wall temperature. The test section was made by a $1 \mathrm{~m}$ long ring-shaped tube, built of $6 \mathrm{~mm}$ inner copper tube $(0.5 \mathrm{~mm}$ thick) and $32 \mathrm{~mm}$ outer stainless-steel tube, insulated by fiberglass. Nanofluids flowed inside the inner tube and saturated steam 
flowed inside the annular section, yielding constant wall temperature boundary conditions. Ten K-type thermocouples were placed on the inner tube wall $10 \mathrm{~cm}$ apart. Two K-type thermocouples were inserted into the flow at the inlet and outlet of test section. It was used a manometer to measure pressure drop. After the test section, the fluid passed through heat exchanger, where water was used as coolant, and then entered flow-measuring section. Flow measuring section consisted of $300 \mathrm{~cm}$ glass vessel with a valve at the bottom. The mass flowrate was measured by the time spent to fill the glass vessel. After injection of nanofluid with specified concentration in the reservoir tank, the pump and the cooling system started. At this moment, the steam line opened to increase the tube wall temperature, and after $30 \mathrm{~min}$, the system reached steady state conditions. The flowrate was adjusted using a valve on the reflux line and the tests were repeated at least 14 times for each concentration. The tests revealed that the increase in heat transfer coefficient due to nanoparticles was much higher than the prediction of single-phase heat transfer correlation used with nanoparticle properties.

Hwang et al. [2] studied the convective heat transfer coefficient of water-based $\mathrm{Al}_{2} \mathrm{O}_{3}$ nanofluids flowing inside a circular tube, which was heated uniformly, in a fully developed laminar flow regime. The experimental setup consisted of a test section (a straight stainlesssteel tube with $1.812 \mathrm{~mm}$ inner diameter and $2500 \mathrm{~mm}$ long), a reservoir tank, a cooler, and a pump. The tube surface was electrically heated, uniformly, by an AC power supply, to yield a constant heat flux. It was thermally insulated by a $150 \mathrm{~mm}$ thick cover, to minimize the heat loss from the tube to the surroundings. Five T-type thermocouples were placed along the test section and a T-type thermocouple at the inlet. A pump controlled the flow rate of the fluid. To preserve a constant temperature at the inlet of the test section, the heated fluid returned to the reservoir tank passing through a chiller.

Water-based $\mathrm{Al}_{2} \mathrm{O}_{3}$ nanofluids with various volume fractions ranging from $0.01 \%$ to $0.3 \%$ were obtained by a two-step method. The heat capacity of water-based nanofluids was measured and was similar to that of water. The enhancement of convective heat transfer coefficient in nanofluids was much higher than that of thermal conductivity. Besides the enhancement of thermal conductivity did not significantly affect the enhancement of convective heat transfer coefficient.

Ho et al. [3] investigated the performance of a forced convective flow of the $\mathrm{Al}_{2} \mathrm{O}_{3}$ /water nanofluid as a coolant in a copper microchannel heat sink. The nanofluid started the circuit from a reservoir tank and it was circulated by a gear pump, keeping constant the flowrate. A thermal bath, installed before the test section, maintained the inlet flow temperature at a constant level. After the test section, the nanofluid passed through another thermal bath and then returned to the reservoir to close the cycle. A volumetric flowmeter monitored the nanofluid flowrate inside the circuit, while the test section consisted of a microchannel heat sink, housing, a cover plate, and two plate heaters. The heat sink was made by 24 parallel rectangular microchannels inserted into an oxygen free copper block. The microchannels were spaced with a fin width of $300 \mu \mathrm{m}$ and each one had a length of $50 \mathrm{~mm}$ (cross-section $283 \mu \mathrm{m} \times 800 \mu \mathrm{m}$ ). Two T-type thermocouples and pressure sensors were placed at the ends of the microchannels to measure the temperature rise and pressure drop through the microchannel heat sink (Figure 2). Six T-type thermocouples were placed in six holes, drilled along the centerline of the base of the heat sink, to measure the temperature at a distance of $6 \mathrm{~mm}$ below the base surfaces of the microchannels. A guard heater was installed parallel to the rear surface of the main heater, to ensure a negligible temperature gradient between the two heaters. A visible increase in the convective heat transfer coefficient was found for the heat sink cooled by the nanofluid. For the highest flow rate, for the nanofluid at $1 \mathrm{vol} \%$ of particle concentration, the convective heat transfer coefficient increased by $70 \%$, compared to the one of pure water. 


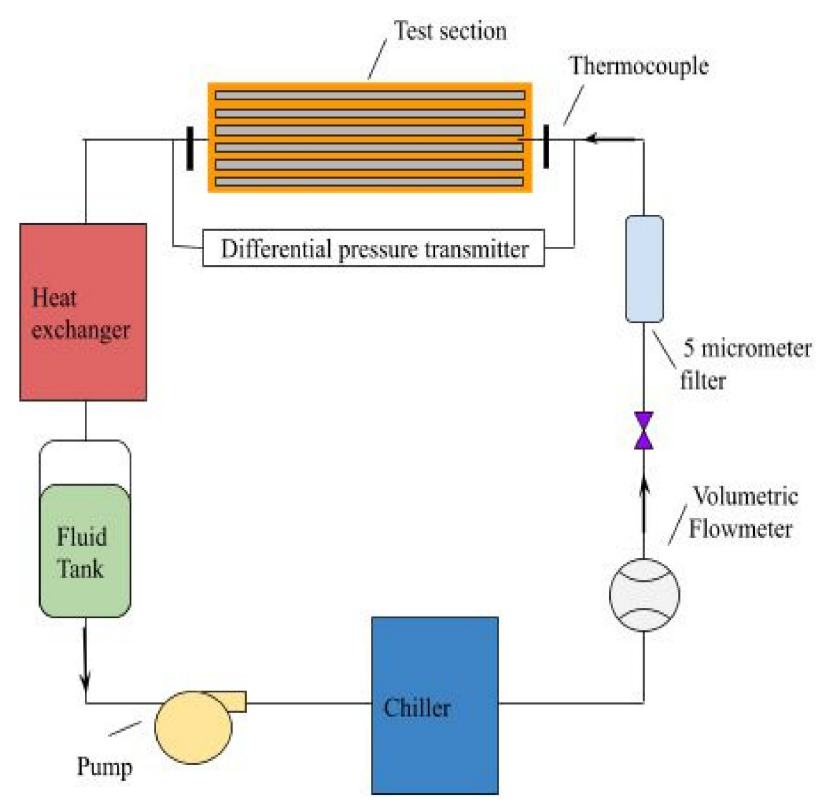

Figure 2. Schematic of the experimental system of the work by Ho et al. [3].

Ho et al. [4] conducted a study on the natural convection of a nanofluid in vertical square enclosures of different sizes. The experimental setup consisted of the test section, electrical heaters, insulation material to limit heat dispersion, nanofluid, electric power supply, thermocouples, and a data acquisition system. The dimensions of the three test sections of this work were $25 \times 25 \times 60 \mathrm{~mm}, 40 \times 40 \times 90 \mathrm{~mm}$, and $80 \times 80 \times 180 \mathrm{~mm}$. The three test sections were heated by two sides, while the other walls were insulated to limit the thermal dispersions. The hot and cold walls were made of copper plates while the others of acrylic material. A nichrome flat wire foil electric heater was used to heat the walls, while the cold wall was made with channels inside, where the thermoregulatory fluid circulated after being treated by a thermal bath. All external surfaces of the test rig were insulated by Styrofoam ( $40 \mathrm{~mm}$ thick) in order to limit heat losses. T-type thermocouples were used at different places along the length and depth directions to register the temperature. The temperature data were processed and recorded by a data acquisition system. The constant temperature conditions were kept on the hot and cold walls and continuously monitored. In the smallest cell, the nanofluid with a particle concentration higher than $0.1 \mathrm{vol} \%$ attained lower and lower heat transfer coefficient by increasing particle concentration. A reduction of the heat transfer coefficient higher than $20 \%$ was observed for nanofluid of $4 \mathrm{vol} \%$ within the cell with a temperature difference of $2^{\circ} \mathrm{C}$. The nanofluid with concentration higher than $2 \mathrm{vol} \%$ showed the same trend, but with a decreased magnitude by increasing temperature differences across the cell. For nanofluid of $0.1 \mathrm{vol} \%$, a heat transfer enhancement of approximately $18 \%$ greater than that of the base fluid for the larger case can be distinguished.

Chandrasekar et al. [5] studied convective heat transfer characteristics of $\mathrm{Al}_{2} \mathrm{O}_{3} /$ water nanofluid flowing through a uniformly heated horizontal tube, with and without coil inserts. The test loop consisted of a pump (RH-P120), calming station, heated test section, a cooling station, and a reservoir. A four-liter stainless steel vessel, equipped with a drain valve, was used as fluid reservoir. The pump pushed the fluid from the reservoir into the test circuit with a maximum flow rate of $2.55 \mathrm{~L} / \mathrm{min}$. A calming section, necessary to ensure a fully developed laminar flow in the test section, was built with a straight copper tube, with an inner diameter of $4.85 \mathrm{~mm}$, and an outer diameter of $6.3 \mathrm{~mm}$ and $800 \mathrm{~mm}$ long. A straight copper tube $(1200 \mathrm{~mm}$ length, $4.58 \mathrm{~mm}$ inner diameter, and $6.3 \mathrm{~mm}$ outer diameter) was used as a test section. The test section was electrically insulated and a nichrome SWG heating wire coated with ceramic beads, providing a maximum power of $300 \mathrm{~W}$, was wrapped on it. Above the electrical winding, a thick insulation of layers of 
ceramic fibers was installed together with asbestos rope, glass wool, and other layers of asbestos rope on the outer surface to limit heat dispersions outside. The test section was insulated by using plastic bushings. RTD PT 100 sensors were placed along the test section to measure wall temperature and inlet/outlet temperature. A differential pressure sensor was installed across the test section to measure pressure drop. After passing through the heater, the fluid flowed through a riser section and then passed through the cooling unit (air heat exchanger) and was collected in the tank at the end. Wire coil inserts were made by using $0.5 \mathrm{~mm}$ stainless steel wires with a coil diameter of $4.5 \mathrm{~mm}$ and coil pitch ratios of 2 and 3. Results showed a $12.24 \%$ increase in the Nusselt number for nanofluid $0.1 \mathrm{vol} \%$ at $\operatorname{Re}=2275$ compared to that of water. Further enhancements in the Nusselt numbers were observed at all Reynolds numbers using wire coil insert, in particular, there was an increase of $21.53 \%$ and $15.91 \%$ using inserts with a coil pitch ratio of 3 and 2 at $\operatorname{Re}=2275$, respectively.

Mansour et al. [6] carried out an experimental investigation to study the mixed convection of $\mathrm{Al}_{2} \mathrm{O}_{3}$ /water nanofluid inside an inclined copper tube, subjected to a uniform heat flux of the wall on its external surface. In the experimental system, the tank containing the working fluid was placed at a constant level above the heated section, made of a copper tube with an internal diameter of $6.35 \mathrm{~mm}$ and $2.24 \mathrm{~m}$ long. A large part of it $(\mathrm{L}=200 \mathrm{D})$ was heated by a constant and uniform heat flux, yielded by a standard flat-ribbon-type electrical resistance (Omega Engineering Inc., Norwalk, CT, USA, 2 m long, 12 mm wide). This resistance was placed on the outer surface of the tube at a constant pitch. Both tube and resistance were insulated by a thick layer $(2 \mathrm{~cm})$ of fiberglass to prevent heat losses. To create the ideal boundary conditions, two adiabatic sections, the inlet and outlet of the test section, were provided. After traversing the test tube, the fluid passed through a valve and was collected into the second lower reservoir. Finally, a magnetic driven centrifugal pump (model MD-20RZ) pushed the fluid from the second tank towards a spiral heat exchanger, where the heat was transferred to a source of cold water at a constant temperature. To measure wall temperature of the outer surface of the tube, 14 T-type thermocouples were placed along the heat section, and four J-type thermocouples in the two adiabatic sections. To measure fluid temperature, two T-type thermocouples were fixed at the inlet/outlet of the tube. Three J-type thermocouples were installed in the insulation material to control heat loss to ambient air. For the experiments, two different inclinations for the tube $\left(\alpha=0-90^{\circ}\right)$ and power supply between 190 and $420 \mathrm{~W}$ were considered.

The results showed that, for a horizontal tube $\left(\alpha=0^{\circ}\right)$, the Nusselt number decreased as the volume concentration increased. For example, at $\operatorname{Re}=500$, considering the particle volume fraction increasing from $0 \%$ to $4 \%$, the Nusselt number decreased from 7.24 to 6.25 , a decrease of approximately $14 \%$. For a vertical tube $\left(\alpha=90^{\circ}\right)$, the Nusselt number decreased with the increasing of the Reynolds number. This behavior was observed for the two particles volume fractions ( $0 \%$ and $4 \%)$.

Saeedinia et al. [7] studied the convective heat transfer phenomenon of the $\mathrm{CuO} / \mathrm{base}$ oil nanofluid in laminar flow conditions inside a smooth tube using different wire coil inserts and subjected to a constant and uniform heat flux. The flow circuit was made by a measuring section, a reservoir, a pump, a cooler, a flow measuring system, a flowcontrolling unit, thermocouples, and a differential pressure sensor. The fluid leaving the test section entered the flow measuring apparatus, partially cooled in the reservoir, then pumped through a cooler, where water was used as coolant and entered the test section again. A copper tube of $14 \mathrm{~mm}$ of inner diameter, $15.8 \mathrm{~mm}$ of outer diameter, and $1200 \mathrm{~mm}$ long was employed as the test section. Wire coil tubes, made of stainless steel, were inserted, and used as horizontal test sections, as shown in Figure 3. The experiments were carried out for plain tube and five different wire coil tubes (T1, T2, T3, T4, and T5). The dimensions of the wire coil tubes are shown in Figure 4, and their geometrical parameters are reported in Table 1. The nanofluid flowing inside the test section was heated by an electrical heating coil wrapped around it. The heater wire was wrapped with high burning resistant silicone rubber, to be electrically insulated from the test section. Two RTDs PT 100 types were used 
to measure, at the inlet and outlet, temperature of the fluid. Six K-type thermocouples were installed at equal axial distance $(143 \mathrm{~mm})$ on the outer surface of the test sections, to measure the wall temperature. In order to circulate oil, a gear pump with $1 \mathrm{HP}$ power, connected to a phase electromotor, was used. The flow measurement section consisted of a $300 \mathrm{~cm}^{3}$ glass vessel with a valve at the bottom. The flow rate was measured by the time required to fill the glass vessel.

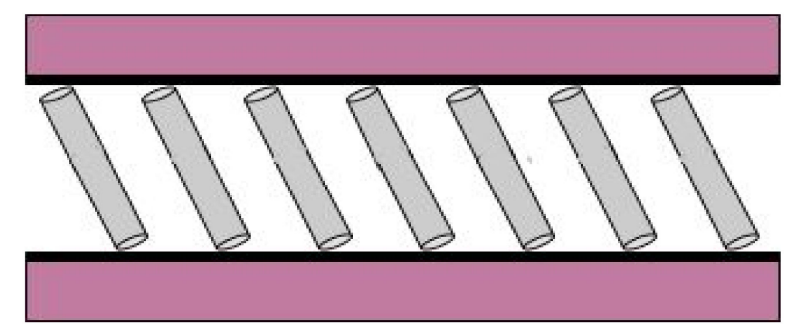

Figure 3. Test section with wire coil insert of the work by Saeedinia et al. [7].



Figure 4. Representation of geometric dimension of wire coil tubes.

Table 1. Geometrical parameters of plain and wire coil tubes ( $\mathrm{mm})$.

\begin{tabular}{cccc}
\hline Tube Set & $\mathbf{d} \mathbf{( \mathbf { m m } )}$ & $\mathbf{p}(\mathbf{m m})$ & $\mathbf{s}(\mathbf{m m})$ \\
\hline T1 & 14 & 30 & 0.9 \\
T2 & 14 & 35 & 1.2 \\
T3 & 14 & 30 & 1.5 \\
T4 & 14 & 30 & 1.2 \\
T5 & 14 & 25 & 1.2 \\
Plain & 14 & - & - \\
\hline
\end{tabular}

The obtained results showed that the convective heat transfer coefficient of nanofluid enhanced compared to pure oil. As the heat flux increased, the heat transfer coefficient increases for both pure oil and nanofluid. The wire coil inserts increased the Nusselt number at all Reynolds numbers in the laminar flow. The maximum rate of heat transfer was obtained for the wire coil with the highest wire diameter (WC3). The Nusselt number increased by $25.6 \%$ and $21.7 \%$ for the nanofluid with $0.15 \mathrm{vol} \%$ concentration flowing in tube sets WC3 and WC5 at the same Reynolds number of 90, compared to one of the same nanofluid flows in the plain tube. The same behavior was observed for all nanoparticle concentrations.

Suresh et al. studied the laminar heat transfer and friction characteristics of dilute $\mathrm{Al}_{2} \mathrm{O}_{3}-\mathrm{Cu}$ /water hybrid nanofluid at $0.1 \mathrm{vol} \%$ through a circular tube, under constant heat flux boundary condition. The experimental setup consisted of a calming section, test section, pump, cooling unit, and a fluid reservoir. The calming section was made of straight copper tube with the dimensions of $1000 \mathrm{~mm}$ in length, $10 \mathrm{~mm}$ inner diameter, and $12 \mathrm{~mm}$ outer diameter. The test section was wound with ceramic beads coated electrical SWG 
nichrome heating wire of electric resistance $120 \Omega$. To minimize heat loss, a glass wool was used on the electrical winding. The terminals of the nichrome wire were attached to an autotransformer. Calibrated RTD PT 100 type sensors, of $0.1^{\circ} \mathrm{C}$ accuracy, were used to measure the entry and exit temperature of the fluids and the outside wall temperature. The fluid after passing through the heated section flowed through a riser section and then through the cooling unit, which was an air-cooled heat exchanger. Finally, the fluid was collected in the reservoir, which consisted of a plastic container of 51 capacity. A peristaltic pump was used to circulate the fluid through the circuit. The experimental results showed that the nanoparticles suspended in water increased the Nusselt number even for a very low volume concentration of $0.1 \%$.

Heyhat et al. [9] carried out an investigation on a convective heat transfer coefficient in a fully developed flow regime. The experimental setup consisted of a reservoir tank, a pump, a needle valve to regulate the flow rate of the fluid, a cooling unit, a test section, a flowmeter, and a pressure drop sensor. The test section consisted of a steam bath crossed by a tube, made by copper, with an in diameter of $5 \mathrm{~mm}$ and $2 \mathrm{~m}$ length. Four electrical heaters (submerged in water) generated the steam at atmospheric pressure. The tank had a small hole that allowed the steam to go out when the heaters were on, to ensure atmospheric pressure. Ten K-type thermocouples were placed on the copper tube wall to measure the wall temperature. Two K-type thermocouples measured the fluid's temperature at the inlet and outlet of the test section. First, the flow passed through a $50 \mathrm{~cm}$ long horizontal insulated copper tube to ensure the fully developed hydrodynamic conditions at the entrance of the test section. The cooling unit included a shell and tube heat exchanger, to control the temperature of the nanofluid. The pressure drop was measured by a differential pressure sensor.

The flowrate was calculated by determining the time required to fill a certain volume. This was typically repeated three times using a precise measuring vessel and a timer. The results showed that the heat transfer coefficient increased by increasing the Reynolds number and increasing the volume concentration. The heat transfer coefficient of $\mathrm{Al}_{2} \mathrm{O}_{3} /$ water at $2 \%$ of volume concentration increased by $32 \%$.

Hashemi et al. [10] carried out an investigation to study the heat transfer and pressure drop of nanofluid flow inside a horizontal helical tube subjected to a constant heat flux. The experimental system consisted of a helical coil with 4 turns and a $14.37 \mathrm{~mm}$ inner diameter, while walls thickness was $0.75 \mathrm{~mm}$. The coil was formed from an initially straight tube of copper. It had a length of $4.073 \mathrm{~m}$, an outer diameter of $324 \mathrm{~mm}$, and a pitch of $55 \mathrm{~mm}$. The nanofluid flowing inside the test section was heated by an electric coil resistance wrapped around, able to yield constant heat flux. Nanofluids were prepared by dispersing $\mathrm{CuO}$ nanoparticles in oil by using an ultrasonic probe (power $400 \mathrm{~W} @ 24 \mathrm{kHz}$ ). The convective heat transfer and pressure drop performance of oil-based $\mathrm{CuO}$ nanofluids flowing inside the straight and helical tubes were investigated experimentally in laminar flow conditions, under constant heat flux. A higher convective heat transfer coefficient was observed for higher weight concentrations of the nanofluids. It was observed that nanofluids have better heat transfer performance when they flow inside a helical tube instead of flowing in a straight tube. In fact, at the same range of the Reynolds number between 10 and 100, a maximum enhancement of $18.7 \%$ in heat transfer coefficient is obtained for the straight tube, while the increase of $30.4 \%$ is obtained for the helical tube.

Kalteh et al. [11] studied heat transfer characteristics for $\mathrm{Al}_{2} \mathrm{O}_{3}$-water nanofluid flowing inside a rectangular microchannel heat sink, for a different Reynolds numbers in an open loop and a constant heat flux. The experimental setup consisted of a fluid tank, pump, test section, collecting container, and a data acquisition system. The pump pushed the working fluid, contained into the reservoir, through a valve and test section until it reached the collecting container. The test section consisted of a microchannel made of silicon wafer $650 \mathrm{~mm}$ thick, which was attached, by using glue, on top of four thin glass stripes with $580 \mathrm{~mm}$ thickness. A layer, made of a $3 \mathrm{~mm}$ thick glass, was attached on top of the glass stripes to form a closed space for fluid flow. The final dimension for the test 
section corresponded to a length of $94.3 \mathrm{~mm}$, a width of $28.1 \mathrm{~mm}$, and a height of $580 \mathrm{~mm}$. A schematic diagram of the test section is shown below in Figure 5.

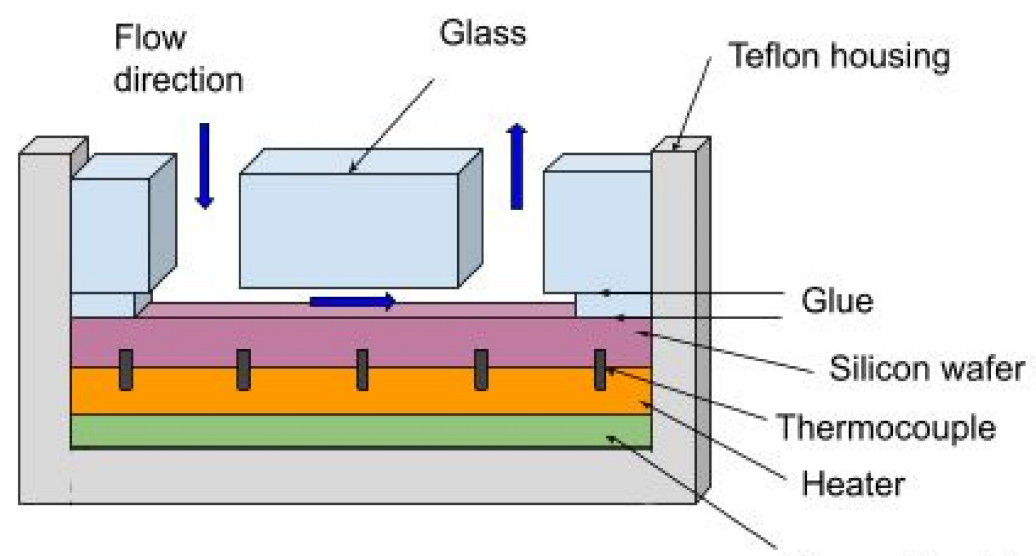

Thermal insulator

Figure 5. Schematic drawing of the test section of the work by Kalteh et al. [11].

A self-electrically-insulated heater (203 mm thick), driven by a DC power supply, was placed at the bottom of silicon wafer to simulate the power yielded by an electronic device. The test section was insulated by using Teflon housing with a thermal insulation layer attached at its bottom. Between the silicon wafer and the heater, five equally spaced T-type thermocouples with $0.13 \mathrm{~mm}$ diameters were placed to measure wall temperature. Moreover, the fluid inlet and outlet temperatures were measured by two T-type thermocouples. For each experiment, the fluid mass flowrate was regulated by a valve and a DC power supply was held at constant voltage and current. After the flow reached a steady state condition, the fluid inlet and outlet temperature, and five wall temperatures, were recorded by a data acquisition system.

It was found that the average Nusselt number increased with an increase of the Reynolds number as well as a decrease in nanoparticle size. At $\operatorname{Re}=500$, the average Nusselt number was 8432 for pure water and it was 19.408 for 3\% nanofluid concentration. This corresponded to $130 \%$ thermal performance enhancement. For a concentration of $1 \%$ nanofluid, with 100 and $30 \mathrm{~nm}$ particle sizes inside, the average Nusselt numbers were 8669 and 15.14, respectively.

Ho et al. [12] explored the performance of $\mathrm{Al}_{2} \mathrm{O}_{3}$ /water nanofluid to replace pure water as coolant in a copper minichannel heat sink. The test module fabricated consisted mainly of a minichannel heat sink, housing, a cover plate, and two plate heaters.

The heat sink consisted of 10 parallel rectangular minichannels of length $50 \mathrm{~mm}$, with a cross-sectional area of $1 \mathrm{~mm}$ in width and $1.5 \mathrm{~mm}$ in height for each minichannel. An electric powered plate heater provided the needed heat input. A guard heater was placed parallel to the rear surface of the main heater, to ensure negligible temperature gradient between the two heaters and to limit the heat loss. The heat sink consisted of 10 parallel rectangular minichannels (length $50 \mathrm{~mm}$, cross-sectional area of $1 \times 1.5 \mathrm{~mm}$ ). The inlet and outlet pendulums were installed at two ends of the minichannels, where two T-type thermocouples and pressure sensors were installed to measure pressure drop and temperature rise across the heat sink. Seven T-type thermocouples were placed $3 \mathrm{~mm}$ below the base surfaces of minichannels along the centerline. All measured quantities were logged by a data acquisition system.

They found good enhancements in the average heat coefficient for the heat sink cooled by the nanofluid. The cooling performance by using the nanofluid seemed to increase with the flow rate.

Hu et al. [13] experimentally studied the heat transfer coefficient, for natural convection, and characteristics of the $\mathrm{Al}_{2} \mathrm{O}_{3}$-water nanofluid in a square enclosure for different volume concentrations, with different Rayleigh numbers ( $\mathrm{Ra}=30,855,746$ and $\mathrm{Ra}=63,943,592$ 
for $0.25 \mathrm{vol} \%$; $\mathrm{Ra}=38,801,494$ and $\mathrm{Ra}=67,175,834$ for $0.5 \mathrm{vol} \%$; $\mathrm{Ra}=55,888,498$ and $\mathrm{Ra}=70,513,049$ for $0.77 \mathrm{vol} \%$ ).

The experimental setup included a heating system (silica gel heater and DC power), cooling system (constant temperature water bath), experimental system (enclosure), measuring system (data acquisition instrument, computer, thermocouples, and heat flow meter), and insulating system (adiabatic nano-board). The fluid was contained by the enclosure, which was $180 \mathrm{~mm}$ long, $80 \mathrm{~mm}$ thick, and $80 \mathrm{~mm}$ high. The left wall was heated by a silica water gel heater, and the right wall was cooled by a constant temperature water bath. Ten T-type thermocouples were mounted on the left and right walls to measure the wall temperature. All the data were recorded by a data acquisition system (Agilent 34972A). The heated power of the silica gel heater was provided by the DC power supply. The flow and temperature of the nanofluid in the enclosure reached a balance when the wall temperatures did not change. The heat transfer coefficient of nanofluid was higher than that of pure water at lower nanoparticle volume fraction $(0.25 \mathrm{vol} \%)$, it was almost the same at $0.5 \mathrm{vol} \%$ and decreased at $0.77 \mathrm{vol} \%$.

Hussein et al. [14] conducted a study on forced convective heat transfer coefficient of $\mathrm{SiO}_{2}$-water based nanofluid in a car radiator. Experiments were performed for four different concentrations of nanofluids $(1,1.5,2.0$, and 2.5$)$ at a base temperature of $25{ }^{\circ} \mathrm{C}$, with flow rates in the range of 2-8 LPM and Reynolds number between 500 and 1750. The experimental setup included a reservoir plastic tank, electrical heater, a centrifugal pump, a flow meter, tubes, valves, a fan, a DC power supply, T-type thermocouples, and a manometer tube with mercury and heat exchanger (automobile radiator). In order to heat the fluid, an electrical heater $(1500 \mathrm{~W})$ inside a tank $(40 \mathrm{~cm}$ height and $30 \mathrm{~cm}$ diameter) was used. A voltage regulator $(0-220 \mathrm{~V})$ provided the power to keep the inlet temperature to the radiator from 60 to $80{ }^{\circ} \mathrm{C}$. A flow meter (0-70 LPM) and two valves were used to measure and control the flow rate. A centrifugal pump ( $0.5 \mathrm{hp}$ and $3 \mathrm{~m} \mathrm{head})$ was used to push the fluid through plastic tubes $(0.5 \mathrm{in})$ from the tank to the radiator at the considered flowrate. Two T-type thermocouples were placed on the flow line to measure the inlet and outlet temperature. Eight T-type thermocouples were fixed to the radiator surface, two in front of the fan and another side of the radiator to measure air temperature. Two small plastic tubes with 0.25 in diameter were connected to the inlet and outlet radiator and joined to the U-tube manometer to measure the pressure drop. The car radiator consisted of laminated fins and 32 flat vertical copper pipes with flat cross section. The space between the rows of tubes were filled with thin perpendicular copper fins. For the air side, near the radiator axis line, an axial fan (1500 rpm) was installed, driven by a DC power supply. The Nusselt number increased with the increase of the Reynolds number and nanofluid volume concentration. The values of the Nusselt number were 17.8, 21, and 25 at the inlet temperature of 60,70 , and $80^{\circ} \mathrm{C}$, respectively. The outlet temperature increased by increasing the flowrate and decreasing the volume concentration of nanofluid. It was observed that the heat transfer enhancement increased with the increase of nanofluid volume concentration and inlet temperature, respectively. At $80^{\circ} \mathrm{C}$, the Nusselt number of $1 \% \mathrm{SiO}_{2}$ nanofluid was $52 \%$ higher than that of water, but it was $32 \%$ at $60{ }^{\circ} \mathrm{C}$. The results proved that $\mathrm{SiO}_{2}$ nanofluid had high potential for hydrodynamic flow and heat transfer enhancement.

Derakhsham et al. [15] studied the mixed convection heat transfer characteristics of the multi-walled carbon nanotube (MWCNT) heat transfer oil based nanofluid inside the smooth and microfin tubes. The tubes were subjected to uniform wall heat flux over the outer surface, which were produced by an electrical coil heater. Experiments were carried out using MWCNT/Oil mixtures with particles of average diameters of $36 \mathrm{~nm}$. The data were acquired for the power supply range of 200-600 W and the particle weight fraction range of $0-0.2 \%$.

The working fluid flowed through a water cooler and entered the heated section. Two tubes were tested: a smooth tube with an outer diameter of $9.525 \mathrm{~mm}$ and an inner diameter of $9.025 \mathrm{~mm}$ and a microfin tube with an outer diameter of $9.52 \mathrm{~mm}, 55$ fins 
with a helix angle of $15^{\circ}$. The nanofluid flowing inside the tube was heated by an electric heated coil with maximum electrical power of $2 \mathrm{~kW}$. In order to reduce the heat losses, two layers of fiberglass ( $2 \mathrm{~cm}$ thick) insulation were wrapped around the heated section. A precise potentiometer was used to adjust the output voltage supplied to the resistance. RTD PT 100 sensors were used to measure the bulk inlet and outlet temperatures. The outside wall temperatures were measured at six axial locations. At each location, three T-type thermocouples were placed at top, side and bottom positions. Furthermore, six T-type thermocouples were installed at equal distances on the tube surface. For both tubes (plain and microfin), the corresponding axial positions of the thermocouples were 150, $300,450,600,750$, and $900 \mathrm{~mm}$ from the inlet of the test section. The flow left the test section and then reached the reservoir. A copper coil was located inside the reservoir to cool the working fluid, which was necessary to keep the inlet temperature the same among different tests. A bypass valve was used to guide a part of the flow into the reservoir without flowing through the test section. A stand was used to change the inclination of the tube. It was found that a higher particle weight concentration induced an augmentation of the Nusselt number in both horizontal and vertical flows. Nusselt number was higher in the horizontal tube than the vertical one. The Nusselt number enhancement was about $10 \%$ by increasing nanoparticle concentration up to $0.2 \mathrm{wt} \%$ in horizontal plain tube for Re up to 150 . The heat transfer coefficient increased when microfin was used instead of plain tube. The maximum enhancement of the Nusselt number was $15 \%$ in the horizontal microfin tube at $0.2 \%$ nanoparticle concentration with a power supply of $600 \mathrm{~W}$ and $\mathrm{Ri}=10$.

Barzegarian et al. [16] carried out an experimental investigation on the effects of using $\mathrm{TiO}_{2}$ /water nanofluid on heat transfer enhancement in a Brazed Plate Heat Exchanger (BPHE) used in a domestic hot water system. The experimental setup included a hot flow closed loop and a cold open loop. The $\mathrm{TiO}_{2} /$ water nanofluid was used as hot fluid. The setup consisted of a brazed plate exchanger as a test section (Figure 6), two centrifugal pumps, digital thermometer, two rotameters, electronic thermostat, two $1.5 \mathrm{kw}$ electric heaters, four K-type thermocouples, differential pressure transducer, two reservoir tanks, and two drain containers. The heat exchanger, pipes, valves, and fittings were insulated. To measure the hot and cold fluid flow rates two rotameters, that were calibrated by measuring the volume of water discharged in drain containers during a specified period, were used. Four K-type thermocouples were used to measure the fluid temperature at the inlet and outlet of the test section. To maintain constant the hot fluid temperature an electronic thermostat and a PT100 type thermocouple were used. A differential pressure transducer was used to measure the hot fluid pressure drop in heat exchanger. Two $1.5 \mathrm{~kW}$ electric heaters were used to supply the thermal energy of hot water tank. For the cold flow loop, tap water was used with its temperature almost constant during the experiment. Results indicated that the convective heat transfer coefficient increased with the enhancement of the Reynolds number, and at a certain Reynolds number, the convective heat coefficient increased by increasing the nanoparticle weight fraction. The maximum enhancements of the convective heat transfer coefficients at $0.3 \%, 0.8 \%$, and $1.5 \mathrm{wt} \%$ were approximately $6.6 \%, 13.5 \%$, and $23.7 \%$, respectively.

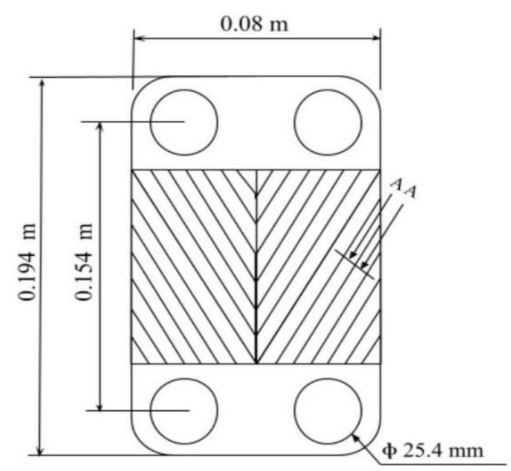

Figure 6. Schematic diagram of heat exchanger plate with a chevron angle of $45^{\circ}$. 
Ebrahimnia-Bajestan et al. [17] developed an experimental study on the heat transfer performance of heat exchangers in solar system with $\mathrm{TiO}_{2}$ / water nanofluid flowing through a uniformly heated tube. For experimental tests, a horizontal straight copper tube $2 \mathrm{~m}$ long with an inner diameter of $7.8 \mathrm{~mm}$ and an outer diameter of $9.6 \mathrm{~mm}$ was used as test section. The tube was heated by a silicon rubber heater capable of $313 \mathrm{~W}$ of power, which was connected to a DC power supply. In order to achieve a constant and uniform heat flux condition along the test section, the heater was wrapped in five layers of heat insulating materials and, to further reduce heat loss, it was thermally isolated by a layer of $2 \mathrm{~cm}$ thick foam. Two sight glass tubes, with inner diameters equal to that of the test section, were mounted before and after the test section to visualize the nanofluid flow and its possible sedimentation. The nanofluid flow rate was regulated by adjusting the rotation speed of the magnetic gear pump. Ten T-type thermocouples were installed along the tube surface to test the wall temperature and, furthermore, two T-type thermocouples were inserted into the flow at the inlet and outlet of the test section to measure nanofluid bulk temperature.

Test results indicated that the heat transfer coefficient increased with nanoparticle concentrations and the Reynolds number and reached maximum values at median Reynolds numbers. For example, at $\operatorname{Re}=940$ with 2.3 vol\% nanofluid, a maximum enhancement in the average heat transfer coefficient of $21 \%$ was obtained. It was also seen that increasing the diameter of the nanoparticles decreased the convective exchange coefficient, even though less significantly at high concentrations. Heat transfer characteristics of nanofluids using a mixture of water and ethylene glycol as base fluid were examined. It was concluded that a higher heat transfer coefficient enhancement was obtained for ethylene glycol based nanofluid than water-based nanofluid at Reynolds numbers greater than 1000 and nanoparticle volume concentration less than $2 \%$. For the other values, the performance of the water-based fluid was better.

Arshad et al. [18] investigated heat transfer characteristics of $\mathrm{TiO}_{2}$, used as a coolant, flowing through a minichannel heat sink. The experimental setup consisted of: a reservoir, two dc brushless pumps (DC30A-1230), a radiator, needle valve (HNVS4FF, Parker), heat sink, three cartridge heaters (CSH-201200/120V, Omega Engineering Inc., Norwalk, USA), dc power supply (6575A, Agilent, Santa Clara, CA, USA), K-type thermocouples (TT-KI30-1M, Omega Engineering Inc., Norwalk, USA), and data acquisition system (34972A, Agilent). The coolant, contained in the reservoir, was driven to the radiator by using the two pumps connected in parallel to preserve flowrate. Then, the coolant passed through the radiator to remove excessive heat and maintain a constant inlet temperature. A valve needle was used to control flowrate. A precise flask was used to measure coolant volume before and after the desired experimental value for $30 \mathrm{~s}$. Final flowrate corresponded to the average of these two values. At last, this coolant passed through the heat sink, to extract heat, and reduce base temperature, and returned to the reservoir to end the loop. Heat sink was made of a copper minichannel with a uniform cross section area. Heat was equally distributed by using three heaters, each of maximum $200 \mathrm{~W}$, that were installed symmetrically at the bottom of the heat sink. Required heating power was provided by dc power supply. In order to measure the inlet/outlet and base temperature, two K-type thermocouples, at entrance/exit of heat sink, and seven K-type thermocouples, equally distributed along the length of heat sink and mounted at the center of heat sink width, were used. The measurements were taken $1.5 \mathrm{~mm}$ below the wall surface of channels and all the data were recorded by a data acquisition system. To measure pressure, drop of coolant, between inlet and outlet of heat sink, a pressure transducer (DPG409-001DWU) was used.

In conclusion, it was found the Nusselt number increased as the Reynolds number increased. This enhancement decreased with the increase of heating power. Maximum enhancement corresponding to $100 \mathrm{~W}$ was observed of $12.75 \%$, while enhancement reduced to $3.51 \%$ and $2.51 \%$ in case of heating power of $125 \mathrm{~W}$ and $150 \mathrm{~W}$, respectively.

Bhanvase et al. [19] investigated the heat transfer enhancement of water based PANI (polyaniline) nanofluid in vertical helically coiled heat exchanger. The experimental setup consisted of a helical coil, thermocouples, cooler, storage tank, pump, and flow meter. The 
helical coil with an inner diameter of $13 \mathrm{~mm}$, an outer diameter of $15 \mathrm{~mm}$, and $10 \mathrm{~m}$ long with 10 turns was used as the test section. The coil had a total diameter of $290 \mathrm{~mm}$ with a pitch of $35 \mathrm{~mm}$. Ten T-type thermocouples were fixed at five different positions at the inner surface and at the core of the tube to measure the bulk fluid temperature and the copper tube surface temperature. Two thermocouples were placed at the end of the coil to measure the inside surface and the core temperature of the fluid leaving the coil. To maintain the inlet temperature of the nanofluid at steady state a cooler was used. The working fluid was pumped through the test section by using a pump. The flow rate was adjusted using a valve after the pump. The assembly of helical coil and thermocouples was placed in a $350 \mathrm{~mm}$ diameter tank containing water at $60^{\circ} \mathrm{C}$ as heating fluid. It was found that the convective heat transfer coefficient increased by increasing the particle volume fraction of nanofluid and Reynolds number. At $\operatorname{Re}=1625$, the improvement in convective heat transfer was approximately $10.5 \%$ and $70 \%$ using nanofluids with $0.1 \mathrm{vol} \%$ and $0.5 \mathrm{vol} \%$, respectively.

Sarafraz et al. [20] carried out an experimental investigation on the thermal characteristics of $\mathrm{Ag}$ / water nanofluid inside a microchannel heat sink (MCHS). The experimental setup consisted of a cooling loop, measuring instruments connected to the test section. Nanofluid circulated inside the hydraulic circuit by means of a tailored mini-pump. The whole system in where the fluid flowed inside was made of stainless steel 316a to minimize the limescale formation and corrosion issues. A bypass cycle was employed to regulate the flow rate of the nanofluid. An ultrasonic flow meter was employed to measure the flow rate in real time. The test section was composed of a heat sink with seven microchannels of rectangular cross section, built on the top of the heat sink. The heat sink was placed inside a cubic cover, made of polydimethylsiloxane (PDMS). This cover not only thermally insulated the boundaries of the heat sink, but created also the plenum to homogeneously distribute the nanofluid in the microchannels. The heat sink was a $4.15 \times 4 \times 2 \mathrm{~cm}$ copper block with seven parallel microchannels, with rectangular cross section $(0.25 \times 0.4 \mathrm{~mm})$. The MCHS was mounted to a heater copper element $(3.4 \times 4.15 \times 4.2 \mathrm{~cm})$. The space between each microchannel was $0.3 \mathrm{~mm}$. Five cartridge heaters were placed inside the heater block and the external walls were insulated by using glass wool, wrapped around the heater. In order to minimize the thermal resistance between the cartridge heaters and the heater block, high conductive silicone paste was injected in the space between. Two pressure sensors were placed at the ends of the test section to record the pressure-drop of the flow. Six K-type thermocouples were placed at different positions close to the microchannels, to measure the axial temperature profile of the microchannels. Two K-type thermocouples were installed on the heater block to control the uniformity of heat flux towards the top surface of the heater. Two RTDs were installed at the two ends of the test section. A brazed flat plate heat exchanger was used for cooling the outlet of the MCHS. All the thermocouples, RTDs, and pressure transducers were connected to a data acquisition device controlled by a PC.

Results showed that increasing the heat flux, the flow rate, the Reynolds number, and the nanoparticles concentration, the heat transfer coefficient increased as well. In particular, at $0.1 \mathrm{wt} \%$ of $\mathrm{Ag} /$ water nanofluid, the heat transfer coefficient enhancement was $45 \%$. The best heat transfer coefficient was recorded at the microchannel entrance and it decreased along with the length of the MCHS.

Sarafraz et al. [21] investigated the characteristics of iron oxide (III)-Therminol 66 oil based nanofluid in a convective radiator heating system. The experimental setup consisted of a convective radiator, a loop section, and the measurement tools. In the tank containing the working fluid, there was an $\mathrm{AC}$ heater connected to a proportion integration derivative controller (PID), which maintained constant the fluid temperature. The coolant was circulated from the tank to the radiator by using a pump (DAB) and a bypass loop was used to control the flow rate. The convective radiator included 45 straight tubes with fins, which improved the performance of heat transfer from the working fluid through the air. An electric fan was used to absorb heat from the radiator using the airflow, while the outlet of the radiator was driven into the tank. Two (Omega Engineering Inc., Norwalk, 
USA) pressure transducers were placed at the inlet and outlet section of the radiator to measure pressure drop. Five thermocouples (RTDs) were fixed at the inlet and outlet sides of the radiator to measure the inlet and outlet temperature of the air. All pipes, joints, valves, and the tank were insulated with $1.5 \mathrm{~cm}$ thick glass wool and wrapped in $3 \mathrm{~cm}$ thick plastic insulating material. At each flow rate, the inlet/outlet temperature, the inlet/outlet pressure, air temperature profile, and wall temperature of the radiator were recorded.

The experimental results showed that the heat transfer coefficient increased as the Reynolds number increased. In particular, when the fluid temperature in the tank was $50{ }^{\circ} \mathrm{C}$, the highest heat transfer coefficient of $2920 \mathrm{~W} /\left(\mathrm{m}^{2} \mathrm{~K}\right)$ was reached for the nanofluid with $0.3 \mathrm{wt} \%$ at the Reynolds number of 1800 .

Shajahan et al. [22] studied the thermal performance of $\mathrm{ZrO}_{2} /$ DI-water based nanofluid in forward and backward flow through a horizontal tube equipped with conical strip inserts. The setup consisted of a reservoir, a pump, a control valve, a rotameter, a cooling unit, a test section, heating arrangement and data logger. A straight circular tube with an inner diameter of $0.010 \mathrm{~m}$, an outer diameter of $0.012 \mathrm{~m}$, and a length of $1 \mathrm{~m}$ was used as test section. A $1000 \mathrm{~mm}$ long rod core was welded with $0.5 \mathrm{~mm}$ thick tapered strip inserts placed equidistant and alternately $25 \mathrm{~mm}$ apart inside the tube. The ratio between the pitch distance $(\mathrm{p})$ and the inner diameter $(\mathrm{d}=10 \mathrm{~mm})$ constituted the twist ratio $(\mathrm{Y}=\mathrm{p} / \mathrm{d})$. The experimental tests were performed for three different twist ratio $Y=2.5,3.5$, and 4.5, obtained considering the pitch length equal to 25,35 , and $45 \mathrm{~mm}$, respectively. The test section was wrapped with a $1000 \mathrm{~W}$ nichrome heating coil. The heater was connected to an autotransformer to control the input power and insulated with glass wool to prevent heat loss to the ambient. The working fluid was pushed from the reservoir to the test section by using a centrifugal pump and the flow rate was regulate by a control valve. After the test section, the fluid passed through a riser section to achieve a uniform flow. Then, the fluid was cooled in the cooling unit and the pressure drop of the fluid was measured by using a U-tube differential manometer. Five K-type thermocouples were placed on the outer surface of the test section at a distance of $0.15,0.30,0.60,0.75$, and $0.90 \mathrm{~m}$ from the inlet side to measure the wall temperature. Two K-type thermocouples were fixed at a distance of $15 \mathrm{~mm}$ from each side of the test section to measure the inlet and outlet fluid temperature. All data were recorded by the data acquisition system.

The experimental results showed that the Nusselt number increased with an increase in the Reynolds number as well as in the volume concentration of the nanofluid. In the forward arrangement, the Nusselt number enhancement with twist ratios of $Y=2.5,3.5$, and 4.5 for the nanofluid with $0.5 \mathrm{vol} \%$ was $130.56 \%, 102.72 \%$, and $64.52 \%$, respectively. In the backward flow, the heat transfer increase was $145.02 \%, 116.57 \%$, and $80.92 \%$ considering twist ratios of $Y=2.5,3.5$, and 4.5, respectively. The highest value in the Nusselt number enhancement was obtained for the nanofluid with a volume concentration of $0.5 \%$ in the backward flow using conical strip inserts with a twist ratio of 2.5.

Asirvatham et al. [23] carried out an experimental investigation on the characteristics of copper oxide nanofluid flow through a copper tube. The experimental setup consisted of a test section, a pump, a flowmeter, and heating device. A copper tube with a length of $1500 \mathrm{~mm}$ and a diameter of $8 \mathrm{~mm}$ was used as the test section. The tube was wrapped with a $5 \mathrm{~mm}$ thick asbestos insulation and a nichrome wire coil-heater $(1 \mathrm{~kW})$ was wound on it. A $40 \mathrm{~mm}$ thick fiber glass wool insulation enclosed the coil to prevent heat loss. The whole arrangement was placed in a casing made of a powder-coated sheet with a length of $1.5 \mathrm{~m}$. The fluid, pushed by a centrifugal pump, passed through the test section and came out as a heated fluid. It was cooled in a bath, which was connected to a cooling system with a temperature controller. The flow rate was adjusted by bypass and needle valves and measured by the flowmeter. To measure the pressure-drop across the test section, two pressure transducers were placed at the inlet and outlet side of test section. Eight thermocouples were installed on the surface of the tube at a distance of $17 \mathrm{~cm}$ from each other to measure the variation of surface temperature along the test section. 
It was found that the convective heat transfer coefficient improved at higher Reynolds number and high heat flux, even if the nanofluid considered had a very low volume fraction concentration $(0.003 \%)$. At a given concentration, the increase in the heat transfer coefficient was greater in the inlet region and decreased with axial distance. The $8 \%$ increase in heat transfer coefficient was obtained for nanofluid with $0.003 \mathrm{vol} \%$ at $\mathrm{Re}=1350$ and inlet temperature of $10^{\circ} \mathrm{C}$.

Naddaf et al. [24] investigated the heat transfer characteristics of multi-walled carbon (MWCNT) and graphene nanofluids using diesel oil as base fluid.

The experimental setup included a straight tube used as the test section, flowmeter, cooling heat exchanger, reservoir, manometer, gear pump, and power supply. Three heat elements were placed along the test section surface in order to guarantee a constant heat flux by using a DC power supply. The test section was also insulated to prevent heat loss. The heated fluid passed through the cooling unit and then collected into the reservoir. The flow rates $(18.75,50,33.33 \mathrm{~mL} / \mathrm{s})$ were adjusted using a flowmeter in order to maintain laminar conditions. Five thermocouples were installed along the tube surface at axial positions of 20,40,60,80, and $100 \mathrm{~cm}$ from the inlet of the test section to measure wall temperature. Two thermocouples were placed at the inlet and outlet section of the test section to measure the fluid temperature. A manometer was used to measure the pressure drop over the test section.

Experimental results showed that the convective heat transfer coefficient increased by increasing the Reynolds number and nanoparticle weight fraction. It also decreased with the axial distance so it assumed a maximum value at the entrance of the test section. The highest enhancement in heat transfer coefficient was observed for graphene nanofluid at $0.5 \mathrm{wt} \%$ at the flow rate of $50 \mathrm{~mL} / \mathrm{s}$.

Sheikhzadeh et al. [25] carried out an experimental investigation on the characteristics of heat transfer using $\mathrm{Al}_{2} \mathrm{O}_{3}$-ethylene glycol-water nanofluid as a coolant in a car radiator.

The experimental system consisted of a car radiator with a fan, pump, heater, thermometers, rotameter, reservoir, heater, tubes, and connectors. The radiator was $330 \mathrm{~mm}$ high, $364 \mathrm{~mm}$ long, and $27 \mathrm{~mm}$ wide, and equipped with helical aluminum fins, with a thickness of $0.11 \mathrm{~mm}$ and spaced $1.84 \mathrm{~mm}$ apart. It included 34 aluminum tubes $(1.5 \times 21.6 \times 300 \mathrm{~mm})$ with a thickness of $0.18 \mathrm{~mm}$, a diameter of $2.84 \mathrm{~mm}$, and spaced $8.02 \mathrm{~mm}$ apart. A high temperature resistant centrifugal pump (DAB ${ }^{\mathrm{TM}}$ A50-180M model) was used to circulate the working fluid. The flow rate was adjusted at 9,11 , and $13 \mathrm{~L} / \mathrm{min}$ by using a rotameter to ensure laminar flow condition. A cylindrical reservoir with a height of $20 \mathrm{~cm}$ and a diameter of $12 \mathrm{~cm}$ was used to contain the working fluid. A $4000 \mathrm{~W}$ electrical heater was placed in the reservoir to heat the fluid. An expansion resource was installed over the reservoir in order to enable the proper expansion of the coolant.

In order to calculate the convective heat transfer the radiator tubes wall temperature was considered constant and the contact thermal resistance of thermometers was neglected.

It was found that the convective heat transfer coefficient of the nanofluid increased with the increase in the Reynolds number, nanoparticle concentration, and flow rate. The maximum enhancement in convective heat transfer was about $10 \%$ for nanofluid with $1.2 \mathrm{vol} \%$ and at a constant flow rate of $13 \mathrm{~L} / \mathrm{min}$. It was also observed that the Nusselt number for the whole range of volume fraction was less than that of the base fluid.

Qasim et al. [26] studied the effect of $\mathrm{ZnO}$ water-based nanofluid on convective heat transfer in a Suzuki Mehran (VXR) 2016 radiator.

The experimental system included a car radiator, a single-stage centrifugal pump (VALCO-55CG), a reservoir, twelve K-type thermocouples, fluid transport pipes, two gate valves, an electric cooling fan, a power supply, an electric water heater with stem thermostat, a ball valve, a manometer, and a rotameter.

The radiator was $370 \mathrm{~mm}$ long, $39 \mathrm{~mm}$ wide, and $390 \mathrm{~mm}$ high, and it consisted of 33 vertical aluminum tubes with a length of $313 \mathrm{~mm}$, a minor diameter of $2.0 \mathrm{~mm}$, and a major diameter of $25.4 \mathrm{~mm}$. On the tube's surface several aluminum fins were mounted. The cooling of the radiator was carried out using a DC electric fan with an operating speed 
of 800-900 rpm. The pump, with the maximum rated head of $21.5 \mathrm{~m}$ and maximum flow rate of $20 \mathrm{~L} / \mathrm{min}$, was used to circulate the working fluid through the flow loop. Its inlet flow line was connected to the reservoir and its outlet flow line was connected to the bypass line and car radiator. Two gate valves were used to adjust the flow rate: the first one was mounted on the bypass line connected to the automobile radiator and the second one on the bypass valve connected to the reservoir. On the mainline, connected to the automobile radiator, was also placed a rotameter to measure the flow rate of the working fluid. The storage tank contained the nanofluid and a $1500 \mathrm{~W}$ electrical water heater, which was used to heat the working fluid at the desired temperature using a single-pole stem heater thermostat. A ball valve was installed on the bottom side of the reservoir in order to drain the fluid. A U-tube manometer was used to measure the pressure drop across the car radiator. Two K-type thermocouples were placed at the inlet and outlet flow line of the radiator to measure the fluid temperature. Nine K-type thermocouples were mounted on the radiator's surface to measure the wall temperature and one thermocouple was placed on the storage tank to measure the working fluid temperature. The experimental setup was run with the aid of the power supply (AC).

The experimental results showed that the thermal performance of the automobile radiator improved using nanofluid instead of the base fluid. It was also observed that the overall heat transfer coefficient, heat transfer rate, and the Nusselt number increased by increasing the flow rate and the volumetric concentration of nanoparticles. The greatest improvement in heat transfer rate, overall heat transfer coefficient, and the Nusselt number was approximately $41 \%, 50 \%$, and $31 \%$, respectively, for the nanofluid with a nanoparticle volume concentration of $0.2 \%$.

Yildiz et al. [27] carried out an experimental investigation on convective heat transfer characteristics in an industrial microchannel using graphite water-based nanofluid. The experimental system consisted of a test section, flowmeter, three water pumps, a needle valve, a heat exchanger, a condensing unit, a storage tank, a cartridge heater, and a DC power supply.

The water pump was used to circulate the fluid, contained in the storage tank, through the flow loop. The flow rate was adjusted and measured by using a needle valve and rotameter. A microchannel heat sink (CP 2001 series) was used as the test section and it was heated using a cartridge heater supplied by a DC power supply. The geometric characteristics of the microchannel are reported in Table 2. In the space between the microchannel heat exchanger and the aluminum body of the heater were mounted the thermocouples to measure the wall temperature. Two thermocouples were placed at the inlet and outlet section of the test section to measure the fluid temperature. All the data were recorded by a data logging system.

Table 2. Geometrical dimensions of the microchannels.

\begin{tabular}{ll}
\hline Parameters of Channel & Dimensions \\
\hline Number & 57 \\
Hydraulic diameter & $1.6 \mathrm{~mm}$ \\
Width & $1 \mathrm{~mm}$ \\
Height & $4 \mathrm{~mm}$ \\
Length & $98 \mathrm{~mm}$ \\
Fin width & $1 \mathrm{~mm}$ \\
\hline
\end{tabular}

Experimental results showed that, at the same Reynolds number and nanofluid inlet temperature, the convective heat transfer coefficient increased by increasing the volume concentration of nanoparticles and flow rate. For nanofluid with $2 \mathrm{vol} \%$, an inlet temperature of $20^{\circ}$, at a flow rate of $5 \mathrm{~L} / \mathrm{min}$ and heat flux input of $1100 \mathrm{~W}$ the maximum enhancement in convective heat transfer was approximately $49 \%$ compared to that of water.

Baghban et al. [28] studied the convective heat transfer performance of $\mathrm{SiO}_{2}$ water based nanofluid in a quadrangular cross-section channel under laminar regime. 
The experimental setup included a test section, three reservoirs, two pumps, two manometers, a flowmeter, a heat exchanger, a dimer to provide a steady heat flux, a Reynolds valve, 11 thermocouples, and a data logger system. A copper tube with an inner diameter of $1 \mathrm{~mm}, 1 \mathrm{~mm}$ thick and $1000 \mathrm{~mm}$ long was used as the test section. A MULTI 5800 SICCE pump, located between the two tanks, was used to circulate the fluid from the first reservoir to the second one and then through the test section at a flow rate of $5800 \mathrm{~L} / \mathrm{h}$. The fluid was directed into the horizontal tube with the aid of the Reynolds valve. After that, the heated fluid reached a cooling unit to adjust the inlet fluid temperature and it was collected in the first reservoir. The pressure drop across the test section was measured with a manometer and the flow rate was adjusted using a flowmeter. Nine SMT-160 thermocouples were mounted on the channel surface to measure wall temper and the other two thermocouples were placed at the inlet and outlet section to measure the fluid temperature. The tube surface was connected to an electrical heating element to guarantee a steady heat flux. To prevent heat loss the test section was insulated with glass wool.

The experimental results showed that at constant Prandtl number, the heat transfer coefficient increased by increasing the Reynolds number and nanoparticle volume concentration. The same trend was observed when the Reynolds number was kept constant and the Prandtl number increased.

Rahimi et al. [29] investigated the natural convection heat transfer performance of DWCNTs-water-based nanofluid in a cuboid enclosure.

The experimental system consisted of a test section, water channel, circulating water baths, power supplier, PT-100 thermocouples, LM-35 temperature sensors, and data logging system. The test section included a cuboid enclosure with inner walls made of copper to guarantee a uniform and smooth temperature and outer walls made of White Polyvinyl Chloride to prevent heat loss. The cuboid enclosure was $100 \mathrm{~mm}$ long, $100 \mathrm{~mm}$ high, and $100 \mathrm{~mm}$ wide. The internal and external surface of water channels was also made in the same way as the test section. The left and right walls of the cube were included in the flow circuit and kept at hot and cold constant temperature by using circulating water baths (PR20R-30 Polyscience) with a temperature range between $-30{ }^{\circ} \mathrm{C}$ and $200{ }^{\circ} \mathrm{C}$. Several layers of white polyvinyl chloride plates were used to insulate the test section and water tubes. Two ultrasonic flowmeters (Burkert type 8081) were used to measure the flow rate. Nine LM-35 temperature sensors were placed on the surface of the copper plate inside the water tubes to measure the wall temperature. Nine PT-100 thermocouples were installed at the back and mid-height of the enclosure to measure the fluid temperature. The thermocouples were able to penetrate inside the enclosure through watertight circular slots. All the data were recorded by a data logger system (SCXI-1303).

The experiments were conducted for four different temperature differences between hot and cold walls $\left(\Delta \mathrm{T}=20,30,40\right.$, and $\left.50{ }^{\circ} \mathrm{C}\right)$ and different volume concentrations of nanoparticles. It was found that the average Nusselt number and heat transfer increased with the increase of Rayleigh number, temperature difference, and volume concentration of nanoparticles up to $0.05 \mathrm{vol} \%$. For nanofluids with a higher volume fraction of nanoparticles, worse thermal performance was observed.

Sajedi et al. [30] carried out an experimental investigation on the characteristics of convective heat transfer coefficient of $\mathrm{SiO}_{2}$ and $\mathrm{Al}_{2} \mathrm{O}_{3}$ water based nanofluid in a vertical finned heat exchanger under laminar regime.

The experimental system consisted of a pump, two reservoirs, a heater, a heat exchanger, risers, and a dimmer. The test section was a vertical aluminum finned heat exchanger with an inner diameter of $7 \mathrm{~mm}$, an outer diameter of $45 \mathrm{~mm}$, a height of $500 \mathrm{~mm}$. It was equipped with 20 fins and each of them was $2 \mathrm{~mm}$ thick, $12.5 \mathrm{~mm}$ apart, and spaced $1.14 \mathrm{~mm}$ apart. A cooling fan discharges air was placed into a Plexiglas tube with a cross-section of $13.5 \times 13.5 \mathrm{~cm}$ and mounted on the longitudinal direction of the heat exchanger. The working fluid was pushed from the $1.2 \mathrm{~L}$ principal tank into the circuit by using a pump with a maximum flow rate of $5200 \mathrm{~L}$ and head of $3.5 \mathrm{~m}$. A reflux line was 
installed at the outlet section of the pump to control the flow rate. The second reservoir was mounted at a higher point and connected to the heat exchanger with a copper tube. In the reservoir was placed a $2000 \mathrm{~W}$ heater equipped with a dimmer in order to reach steady-state condition and to guarantee a constant inlet temperature $\left(40,50,60\right.$, and $\left.70{ }^{\circ} \mathrm{C}\right)$. Ten SMT-160 temperature sensors were placed in the longitudinal direction to measure the wall temperature. Two thermocouples were installed at the inlet and outlet section of the test section to measure the fluid temperature.

It was found that the convective heat transfer coefficient increased by increasing the Reynolds number, the volume concentration of nanofluid and inlet temperature. The greatest enhancement was $11.01 \%$ and $13.5 \%$ for silicon oxide and alumina nanofluid with $2.5 \mathrm{vol} \%$ at $\operatorname{Re}=1500$ and an inlet temperature of $70^{\circ} \mathrm{C}$.

Phanindra et al. [31] carried out an experimental investigation on the heat transfer in a concentric tube heat exchanger using $\mathrm{Al}_{2} \mathrm{O}_{3}-\mathrm{Cu}$ / oil-based nanofluid.

The experimental system consisted of four reservoirs, a test section, flowmeter, thermostats, two pumps, two sections for hot fluid, and two sections for cold fluid. The test section was a single pass concentric heat exchanger with a length of $1000 \mathrm{~mm}$, an inner diameter of $16 \mathrm{~mm}$, an outer diameter of $40 \mathrm{~mm}$, and an internal tube thickness of $1 \mathrm{~mm}$. The inner pipe was made of copper and the external tube was insulated with $3 \mathrm{~mm}$ glass wool to prevent heat loss. Each side of the heat exchanger was connected to two storage tanks that contained hot fluid and cold nanofluid. The pumps were installed in the reservoirs to circulate the nanofluid through the inner pipe and the hot fluid in the shell side of the heat exchanger at a volumetric flow rate of 0.5-1.5 LPM and 2-4 LPM, respectively. Two thermostats were mounted at the inlet/outlet section of the heat exchanger to measure the inlet/outlet fluid temperature.

The experimental results showed that the convective heat transfer coefficient increased using $\mathrm{Al}_{2} \mathrm{O}_{3}-\mathrm{Cu}$ /oil based nanofluid instead of pure oil and it reached a higher value by increasing the Reynolds number. The maximum enhancement in the Nusselt number was $12.06 \%$ for nanofluid with $0.1 \mathrm{vol} \%$ at $\operatorname{Re}=1820$.

Akram et al. [32] carried out an experimental investigation on the thermal performance of a flat-plate solar collector using f-GNPs, $\mathrm{ZnO}$, and $\mathrm{SiO}_{2}$ water based nanofluid as working fluid.

The experimental system consisted of a test section, cool water bath, thermocouples, flowmeter, and a data logging system. A solar collector with a length of $1.135 \mathrm{~m}$, a width of $0.6 \mathrm{~m}$ and a thickness of $0.09 \mathrm{~m}$ was used as the test section. The flat-plate collector included a T-shaped aluminum stand, a frame made of polypropylene (PP) sheet, a copper absorber plate with a thickness of $2 \mathrm{~mm}$, copper riser tubes with an inner diameter of $0.0116 \mathrm{~m}$, an outer diameter of $0.0127 \mathrm{~m}$, and spaced $0.128 \mathrm{~m}$ apart, a $0.005 \mathrm{~m}$ thick glass, a layer of iso-wool ceramic fiber as an insulator and a base with adjustable angle set at $30^{\circ}$. An alloy with $\mathrm{Sn} / \mathrm{Ag}$ ratio of 96.5/3.5 was used for each pipe in order to settle the copper absorber plate straight to the riser tubes. A flexible adhesive heater was mounted over the copper absorber plate, which had to preserve its flatness without any corrugation to guarantee uniform heat flux. At the outlet and inlet section of the solar collector PT-100 resistance temperature sensors (RTDs) were placed to measure the inlet/outlet fluid temperatures. T-type self-adhesive thermocouples (SA1XLT-72, Omega, USA) were installed along the surface of the absorber plate and riser tubes to measure ambient temperature. All the data was recorded by an eighteen-channel data logger (EC18).

The experimental results showed that the convective heat transfer coefficient was higher for nanofluid at a higher Reynolds number and weight nanoparticle concentration. The greatest enhancement in thermal performances for f-GNPs, $\mathrm{SiO}_{2}$, and $\mathrm{ZnO}$ nanofluid with a weight nanoparticle concentration of $0.1 \%$ at a mass flow rate of $1.6 \mathrm{~kg} / \mathrm{min}$ was $17.45 \%, 12.36 \%$, and $13.05 \%$, respectively.

Ahmed et al. [33] investigated the characteristics of convective heat transfer using $\mathrm{CuO}$ and $\mathrm{Al}_{2} \mathrm{O}_{3}$ water based nanofluids as working fluid in an air conditioner. 
The experimental setup included a compressor, a condenser, an expansion valve, temperature sensors, a wattmeter, and an evaporator. The evaporator consisted of a 7-L tank filled with water in which was placed a heating exchanger coil. The condenser included instead a 7-L reservoir equipped with a cooling heat exchanger coil and filled with nanofluids. The inner diameter of the helix of the evaporator and condenser coils was $13 \mathrm{~cm}$. Spiral tubing was mounted on the inlet and outlet sections of the compressor to avoid vibration throughout the system. Two pressure gauges were installed near the condenser and evaporator sections to measure the fluid pressure. Two K-type thermocouples were placed vertically into the jackets of the evaporator and condenser to measure fluid temperature. Experiments were performed at a steady state, with fluid temperatures of $40^{\circ} \mathrm{C}$ and $20^{\circ} \mathrm{C}$ in the evaporator and the condenser, respectively. R134a was used as the refrigerant (CFC-free). The connecting pipes were $2 \mathrm{~m}$ long and with a diameter of $6 \mathrm{~mm}$.

It was noticed that the heat transfer increased by increasing the volume nanoparticle fraction from $1 \%$ to $5 \%$. The maximum enhancement in thermal performance of the air conditioning system using $\mathrm{Al}_{2} \mathrm{O}_{3}$ and $\mathrm{CuO}$ water based nanofluid was $21.9 \%$ and $29.5 \%$, respectively.

\section{Experimental Measurements and Setups for Forced Convection under Turbulent Regime}

Ibrahim et al. [34] carried out and experimental investigation on the characteristics of heat transfer using $\mathrm{Al}_{2} \mathrm{O}_{3}$ non-Newtonian-water-carboxyl methylcellulose (CMC)-based nanofluid in a helical heat exchanger equipped with common and novel turbulators.

For this study, a helical heat exchanger with an inner diameter of $15 \mathrm{~mm}$ and a propeller pitch of $20 \mathrm{~mm}$ was used as test section. The experimental runs were conducted at a constant wall temperature of $400 \mathrm{~K}$ and the shell heat flux was neglected.

It was observed that the thermal performance of helical heat exchanger equipped with corrugated turbulators was 10\% higher compared to that with smooth channels using nanofluid with a volume concentration of $1 \%$. The heat transfer increased with the increase of the Reynolds number, nanoparticle volume fraction, and the diameter size of nanoparticle (20-50 nm). In particular, the maximum enhancement in thermal performance index was $15 \%$ using $4 \mathrm{vol} \%$ nanofluid in heat exchanger with corrugated channels at a $\mathrm{Re}=5000$. Finally, optimum results were obtained using $\mathrm{H}_{2} \mathrm{O} 99.5 \%: 0.5 \% \mathrm{CMC} / \mathrm{Al}_{2} \mathrm{O}_{3}$ nanofluid with a volume fraction concentration of $4 \%$ and nanoparticle size of $50 \mathrm{~nm}$ at $\operatorname{Re}=5000$.

Askari et al. [35] studied the effects of kerosene-based MWCNTs and graphene nanofluids on convective heat transfer coefficient. The setup consisted of a test section, flow control valves, a pump, a nanofluid tank, and a cooling unit. A copper tube with a diameter of $10 \mathrm{~mm}$ and a length of $90 \mathrm{~cm}$ was used as the test section. The tube was wrapped with a heating tape wire transformer to provide heat input and insulated by $4 \mathrm{~cm}$ rock wool to reduce heat loss. Eight thermocouples were placed on the tube surface and two at the inlet/outlet section to measure the fluid temperature. The flow inlet temperature was kept constant at $35^{\circ} \mathrm{C}$ and the heating tap was able to make a $10^{\circ} \mathrm{C}$ difference between inlet and outlet fluid temperatures. A pump was used to circulate the working fluid at a specific flow rate in the range of $0.01-0.05 \mathrm{~L} / \mathrm{s}$. The fluid passed through the test section and reached a shell and tube heat exchanger made of 14 inside tubes with a diameter of $7 \mathrm{~cm}$ and a length of $580 \mathrm{~mm}$ to keep the fluid temperature constant.

Results showed that the convective heat transfer coefficient increased by increasing the Reynolds numbers and nanoparticle concentrations. The heat transfer coefficient enhancement was 40.26 and $22.79 \%$ for MWCNTs and graphene nanofluids at a Reynolds number of 4448 and $0.5 \mathrm{wt} \%$.

Saghir et al. [36] investigated the thermal performance of forced convection in porous media using $\mathrm{Al}_{2} \mathrm{O}_{3}$ and $\mathrm{TiO}_{2}$ /Ethylene glycol and water-based nanofluid. The experimental system included pumps, valves, 10 T-type thermocouples, a rotameter, and a data logging system. The test section consisted of a metal foam block connected to a heater with trapezoidal inlet/outlet section. A potentiometer, a voltmeter, and an ammeter were used 
in order to control heat flux. The experiments were performed at four different flow rates at steady-state conditions and constant inlet temperature.

It was found that by using ethylene glycol instead of water as base fluid, the thermal performance improved by $10 \%$, considering the Nusselt number as a term of comparison. In particular, at a flow rate of $0.15 \mathrm{USGPM}$, an inlet temperature of $20{ }^{\circ} \mathrm{C}$, and a heat flux of $60,000 \mathrm{~W} / \mathrm{m}^{2}$, the Nusselt number was higher using titanium oxide ethylene glycol-based nanofluid in lieu of aluminum oxide ethylene glycol-based nanofluid.

Selvakumar et al. [37] studied convective heat transfer coefficient characteristics for $\mathrm{Al}_{2} \mathrm{O}_{3}-\mathrm{Cu} /$ water nanofluid in a thin-channeled electronic heat sink of overall dimensions $59 \times 59 \times 12.6 \mathrm{~mm}$.

The main components of the experimental setup were a heated aluminum block, a high-density cartridge heater, with electronic heat sink (EK-Supreme), an air-cooled cross-flow heat exchanger, and a peristaltic pump. An aluminum block with dimensions $55 \times 55 \times 75 \mathrm{~mm}$ was used as the heated block in which a high-density $150 \mathrm{~W}$ cartridge heater was inserted. This block simulated the heat generated by a generic electronic equipment. The contact between the two surfaces occurred at discrete point. Thermal interface material (TIM) was applied between the two surfaces to avoid high thermal resistance and to improve the conductance at the interface on both the surfaces. A $50 \mathrm{~mm}$ thick layer of glass wool was provided all around the heated block-heat sink assembly to prevent heat losses. To circulate the fluid through the system, a peristaltic pump was used. An electric current to the high-density cartridge heater was provided by an autotransformer for any required voltage. Four K-type thermocouples were mounted into the heated block from bottom up to its top surface to measure the bottom surface temperature of the heat sink and the interface temperature. Two more K-type thermocouples were used to measure fluid inlet and outlet temperatures. One more thermocouple was used to monitor the temperature at the boundary of insulation. $U$ tube manometer was used to measure the pressure drop between the inlet and outlet. At the center of the copper base of the heat sink thin channels, $0.3 \mathrm{~mm}$ wide and $2 \mathrm{~mm}$ thick, were produced in an area of $32 \times 28 \mathrm{~mm}$. In this way, the convective heat transfer increased by increasing the exposed area. A stainless steel jet plate kept on the thin channels was used to accelerate the flow through the channels. The inlet of the block was divided into two paths: the flow entered through the inlet orifice and split into two paths and then passed through the thin channels. The flow moved from the center towards left and right through the channels. The heat transfer performance of the nanofluid was studied by conducting experiments in the mass flow rate range of $0.0131-0.0408 \mathrm{~kg} / \mathrm{s}$.

It was found that convective heat transfer coefficient was higher by using the nanofluid as a working fluid instead of deionized water. It further increased by increasing the mass flow rate. For a particular mass flow rate of $0.0178 \mathrm{~kg} / \mathrm{s}$, the increase in convective heat transfer coefficient, when hybrid nanofluid was used as coolant in the heat sink, was $25.2 \%$ compared to that of deionized water.

Nguyen et al. [38] conducted an experimental investigation to study the heat transfer performance of $\mathrm{Al}_{2} \mathrm{O}_{3}$-water based nanofluid in a confined and submerged impinging jet on a flat, horizontal, and circular heated surface.

The experimental liquid impinging jet system consisted of a closed circuit mainly composed of a $10 \mathrm{~L}$ open reservoir and a centrifugal pump to ensure a continuous forced circulation of working fluid. The horizontal heated surface was a cylindrical all-aluminum body with a diameter of $100 \mathrm{~mm}$ and total length of $100 \mathrm{~mm}$. It was electrically heated by means of two $100 \mathrm{~W}$ cartridge heaters (Omega Engineering Inc., Norwalk, CT, USA). The circular surface on top of this block was horizontal mirror-machined and with a diameter of $30 \mathrm{~mm}$, corresponding to the area on which the fluid jet coming from a vertical nozzle impacted. The nozzle had a diameter of $3 \mathrm{~mm}$. The distance between the nozzle and the impact surface was adjusted using a mechanical guide. The whole aluminum block was fixed on a wooden and thick base. To reduce heat loss from the block to its base, two Teflon disks were placed, one on the top around the $30 \mathrm{~mm}$ circular surface and the 
other one between the aluminum block and its wooden base. The aluminum body was also insulated by using a $50 \mathrm{~mm}$ thick layer of Styrofoam wrapped around its surface. A cylindrical Plexiglas reservoir with a diameter of $125 \mathrm{~mm}$ and $150 \mathrm{~mm}$ high was placed on the top of the upper Teflon disk, to create a confined space for the swamped jet. This reservoir was open to the atmosphere through a tiny orifice in its cylindrical cover. On the reservoir wall, two separate outlet openings at height of $5 \mathrm{~mm}$ and $35 \mathrm{~mm}$ above the upper Teflon disk, offer two different thickness of the liquid layer above the circular heated surface. A mini air-cooled radiator was used to dissipate heat into the ambient air and a collecting-weighting station equipped with a three-way valve was used for measuring the mass flow rate of the circulating liquid inside the system. Seven K-type thermocouples were installed at different location in the liquid system to measure fluid temperatures. One was placed at the fluid inlet pipe to measure fluid temperature before the nozzle and the second one was placed in the reservoir to control the fluid exit temperature. The third one was mounted along the main axis, inside a hole of the aluminum block, to measure the temperature within the solid region close to the heated circular surface. Its junction tip was located at a distance of $4.5 \mathrm{~mm}$ beneath the heated surface. Another K-type thermocouple was used to monitor the ambient air temperature. For the test, three different nozzle-heated surface distances $(2,5$, and $10 \mathrm{~mm})$ and three different volume fractions $(0 \%, 2.8 \%$, and $6 \%)$ were considered.

Results showed different trends, depending on the distance nozzle-heated surface and nanofluid concentration considered. For the case with $2 \mathrm{~mm}$, the highest heat transfer was obtained for distilled water; in contrast, for nanofluid, 2.8 and $6 \mathrm{vol} \%$ the heat transfer coefficients remain lower than those corresponding to water. A reverse trend was found for distance of $5 \mathrm{~mm}$ : in this case, the best thermal performance was obtained using nanofluid with a particle volume fraction of $2.8 \%$. For distance of $10 \mathrm{~mm}$, distilled water and $2.8 \%$ nanofluid had similar heat transfer performance. The same behavior was observed regarding the dependence of the Nusselt number with respect to the Reynolds number and the volume fraction of the particles. For example, for the $2.8 \%$ particle volume fraction nanofluid at $\operatorname{Re}=60,000$, the Nusselt number increased from 82 (for $2 \mathrm{~mm}$ distance) to 130 (for $5 \mathrm{~mm}$ ), but decreased to 95 (for $10 \mathrm{~mm}$ ).

Fotukian et al. [39] studied turbulent convective heat transfer performance and pressure drop of $\mathrm{CuO}$ /water nanofluids flowing through a circular tube. The test section was made of a stainless steel annular tube $1 \mathrm{~m}$ long with an inner copper tube of $5 \mathrm{~mm}$ of inner diameter and $0.5 \mathrm{~mm}$ of thickness and $32 \mathrm{~mm}$ of outer diameter. Saturated steam flowed inside the annular section between the concentrically arranged tubes, while the nanofluid flowed inside the inner tube. Ten J-type thermocouples were placed on the surface of the inner tube, while two J-type thermocouples were placed into the flow at the inlet and outlet of test section to measure bulk temperature of the fluid. To minimize the heat loss to the surrounding, the test section was insulated by means of fiberglass. A shell and tube type heat exchanger were used to cool nanofluids exiting from the test section by means of water as coolant. To prepare the nanofluid suspensions, the equivalent weight of nanoparticles according to their volume was measured and gradually added to distilled water while mixing in a flask. Suspension was then vibrated for $10 \mathrm{~h}$ in an ultrasonic mixer. No particles precipitation was observed after $5 \mathrm{~h}$. They found that the heat transfer coefficient increased about $25 \%$ compared to pure water. In turbulent regime and in the range of the studied concentrations, increasing the nanoparticles concentration did not affect the enhancement of heat transfer coefficient. The wall temperature of the test tube decreased very fast when the nanofluid was employed. The maximum increase of pressure drop was about $20 \%$ for nanofluid with $0.03 \%$ of volume concentration.

Zamzamian et al. [40] investigated the effects of forced convective heat transfer coefficient in turbulent flow for nanofluids with $\mathrm{Al}_{2} \mathrm{O}_{3}$ nanoparticles and $\mathrm{CuO}$ nanoparticles in ethylene glycol, using a double pipe and a plate heat exchanger. The inner pipe (diameter $12 \mathrm{~mm}$, thickness $1 \mathrm{~mm}$, length $70 \mathrm{~cm}$ ) of the heat exchanger was made of copper, while the shell was made of green pipes (diameter $50.8 \mathrm{~mm}$ ). The fluxes of the fluids inside the heat 
exchanger were arranged in opposite directions. The plate heat exchanger was similar to traditional home radiators (size $40 \mathrm{~cm}$ high, $60 \mathrm{~cm}$ long) and exchanged heat freely with the ambience by means of 4 fins. The nanofluids were prepared at different concentrations and then poured into the reservoir. The pump was started and, after a lapse of time from 5 to $10 \mathrm{~min}$, the system was stabilized at the desired temperature $\left(45^{\circ} \mathrm{C}, 60^{\circ} \mathrm{C}\right.$, and $75^{\circ} \mathrm{C}$ for each nanofluid sample). Flowmeters were set at $3 \mathrm{~L} / \mathrm{min}$ for nanofluids inside both heat exchangers, and $2.5 \mathrm{~L} / \mathrm{min}$ for the cold water flowing inside the shell of the double pipe exchanger. For each sample, the values on digital thermometers were read and recorded, to be used later for data analysis. With the use of nanofluids, a significant increase in the convective heat transport coefficient was found. A greater enhancement was observed with increasing temperature and nanoparticle concentration.

Suresh et al. [41] investigated the convective heat transfer and friction factor in a plain and helically dimpled tube under turbulent flow with constant heat flux.

The experimental campaign was carried out first with a plain tube system and in a second moment, a dimpled tube (4.85 mm diameter, $800 \mathrm{~mm}$ length) was used. A pipe of the same dimension was used to take temperature readings and pressure drop measurement. In the first phase, a straight copper tube with $1200 \mathrm{~mm}$ length, $4.85 \mathrm{~mm}$ inner diameter, and $6.3 \mathrm{~mm}$ outer diameter was used as the test section. To minimize the heat loss, resulting by axial heat conduction, the test section was thermally insulated from its upstream and downstream sections by plastic bushings. A differential pressure sensor was placed on the test section. Subsequently the dimples were arranged helically with a pitch ratio $(=\mathrm{p} / \mathrm{d})$ of 2 on the test section. The dimpled diameter and depth were maintained at a constant value of $3 \mathrm{~mm}$ and $0.6 \mathrm{~mm}$, respectively.

Their results showed that the Nusselt number had increased by about $19.49 \%, 27.06 \%$, and $39.53 \%$ under turbulent flow for dimpled tube with $0.1 \%, 0.2 \%$, and $0.3 \%$ nanofluid, respectively, compared to plain tube with distilled water.

It was observed that the dimpled tube performed approximately $10 \%$ better than the plain tube with nanofluids. The performance of the dimpled tube is independent of the volume concentration of nanofluid.

Syam Sundar et al. [42] investigated forced convection heat transfer in a circular tube with $\mathrm{Fe}_{3} \mathrm{O}_{4}$-water nanofluid. The experimental setup consisted of a copper tube, a chiller, a collecting tank, a storage tank, a pump, and a data acquisition system. The copper tube with an internal diameter of $0.014 \mathrm{~m}$ and with a length of $1.7 \mathrm{~m}$ was used as test section. To create a constant heat flux boundary condition, the test section was wound with two 20-gauge nichrome heaters having a resistance of $53.5 \Omega / \mathrm{m}$ and $1000 \mathrm{~W}$ of maximum power. The space between the test section and the outer casing was filled with rock wool insulation to reduce the heat loss to the environment. The fluid was pushed by a pump through the test section. The suction side was connected to a $30-\mathrm{L}$ stainless steel storage tank. The working fluid, heated in the test section, passing through the chiller, was cooled to reach the steady state condition more quickly. Five thermocouples were placed at the distance of $0.1875,0.375,0.75,1.125,1.312 \mathrm{~m}$ on the surface of test section to measure wall temperature. Two thermocouples were installed at the inlet and outlet of test section to measure inlet/outlet temperature. U-tube manometer, with carbon tetrachloride $\left(\mathrm{CCl}_{4}\right)$ as manometer liquid, was used to measure the pressure drop across the test section. The experimental results showed that Nusselt number increased with the increase of the Reynolds number and volume concentration. In a simple pipe, the increase in heat transfer coefficient of $\mathrm{Fe}_{3} \mathrm{O}_{4}$-water nanofluid at $0.6 \%$ volume concentration was $20.99 \%$ and $30.96 \%$ for the Reynolds number of 3000 and 22,000, respectively, compared to water.

Pandey et al. [43] investigated the effects of $\mathrm{Al}_{2} \mathrm{O}_{3}$-water nanofluids as coolants on heat transfer in a counter-flow corrugated plate heat exchanger (PHE) for different flow conditions. The experimental setup included a hot water loop, a coolant loop, and a measurement system. The path of the fluids and the components included in the two cycles are shown in Figure 7. The test section of the PHE had three channels formed by 
the corrugated plates with a corrugation angle of $30^{\circ}$ made of 20 gauge (approximately $1.27 \mathrm{~mm}$ thick) mild steel sheets (Figure 8).

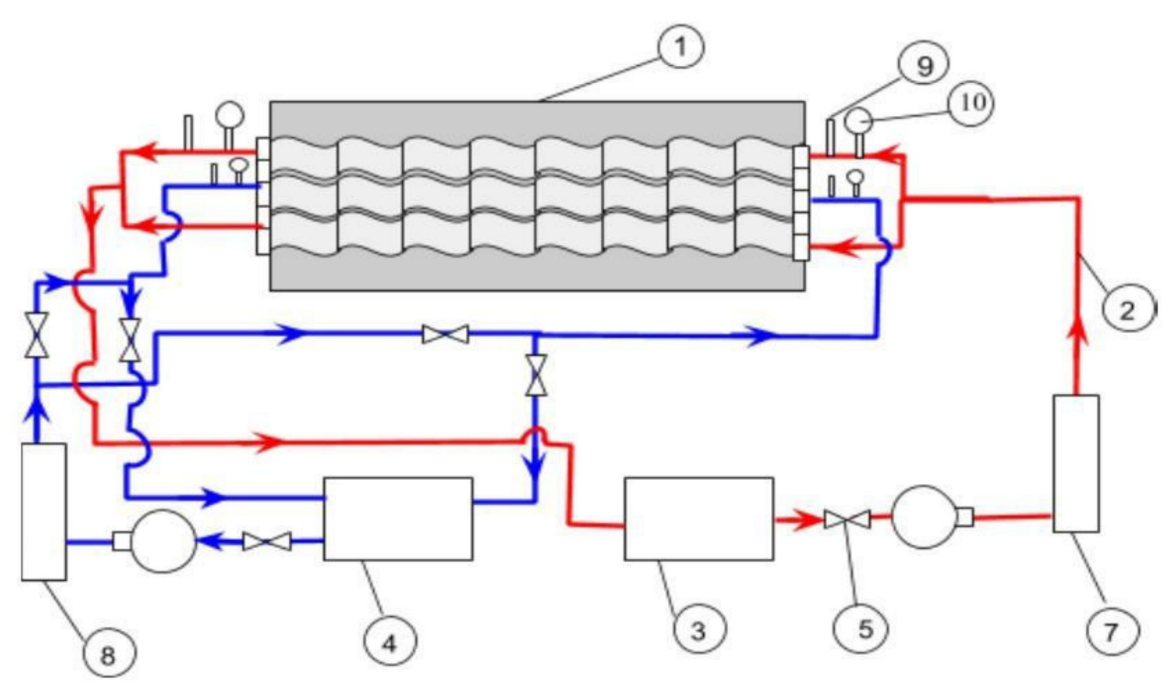

1. Insulation;

2. Hot fluid pipe;

3. Hot fluid tank;

4. Cold fluid tank;

5. Gate valves;

6. Pumps;

7. Hot fluid rotameter;

8. Cold fluid rotameter;

9. Thermometer wells;

10. Pressure gauge

Figure 7. Schematic of experimental setup described in [43].

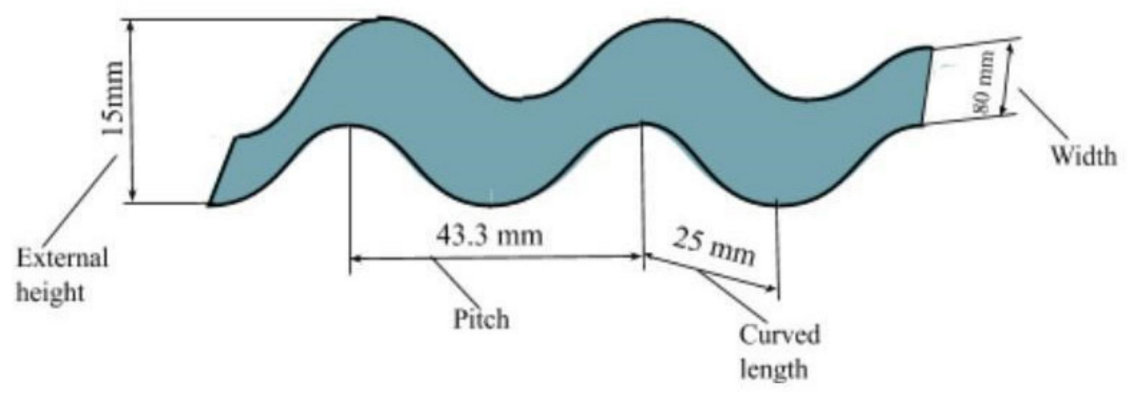

Figure 8. Corrugated plate in test section.

Hot water flowed through the two external corrugated channels to keep the surfaces of the channels at a constant temperature, while the coolant flowed through the central channel in counter flow. J-type thermocouples, wrapped in a copper tube and inserted into plates, were used to measure the temperature of the fluid: 32 in the hot water channel and 15 in the coolant channel. The corrugated PHE and pipelines were insulated to reduce heat loss. A flow straightener was installed at the entrance of the test section to maintain the uniformity of the inlet flow. The flowrate was measured with a water rotameter and was maintained at desired value. Experiments were carried out for 2.0, 2.5, 3.0, 3.5, 4.0, 4.5, and 5 LPM for the refrigerant, and 2.0, 2.5, 3.0, 3.5, 4.0, 4.5, and 5 LPM for hot water for each of the aforementioned refrigerant flowrates. The experimental data were used to calculate the heat exchange rate, convective heat transfer, Nusselt number, and Péclet number. The thermophysical properties of the nanofluid were determined at $27^{\circ} \mathrm{C}$. At a fixed Péclet number, the convective heat transfer coefficient of the nanofluid in the range of $0.3-2 \mathrm{vol} \%$ increased up until it reached an optimal value for $2 \%$ nanofluid and then decreased. For instance, at $\mathrm{Pe}=7700$, the values of the heat transfer coefficient for 2, 3, and $4 \%$ nanofluid were $110 \%, 107.3 \%$, and $104.6 \%$, respectively, of the corresponding value for water. The heat transfer rate decreased as the particle loading increased. So, the use of nanofluids with volume fractions higher than $2 \mathrm{vol} \%$ should be avoided.

Selvakumar et al. [44] studied the effects of $\mathrm{CuO} /$ water nanofluids in a thin channel copper heat sink under constant heat flux.

The experimental setup consisted of a heated aluminum block, a block made by a high-density cartridge heater for water, air cooled cross flow heat exchanger, and peristaltic 
pump. An aluminum block measuring $55 \times 55 \times 75 \mathrm{~mm}$ was used as a heated block to recreate the heat generated by any electronic equipment. The high-density cartridge heater was inserted into a special cavity present in the aluminum block. In order not to damage the heater, there must be no air in the gap between the block and the heater. Electric current to the high-density cartridge heater was provided by an autotransformer for any required voltage. A thin-channeled copper block $(55 \times 55 \times 19 \mathrm{~mm})$ for water was set over the aluminum block. A peristaltic pump was used to circulate the fluid through the system. Four K-type thermocouples were placed at different locations in the aluminum block to measure the interface temperature. Two more K-type thermocouples were installed to measure the inlet/outlet fluid temperature. The whole assembly was placed inside a wooden casing measuring $160 \times 160 \times 160 \mathrm{~mm}$. The latter was thermally insulated with $50 \mathrm{~mm}$ thick glass wool to minimize thermal losses to the surroundings. U tube manometer was used to measure the pressure drop between the inlet and outlet. A plastic vessel of $3 \mathrm{~L}$ capacity was used as a reservoir. The hot fluid exiting the block was cooled using an air-cooled heat exchanger, whose performance was adjusted by varying the speed of the fan installed in the cooling system.

The experimental results revealed that convective heat transfer coefficient increased by increasing volume flow rate of fluid and nanoparticle volume concentration. For instance, at a volume flow rate of 2.44 LPM the increase in the convective heat transfer coefficient for $0.1 \%$ and $0.2 \%$ volume concentration nanofluids compared to that of water was respectively $18.27 \%$ and $29.63 \%$.

Kannadasan et al. [45] carried out an experimental investigation on heat transfer characteristics of $\mathrm{CuO} /$ water nanofluids in helically coiled heat exchanger, held in horizontal and vertical positions.

Both horizontal and vertical setups had a shell side loop and helical coiled tube side loop. Hot water flowed through the shell side and nanofluid flowed through the helical coiled tube side. The shell side loop consisted of storage vessel with a $1.75 \mathrm{~kW}$ heater, magnetic pump and thermostat. The tube side circuit consisted of a mono block pump, flow control valve on tube side, test section, cooling unit, and a $5 \mathrm{~L}$ storage tank. The coil was formed initially with a straight tube of copper. The helical tube was made by copper with an inner diameter of $9 \mathrm{~mm}$ and an outer diameter of $10.5 \mathrm{~mm}$. The pitch of the coil was $17 \mathrm{~mm}$ and there were 13 turns. The shell was made of mild steel with an outer diameter of $124 \mathrm{~mm}$ and a length of $370 \mathrm{~mm}$. To avoid the entrance effect in helical tube, a calming section $270 \mathrm{~mm}$ long, and with a $93 \mathrm{~mm}$ coil diameter, was provided. Once the water had reached the desired temperature, the pump side was activated on the shell. Eight K-type thermocouples were used to measure the surface wall temperature and inlet/outlet temperature of shell and tube side. A U-tube manometer was placed across the helical tube to measure pressure drop. Mass flow rate was kept constant at $0.15 \mathrm{~kg} / \mathrm{s}$ on shell side and the flow on the tube side was adjusted by using a valve. On the flow pipe connecting the cooler section to the reservoir, a three-way valve was placed to control mass flow rate and the cleaning of the system after each experimental run. Test results showed that Nusselt number increased with an increase in the Dean number, and, in particle, volume fraction for both helical coiled tube arrangements. For horizontal helical coiled tube, at De $=2654$, the increase of the Nusselt number for nanofluid of $0.2 \%$ volume concentration was $47 \%$, compared to that of water. For vertical helical coiled tube, the maximum increase of $48 \%$ in the Nusselt number was obtained for nanofluid of $0.2 \%$ volume concentration at $\mathrm{De}=1592$.

Arani et al. [46] investigated the effect of nanoparticle volume fraction on the convection heat transfer coefficient of $\mathrm{TiO}_{2}$-water nanofluids. The setup was arranged as three closed-loop circuits consisting of three cycles. The nanofluid cycle setup was composed by a tank, a pump with bypass line, heat transfer test section and a water heat exchanger in order to cool the tested nanofluid. The heat transfer section was made of two concentric tubes; the inner one (made of copper with an inner diameter of $9.18 \mathrm{~mm}$ and outer diameter of $9.48 \mathrm{~mm}$ a length of $128.8 \mathrm{~cm}$ ) had a length so to create a fully developed turbulent flow inside at a Reynolds number of 51,000 was at about $22 \mathrm{~cm}$ from the entrance. A straight 
plastic tube ( $80 \mathrm{~cm}$ long) was employed to diminish the axial heat transfer flux from test section. The outer tube was made of stainless steel (inner diameter $26.02 \mathrm{~mm}$ and outer diameter $28.30 \mathrm{~mm}$ ). Two K-type thermocouples were placed at the inlet and the outlet of the test section to measure the bulk temperature of the flow. Eight K-type thermocouples were installed at $12 \mathrm{~cm}$ apart. The test section was heated by hot water, which flew over the copper tube. The heated length of the copper tube was $98.9 \mathrm{~cm}$. The heat transfer section was insulated by a $10 \mathrm{~cm}$ thick glass wool, in order to minimize heat loss to the ambient.

The second cycle contained equipment to generate and control the flowrate of hot water at the desired temperature: reservoir tank made of two sections, two heaters with power of 1000 and $2000 \mathrm{~W}$, installed in a smaller tank, a temperature controller with PT100 sensor, two K-type thermocouples, and a rotameter, used to measure and adjust the hot water flowrate. The third cycle contained pump, nanofluid heat exchanger, bypass line, condensing unit, temperature controller with PT100 sensor and an ordinary dry bulb thermometer to measure the room temperature. A slop mercury manometer was used to measure the pressure drop. The angle of the manometer was 48.5 degrees with the horizontal line. In order to prepare the nanofluids by dispersing the nanoparticles in a base fluid, special mixing and stabilization methods of the nanoparticles were required.

The results indicated that nanofluids have a higher Nusselt number than the base fluid. Nusselt number increased by increasing the nanoparticle volume fraction of nanoparticles.

Hajian et al. [47] carried out an experimental investigation on effects of nanofluid on the thermal performance of a cylindrical heat pipe, in both transient and steady states. Silver in DI-water nanofluid was prepared at various concentrations of 50, 200, and $600 \mathrm{ppm}$.

The experimental setup contained the heat pipe, an electric heat source, a convective heat sink, RTDs (PT-100), insulations, pressure gauges, and a temperature data logger. The Erlenmeyer flask, which contained the working fluid, was placed under the pressure of 10-2 Torr for $10 \mathrm{~min}$ to remove dissolved gases. The heat pipe type is circular and capillary driven, $1000 \mathrm{~mm}$ long, $4.07 \mathrm{~mm}$ thick, and with a diameter of $33.5 \mathrm{~mm}$. Evaporator and condenser sections were 200 and $250 \mathrm{~mm}$ long, respectively. The wick was made by eight layers of $30 \times 30 \mathrm{~mm}$ square pattern screen mesh and its thickness was $3.7 \mathrm{~mm}$. The pipe, wick, and caps were made of stainless steel. After inserting the wick into the tube, the entire tube, wick, and caps were rinsed with trichloroethane, deionized water, and methanol. The passivation of the heat pipe was carried out by means of a solution of nitric acid at $60 \%$ in DI water. The density of the DI water was considered to calculate the required amount of working fluid to be injected into the heat pipe. To prevent possible drying of the wick, $12 \%$ of extra liquid volume was added to inject $250 \mathrm{~mL}$ of deionized water into the heat pipe and the same amount of liquid was used for the nanofluid tests as well. Two caps connected the heat pipe and the vacuum valves. Some electrical heaters were used as heat source unit and attached to the evaporator section. The heat source was connected to an AC power supply and could provide a maximum thermal power of approximately $600 \mathrm{~W}$. A cooling block was installed on the condenser section, part of an open loop cooling system with water as coolant. The cooling block was a shell and tube type heat exchanger. It was made by two walls and between them was filled with polyurethane foam as an insulator. Two RTDs were placed at the inlet and outlet of the cooling block to measure the cooling temperature rise and seven RTDs were fixed on the outer surface of the heat pipe. The thermal performance tests were carried out for heat rates of 314,385 , and $488 \mathrm{~W}$, corresponding to 160,180 , and $200 \mathrm{~V}$ as the heat source inputs, respectively. The coolant volumetric flow rate was set at $1000 \mathrm{cc} / \mathrm{min}$ for all tests. The average temperature of the condenser was about $25^{\circ} \mathrm{C}$ and the temperature of the heat surface temperature was more than $150^{\circ} \mathrm{C}$. Thermal resistance of the heat pipe decreased by increasing the heat rate. Moreover, $50 \mathrm{ppm}$ nanofluid showed the best steady state thermal performance so that it made about 30\% decrease in the heat pipe thermal resistance at $488 \mathrm{~W}$, compared to DI-water. However, 200 and $600 \mathrm{ppm}$ of nanofluid did not enhance the heat pipe performance. The definition of the heat pipe response time was based on the variation of heat pipe surface temperature for a specific point. The chosen point for the tests was the middle point of the adiabatic section, given its 
distance from evaporator and condenser. The heat pipe with $50 \mathrm{ppm}$ nanofluid had better performance than the other fluids, so that its response time, at higher heat rates, was about $20 \%$ less than the heat pipe with DI-water.

Arani et al. [48] investigated the convective heat transfer coefficient characteristics in fully developed turbulent flow of $\mathrm{TiO}_{2} /$ water nanofluid. For the experimental tests, nanoparticles of diameter of $10,20,30$, and $50 \mathrm{~nm}$ and volume concentration from $1 \%$ to $2 \%$ were studied.

The experimental setup had three closed loop circuits. The nanofluid test rig contained a collection tank, a pump with a bypass line, test section and a water heat exchanger to cool the nanofluid. The test section consisted of two concentric copper tubes. Part of the test section was heated by hot water flowing over the copper tube. The heated length of the test section was $98.8 \mathrm{~mm}$. The second cycle contained equipment to create and control the flow rate of hot water at desired temperature. The temperature of the hot water was controlled by a temperature controller equipped with PT100, while two K-type thermocouples were used to measure the inlet and outlet and temperature in the test section. A rotameter measured and adjusted the flow rate. The third cycle was composed by a pump, a heat exchanger for the nanofluid, a bypass line, a condensing unit, and a temperature controller. This unit regulated the fluid's temperature by changing the power of the chiller. A manometer was used to measure pressure drop.

The experimental results showed that at high Reynolds numbers, the values of the Nusselt number increased by changing the diameter of nanoparticles from 50 to $30 \mathrm{~nm}$ and from 30 to $20 \mathrm{~nm}$. By decreasing the diameter of nanoparticles from 20 to $10 \mathrm{~nm}$, a lower Nusselt number was obtained. The Nusselt number increased by increasing the Reynolds number and nanoparticle concentration for all nanofluids. The value of the maximum increase in the Nusselt number compared to that of water was $98.87 \%$ and it was obtained for nanofluid with a nanoparticle diameter of $20 \mathrm{~nm}$ and nanoparticle volume concentration of $2 \%$ at $\operatorname{Re}>26,000$.

Sahin et al. [49] investigated the heat transfer characteristics of $\mathrm{Al}_{2} \mathrm{O}_{3}$ /water nanofluid inside a circular tube.

The experimental setup consisted of a reservoir, a collecting tank, a pump, an aluminum pipe as test section, a heating unit, a cooling unit, and a measuring unit. The test section was $770 \mathrm{~mm}$ long and had an inner and outer diameter of 11.7 and $14.7 \mathrm{~mm}$, respectively. The test pipe was insulated with a layer of glass wool and Rockwool insulation. In order to provide a constant heat flux boundary condition, the test pipe was heated by coiled heaters, with a current of $10.7 \mathrm{~A}$, and $2000 \mathrm{~W}$ heater power at $187 \mathrm{~V}$. To ensure constant heat flux along the test tube the electrical power input to the heater was controlled by a Variac transformer. The power supplied to the heater was controlled and measured by a power analyzer (Hioki USA Inc., Plano, TX, USA). Seven copper constantan thermocouples were mounted on the test section to measure the inlet/outlet and surface temperature of the working fluid. The readings of thermocouples were recorded by a data acquisition system and the average value of these readings was calculated. The flow rates were measured with an electromagnetic flowmeter (Euromag International, Mestrino, Italy).

This study showed that the Nusselt number increased adding nanoparticles into pure water when the particle volume concentration was lower than 2 vol\%. So, the Nusselt number of nanofluid with $2 \mathrm{vol} \%$ concentration was higher compared to pure water, but lower than that of 0.5 and $1 \mathrm{vol} \%$ nanofluid. The heat transfer coefficient reached the highest value of $110 \%$ at $\operatorname{Re}=8000$ and $0.5 \mathrm{vol} \%$.

Azmi et al. [50] studied the heat coefficients for $\mathrm{SiO}_{2}$ / water nanofluid, with a volume concentration up to $4 \%$ for a flow in a circular tube under constant heat flux boundary conditions. The experimental set up included a circulating pump, a flowmeter, a heater, a control unit, some thermocouples, pressure sensors, a chiller, a tank, and the test section. The heaters enclosed a copper tube $1.5 \mathrm{~m}$ long and with an internal diameter of $16 \mathrm{~mm}$ and an external diameter of $19 \mathrm{~mm}$ which constituted the test rig. The total length of fluid flow in the tube was approximately $4.0 \mathrm{~m}$, which was able to generate turbulent conditions. A 
pump was employed to circulate the fluid in the test section connected to a tank ( $30 \mathrm{~L}$ of total volume). The test section was heated by wrapping two nichrome heaters, with a total power of $3 \mathrm{~kW}$. The tube was wrapped with ceramic fiber insulation to minimize the heat loss to the surroundings. K-type thermocouples were used to measure the temperature in many points: five were placed on the surface of the tube wall while two were placed to measure the inlet and outlet temperatures of the fluid. A digital flowmeter was connected between the pump and the inlet of the test section, which detected flowrates in the range of 5-16 LPM. A chiller of $1.2 \mathrm{~kW}$ was placed between the test section and the tank. A constant power of $600 \mathrm{~W}$ was supplied to the heater, while the chiller was regulated to have a constant fluid temperature of $30^{\circ} \mathrm{C}$ at all the investigated flowrates. A pressure sensor was placed on the test section to measure the pressure drop. The data logger recorded the surface and fluid temperatures every $5 \mathrm{~s}$. The flowrate, the pressure-drop, the temperatures of the fluid at the inlet and outlet, and the surface temperatures were measured in steady state conditions. The heat transfer coefficients, in the Reynolds number range between 5000 and 27.000, increased with volume concentration up to $3 \%$ and decreased thereafter. The enhancement in the Nusselt number at 3 vol\% was between $29.6 \%$ and $38.5 \%$, instead.

Rabienataj Darzi et al. [51] carried out an experimental study in order to find out the effects of $\mathrm{Al}_{2} \mathrm{O}_{3}$-water nanofluid on the heat transfer for a turbulent flow through a double-tube heat exchanger.

The test loop consisted of hot and cold-water pumps, hot water tank, nanofluid tank (cold fluid), and cooling unit. A copper tube with inner diameter of 8.1 and outer diameter of $9.57 \mathrm{~mm}$, and a steel tube with diameter of $150 \mathrm{~mm}$ were chosen as the test section. The test section was $220 \mathrm{~cm}$ long. The outer surface of the test section was insulated from the surrounding using a thick layer of glass wool. To minimize the heat loss due to axial heat conduction, the test section was thermally insulated at its upstream and downstream sections by plastic bushings. The temperature of inlet/outlet of tubes and the wall temperature were measured by placing K-type thermocouples. The pressure drop along the test section was measured by Rosemount 3051 pressure transmitter.

Results indicated that by increasing the concentration of nanofluid, the heat transfer, and the Nusselt number increased at a higher Reynolds number.

Syam Sundar et al. [52] experimented the effects of $\mathrm{MWCNT}-\mathrm{Fe}_{3} \mathrm{O}_{4} /$ water on the convective heat transfer coefficient for a fully developed turbulent flow through a uniformly heated at constant heat flux circular tube. The experimental setup consisted of a chiller, collecting tank, storage tank, variable pump, bypass valve arrangement, and circular copper tube, which was $1.75 \mathrm{~m}$ long with an inner diameter of $0.014 \mathrm{~m}$ and outer diameter of $0.016 \mathrm{~m}$. The test section was placed in a straight square channel and heated with nichrome heater (20 mm gauge, $53.3 \Omega / \mathrm{m}$ resistance, and $1000 \mathrm{~W}$ maximum capacity) to create constant heat flux boundary condition. The ratio between length and diameter of the test section was sufficient to create a hydrodynamic flow. The gap between the test tube and the square duct was filled with rock wool insulation. Seven PT-100 thermocouples were used to measure inlet/outlet temperature and wall temperatures of the tube. To achieve the steady state condition, the temperature at the inlet and outlet of the test tube was maintained constant using the chiller. In order to create a close loop of the nanofluids, the test section was connected to the storage tank through the chiller. A pump was used to circulate the nanofluids with the suction side connected to the storage tank. The storage tank was made of stainless steel with a capacity of $30 \mathrm{~L}$. The pressure drop was measured using a U-tube manometer between two ends of the test tube, as shown in Figure 9. The inlet, outlet, wall temperature, and mass flow rate of nanofluid were recorded at the steady state condition. An enhancement of the Nusselt number for nanofluid was obtained by increasing the Reynolds number and nanoparticle volume concentration. 


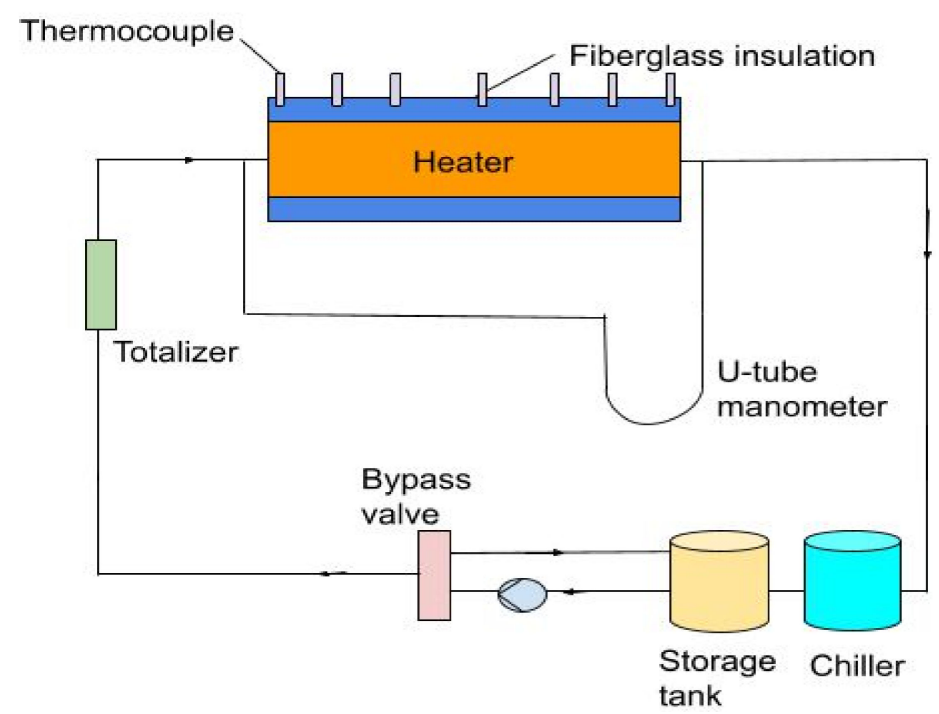

Figure 9. Schematic of experimental apparatus described in [52].

Eiamsa-ard et al. [53] conducted an experimental study on the effects of $\mathrm{TiO}_{2}$-water nanofluid on the heat transfer coefficient employing overlapped dual twisted tapes (O-DTs). The experiment was repeated using different overlapped twist ratios (yo/y $=2.5,2.0,1.5)$ and different volume concentrations of nanofluid. The tapes were made of aluminum sheets ( $0.88 \mathrm{~mm}$ thick, $8 \mathrm{~mm}$ width). As can be seen in Figure 10, the overlapped dual twisted tapes (O-DTs) were built by coupling the twisted tape with twist length of $24 \mathrm{~mm}$ (y) with each of the other three tapes at different twist lengths (yo $=36,48,60 \mathrm{~mm}$ ). Three pairs of overlapped dual twisted tapes were built (yo/y $=1.5,2.0,2.5)$.

The experimental facility consisted of a heat exchanger, a water tank, overhead tank, thermocouples, a data logger, a manometer, a pump, a rotameter, a multimeter, and a transformer. The tube (diameter $19 \mathrm{~mm}, 1000 \mathrm{~mm}$ long, $1.5 \mathrm{~mm}$ thick) was made of copper and was heated by an electrical heater wire, controlled by a Variac transformer and wounded around, yielding a constant heat flux. The outer surface of the tube was thermally insulated to minimize convective heat loss to the ambient. Fifteen T-type thermocouples were placed on the upper, lower, and sidewalls, to measure local temperatures. The inlet bulk fluids, at a temperature of $26^{\circ} \mathrm{C}$, were pumped by a centrifugal pump through the tank, rotameter, and then the heat transfer test tube; the latter was measured using a manometer under an isothermal condition. The test fluids were heated by the electrical heater, electronically controlled. The temperature, volumetric flow rate, and pressure drop of the tested fluids were measured when the fluid reached steady state conditions. The thermal and fluid-dynamic properties of fluids were evaluated based on the average temperature of tube wall and inlet/outlet temperatures.

In conclusion, the Nusselt number consistently increased with increasing the Reynolds numbers, and the heat transfer coefficient enhancement was higher for O-DTs, with twist ratios (yo/y) smaller.

Hemmat Esfe et al. [54] conducted an empirical study on $\mathrm{MgO}$ water nanofluid through a circular straight pipe for turbulent flow. For this study were considered nanoparticles with diameter of $60,50,40$, and $20 \mathrm{~nm}$ and volume concentration of $0.5,1,1.5$, and $2 \%$. The nanofluid, contained into a reservoir, flowed in the cycle, which consisted of a pump, a collection tank, test section and a plate water heat exchanger for cooling the working fluid. Two concentric circular pipes were used as test section. Hot water, provided by a hot water tank, flowed over copper tube to heat the test section. In order to maintain hot water at the desired temperature a cycle with specific equipment were used. The working fluids circulated in the cycles thanks to the use of pumps. The flowrate was measured by a flow meter. Thermocouple were placed on top surface of test section to measure fluid wall temperature. All data were recorded by a data acquisition system. 


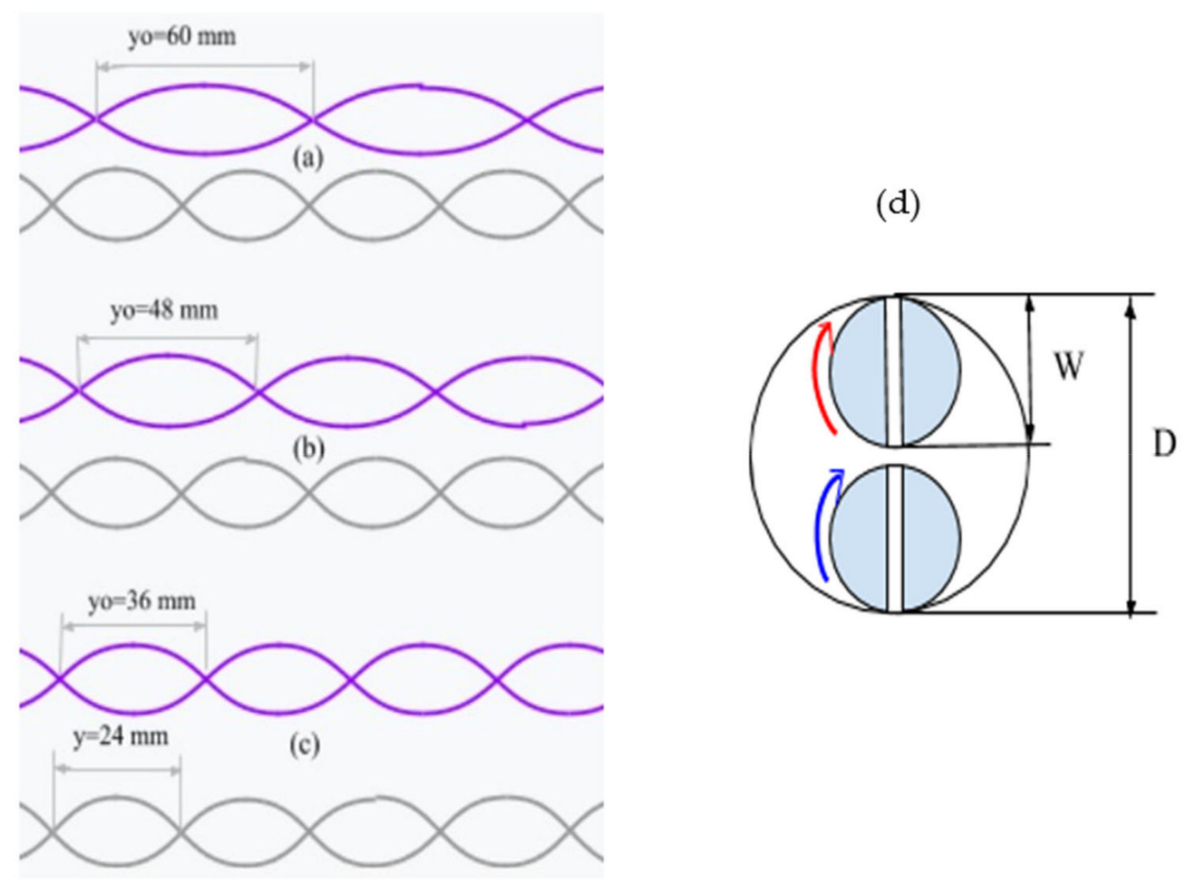

Figure 10. O-DTs: (a) yo $/ \mathrm{y}=2.5 ;(\mathbf{b})$ yo $/ \mathrm{y}=2.0 ;$ (c) yo $/ \mathrm{y}=1.5 ;$ (d) front view.

Results showed that heat transfer coefficient and the Nusselt number were increasing functions of the Reynolds numbers. Heat transfer increased by increasing nanoparticles volume fraction too. The ratio between Nusselt number of nanofluid and water was calculated for each value of nanoparticles volume fraction. The maximum thermal performance was obtained for nanoparticles with the smallest diameter and the highest volume fraction. Heat transfer increases with the concentration of nanoparticles in the nanofluid and with the increase of the Reynolds number, but it decreases in nanoparticles diameter.

Ali et al. [55] investigated the heat transfer effects of water-based nanofluids on the performance of a car radiator. Experimental setup consisted of a data acquisition unit, a pump, a flow meter, a heat exchanger, a cooling fan, a tank, a heater, thermocouples, and flow lines, to regulate the fluid in a circuit. Two gate valves were used in the experimental rig to control the fluid flux in the circuit. The pump gave a constant flow rate of $25 \mathrm{LPM}$ and took the fluid from the storage tank $(543 \times 153 \times 686 \mathrm{~mm})$. A recirculating pipeline was placed attached to the pump, using a gate valve, to pass the extra fluid back to the tank to regulate the fluid flow rate. A heater (power $6 \mathrm{~kW}$ ), with a temperature controller, was installed in the tank to heat the nanofluid. The required inlet temperature of the radiator was controlled by a temperature sensor. Thermocouples (K-type) were placed on the inlet and outlet of the radiator middle tube. The temperature was measured through the data acquisition system (Agilent 34972-A). The radiator (dimension reported in Table 3) was made with 32 vertical tubes of aluminum and the distance between the tubes was filled with thin perpendicular louvered fins. The radiator cooling was achieved by using a forced draft fan (700-800 RPM), which was the same used in common car radiators. The experiment was carried out at constant flow rates for specific intervals of time at 7, 8, 9, 10, $11 \mathrm{LPM}$ at $55^{\circ} \mathrm{C}$. An experimental test was performed to observe the effect of inlet temperature on the performance of the nanofluid at specific concentration at three different temperatures $\left(45^{\circ} \mathrm{C}, 50{ }^{\circ} \mathrm{C}, 55^{\circ} \mathrm{C}\right)$. The experimental setup showed that heat transfer increases by increasing the volume concentration of the nanoparticles. The maximum increase of $46 \%$ was achieved at $0.2 \mathrm{vol} \%$ and low flow rate (7 LPM). An increase in the fluid inlet temperature from $45{ }^{\circ} \mathrm{C}$ to $55^{\circ} \mathrm{C}$ showed a $4 \%$ increase in the rate of heat transfer. 
Table 3. Dimensions of radiator.

\begin{tabular}{lc}
\hline Length $\times$ Width $\times$ Height $\left(\mathbf{m m}^{3}\right)$ & $\mathbf{2 5 . 1 3} \times \mathbf{1 . 2 6} \times \mathbf{3 5 0}$ \\
\hline Peripheral area of tube $\left(\mathrm{mm}^{2}\right)$ & $18,479.3$ \\
Hydraulic diameter $(\mathrm{mm})$ & 2.4105 \\
Perimeter $(\mathrm{mm})$ & 57.298 \\
Total tube area $\left(\mathrm{mm}^{2}\right)$ & 381.8 \\
\hline
\end{tabular}

Sadeghinezhad et al. [56] investigated the heat transfer characteristics of a graphene nanoplatelet (GNP) nanofluid in a horizontal stainless-steel tube subjected to a uniform heat flux at its outer surface in turbulent flow conditions.

The experimental setup consisted of a flow circuit with a bypass line, a heating unit, a cooling unit, measuring instruments and a control unit. The circuit included a pump, a magnetic flow meter, a tank, a differential pressure sensor, and a test section. The nanofluid was pumped from a tank by a pump at a flow rate in the range $0-10 \mathrm{~L} / \mathrm{min}$. The pump flow was regulated by an inverter and the flow rate and pressure drop were measured using a magnetic flow meter and a differential pressure unit. A stainless-steel tube (dimensions: length $1400 \mathrm{~mm}$, inner diameter $10 \mathrm{~mm}$, outer diameter of $12 \mathrm{~mm}$ ) was used as test section that was heated by using an ultra-high-temperature heating tape at a maximum power of $900 \mathrm{~W}$ (connected to a Variac transformer and a watt/amp meter). Five K-type thermocouples were placed at equal axial distances on the outer surface of the test tube while 2 RTD (PT 100) sensors were used to measure the fluid temperature at the inlet and outlet of the test section. A thick glass wool wrapping was used to reduce the heat loss to the ambient.

Finally, it was found that the Nusselt number increased as the Reynolds number and heat flux increased. The Nusselt number increased up to $75 \%, 79 \%$, and $83 \%$ for the heat fluxes of $8231,10,351$, and $12,320 \mathrm{~W} / \mathrm{m}^{2}$, respectively, at $0.1 \mathrm{wt} \%$.

Zarringhalam et al. [57] carried out an experimental investigation on the effect of nanoparticle volume fraction and Reynolds number on the heat transfer coefficient of $\mathrm{CuO}$-water nanofluid flow inside a horizontal double tube counter flow heat exchanger.

The experimental setup was composed by two centrifugal pumps, a heat transfer test section, a counter flow heat exchanger, a reservoir, a digital data logger. The test section was designed to hold a maximum of $2.7 \mathrm{~L}$ of liquid. It consisted of a horizontal copper tube heat exchanger supplied by a double concentric tube. The test section was heated by hot water, which flowed over the copper tube and its heated length was $111 \mathrm{~cm}$. Two RTD-PT100 temperature sensors were mounted at the inlet and outlet of the test section to measure working fluid temperature. Furthermore, eight K-type thermocouples were placed on the copper tube surface at equal distance of $13 \mathrm{~cm}$ to measure wall temperature. The system could be seen as the composition of three different circuits, as shown in Figure 11. The first one, the nanofluid loop, included a pump, test section, tank, and a water heat exchanger to cool the working fluid. The second cycle contained the equipment for controlling the flow of hot water: PT-100 sensors to control hot water temperature, two K-type thermocouples placed into the flow to measure the bulk temperature of hot water and a flow meter to adjust its flow rate. The third cycle was composed of a pump, nanofluid heat exchanger, a bypass line, a condensing unit and a temperature controller with a PT-100 sensor. By changing the power of the condensing unit, it was possible to regulate the nanofluid temperature at the inlet and outlet of the test section. It was observed that the heat transfer coefficient of the nanofluid in all cases was greater than that of pure water and it increased with the increase of the Reynolds number and nanoparticle volume concentration. For example, at Reynolds number of about 14,700 the enhancement in heat transfer coefficient for nanofluid with $0.0625 \%, 0.125 \%, 0.25 \%$, and $0.5 \%$ volume concentration were $12.43 \%$, $13.74 \%, 15.78 \%$, and $20.27 \%$, respectively. It was found that the trend of the heat transfer coefficient increase was approximately similar to the increase in nanoparticle volume concentration and the Reynolds number, except for $2 \%$ nanofluids, which showed better performance at lower Reynolds numbers. Indeed, the maximum enhancement of $57 \%$ was 
observed for nanofluids with a volume concentration of $2 \%$ at $\operatorname{Re}=3677$. The maximum increase in the Nusselt number was about $27 \%$ for $2 \%$ volume concentration at $\operatorname{Re}=2942$.

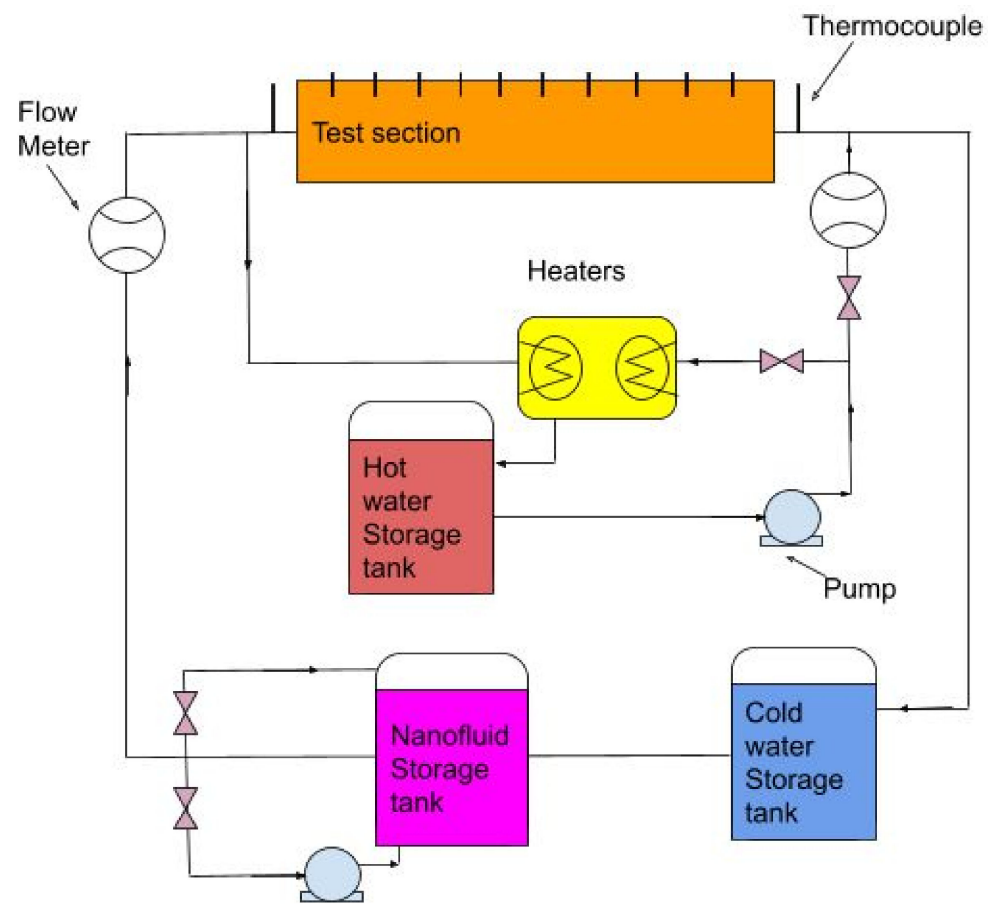

Figure 11. Schematic of experimental apparatus described in [57].

Ranjbarzadeh et al. [58] investigated the effects of using water/graphene oxide nanofluid, in a turbulent regime, on a heat transfer coefficient in a copper pipe, with isothermal boundary conditions. The experimental setup could represent a coolant system, such as the air-cooling heat exchanger. A fluid flow closed circuit was used as an experimental system (Figure 12). It was made of a reservoir tank; a TAIFU electro pump (GRS25/6); a copper tube, which was the test section, with an internal diameter of $8.5 \mathrm{~mm}$ and an external diameter of $10 \mathrm{~mm}$; a glass rotameter; a differential pressure gauge (PM9102); K-type thermocouples to measure inlet/outlet temperatures and the pipe surface temperature at different intervals; four $2 \mathrm{~kW}$ heating elements; and a plumbing system. It was obtained that the convective heat transfer coefficient of the nanofluid increased by $40.3 \%$ through the addition of graphene oxide nanosheets. The maximum augmentation in the Nusselt number for a $0.1 \%$ concentration was of $17.6 \%$.



Figure 12. Schematic of the system reported in [58]. 
Azmi et al. [59] studied the characteristics of the heat transfer coefficient of $\mathrm{TiO}_{2} /$ water nanofluid at an average temperature of $30{ }^{\circ} \mathrm{C}$ in a tube with tapes of different twist ratios. The experimental system consisted of a chiller, collecting tank, water pump, flow meter, pressure transducer, control panel, and test section. A copper tube with a length of $1.5 \mathrm{~m}$, an inner diameter of $16 \mathrm{~mm}$, and an outer diameter of $19 \mathrm{~mm}$ enclosed with the heater and the ceramic fiber insulation was used as the test section. The twisted tapes consisted of $1 \mathrm{~mm}$ thick and $16 \mathrm{~mm}$ wide aluminum strips, as shown in Figure 13. They were fabricated with different twist ratio (H/D) of 5, 10, and 15 and with the width $(\mathrm{H})$ of $0.08,0.16$, and $0.24 \mathrm{~m}$, respectively. The working fluid, contained in a 30-L stainless steel tank, was pushed through the copper tube by using a pump of $0.5 \mathrm{hp}$. The test section was wrapped with two $1.5 \mathrm{~kW}$ nichrome heaters to achieve uniform heating. A constant value of $600 \mathrm{~W}$ was supplied by the heaters to the test section. The tube was enclosed in ceramic fiber insulation to minimize heat loss to the atmosphere. K-type thermocouples were placed on the copper tube surface at $0.25,0.5,0.75,1.0$, and $1.25 \mathrm{~m}$ from the inlet of the tube to measure temperatures at various locations. A flow meter capable of measuring in the 5-16 LPM range was connected to the test section. A $1.4 \mathrm{~kW}$ chiller was connected to the collecting tank to control the inlet fluid temperature and was adjusted to obtain a liquid average temperature of $30{ }^{\circ} \mathrm{C}$ in the test section. Experiments were carried out at different flow rates to determine the heat transfer coefficients of the nanofluid for the maximum volume concentration of $3.0 \%$.

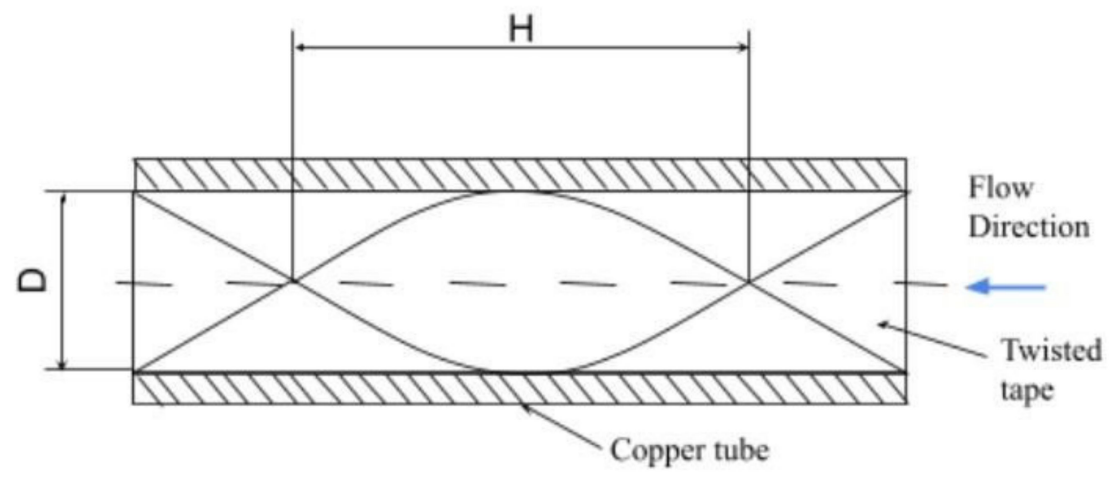

Figure 13. Twisted tape configuration.

Results indicated higher value of convective heat transfer coefficient for a flow in a tube with twisted tape inserts compared to values for a flow in a plain tube. In particular, the heat transfer coefficient increased with the increase of the Reynolds number and decreased with twist ratio enhancement. However, the nanofluid heat transfer coefficient in the Reynolds number range of 8000-30,000 increased with volume concentration up to $1.0 \%$ and decreased at higher concentration. The maximum enhancement in heat transfer coefficient at $1.0 \%$ volume concentration was $81.1 \%$ at $\operatorname{Re}=23,917$ for a flow in a tube with twisted tape inserts with a twist ratio of 5 .

Lv et al. [60] investigated the heat transfer performance of free single jet impingement using $\mathrm{SiO}_{2}$ /water nanofluid in turbulent flow. The experimental apparatus consisted of a reservoir tank, a pump, a cooler, a thermostat water bath, a flow meter, a jet chamber, and a test section. The working fluid flowed from the tank to a heat exchanger using a pump. It reached the nozzle and then hit a horizontal surface of a hot copper cylinder in the jet chamber. The falling liquid flowed back into the tank. To maintain the temperature of the working fluid at $30{ }^{\circ} \mathrm{C}$ a water-cooled heat exchanger was used. A flow rate of the fluid was controlled by two valves, one in the main flow loop, and one in the bypass line, and was measured by a turbine flow meter. The test section was composed of the copper cylinder heated by a bottom heating disk. The heating power was controlled by using a Variac transformer. The cylinder had a diameter of $100 \mathrm{~mm}$, equal to that of the heating disk, and a height of $50 \mathrm{~mm}$. In correspondence of three different horizontal planes of the copper cylinder, holes with a $1.3 \mathrm{~mm}$ diameter were made for the adjustment of K-type 
thermocouples to measure the temperature variation between the various planes. Seven K-type thermocouples were placed on the upper surface of the roller, three at the middle surface, and three at the bottom. Moreover, one thermocouple was installed before the jet exit to measure the temperature of the working fluid. All the data were recorded by a data acquisition system (Agilent 34970A).

It was found that the heat transfer coefficient of nanofluids increased with the jet-target distance (H/D): the highest value was obtained at $H / D=4$ while the lowest at $H / D=2$.

The angle between the axis of the jet and the horizontal plane was defined as the impact angle. Considering different values of the angle of impact $\left(50^{\circ}, 60^{\circ}\right.$, and $\left.90^{\circ}\right)$ at the same Reynolds number, it was found that the heat transfer coefficient increased with the angle of impact, therefore the vertical impinging had the best thermal performance. Lastly, the convective heat transfer coefficient of nanofluid increased by increasing the Reynolds number and particle volume fraction. For the same jet-to-target distance $\mathrm{H} / \mathrm{D}=4$ when nanoparticle volume concentration raised from $1 \%$ to $3 \%$ at $\operatorname{Re}=8300$ the enhancement in heat transfer coefficient was $13 \%$ and $49 \%$, respectively.

Sheikholeslami et al. [61] carried out an experimental procedure to study hydrothermal behavior of refrigerant-based nanofluid (nano-refrigerant) during condensation inside a horizontal tube. $\mathrm{R} 600 \mathrm{a}$ and $\mathrm{CuO}$ were used as base fluid and nanoparticle, respectively. The experimental setup, represented in Figure 14, contained gear pump, heater, evaporator, test condenser, post condenser, bypass path, and flow meter. The heater and the evaporator were placed before the test condenser to adjust vapor quality. The $3 \mathrm{~kW}$ electrical resistances of the heater and the evaporator were made of glass wool pads. The test condenser was made from a shell and tube counter flow heat exchanger with the inner tube of $8.6 \mathrm{~mm}$. The working fluid flowed inside the internal tube and the cooling water flowed in the annulus. To measure the temperature at the external surface of the tube, $24 \mathrm{~K}$-type thermocouples were placed at 6 sections along the test section. The temperature of the tube coincided with the average value of 4 thermocouples at each section. In order to measure the amount of heat transfer between the working fluid and the cooling water two thermocouples were installed at the inlet and outlet sides of the test section. A PDM-75 pressure transducer sensor (DP) was used to estimate the pressure drop along the test section. The pressure at inlet and outlet sides were measured by EN 837-1 WIKA model pressure gauges. A counter flow heat exchanger with a $12 \mathrm{~m}$ coiled tube was employed as a post condenser. A receiver was installed after the post condenser to ensure that the working fluid was completely condensed before reaching the gear pump. In order to compensate for the pressure drop of the whole system, a magnetically gear pump was placed after the receiver that drove the working fluid in the system. A Fisher rotameter was installed to measure the flow rate of the working fluid. The pure refrigerant (R600a) flowed inside the system through a bypass line and Polyester oil (POE) was used as lubricant. To this end, the two ball valves in the bypass direction were closed and a pump vacuums the path. The $\mathrm{POE} / \mathrm{CuO}$ mixture was manually injected to the bypass line by a syringe. Finally, the injection valve was blocked and the right ball valve was opened to let the oil/nanoparticles be mixed with the refrigerant passing through the experimental setup. Results showed that condensation heat transfer coefficients were grown with vapor quality. Such enhancement in heat transfer coefficient was mainly because of reducing the liquid film thickness on the interior wall of the tube as a result of the development of the annular flow pattern, diminishing the thermal resistance; condensation heat transfer coefficient increased with nanoparticle mass concentrations.

Subramani et al. [62] studied heat transfer and the flow characteristics of nanofluids through a parabolic trough solar collector (PTSC). The design parameters for a solar PTSC were aperture, rim angle, acceptance angle, focus, depth, arc length, and receiver tube diameter. The collector was made of an anodized aluminum reflector sheet with a reflectance of 0.94 . The receiver copper tube was $2 \mathrm{~m}$ long with inner diameter of $13 \mathrm{~mm}$ and outer diameter of $16 \mathrm{~mm}$. A transparent borosilicate glass tube, with an internal diameter of $30 \mathrm{~mm}$ and an external diameter of $34 \mathrm{~mm}$, enveloped the receiver tube. The 
system was sealed by a high temperature resistant cork for maintaining a partial vacuum to minimize the convective heat losses and harnessing the incident solar energy by the greenhouse effect. The absorber tube was covered with $1 \mathrm{~mm}$ of carbon black powder. The outer surface temperature was measured with WIKA TC50, and thermocouples were placed at lengths of 20,50,90,120, and $160 \mathrm{~cm}$ apart. The trough was always situated at solar noon. The centrifugal pump, driven by a rotameter, circulated the nanofluid coming from the tank. The temperature of nanofluid was reduced by the absorber tube, connected to the heat exchanger, and, simultaneously, was balanced by a constant temperature bath. To measure the direct solar radiation and the wind velocity a pyranometer (SP Lite 2 silicon) and a vane-type anemometer were used, respectively.

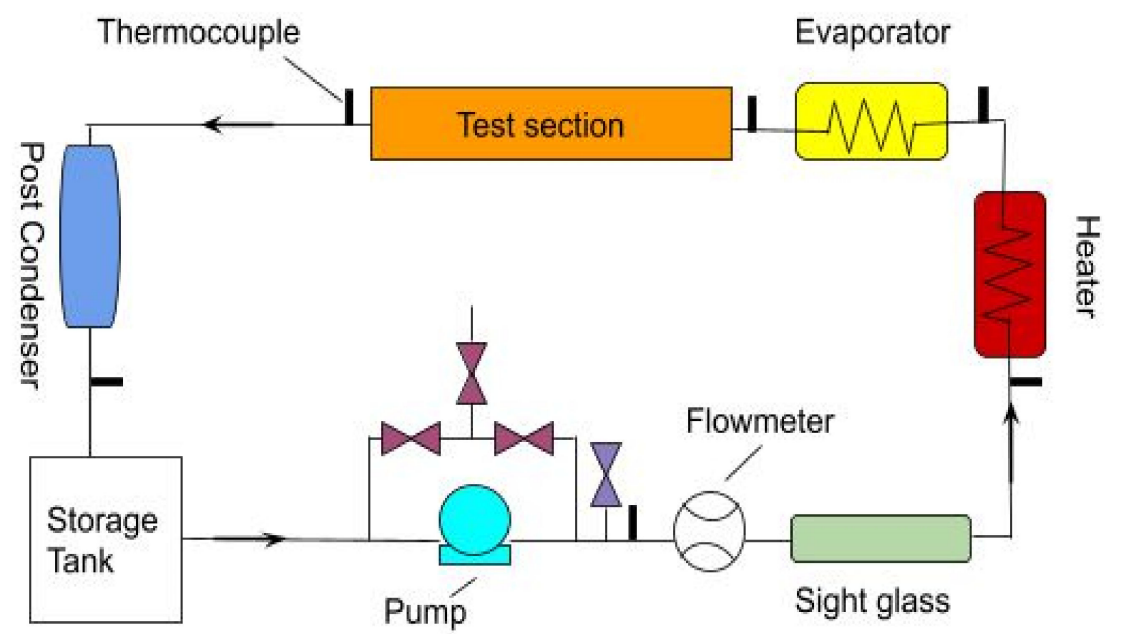

Figure 14. Schematic of experimental setup described in [61].

The absorbed energy factor was improved using nanofluid with a higher nanoparticle concentration. However, by doing so, the Reynolds number decreased and the Nusselt number, too. An optimal result was achieved for nanofluid at $0.2 \mathrm{vol} \%$ : an enhancement of $22.76 \%$ of convective heat transfer compared to that of water was observed.

Said et al. [63] studied the performance of a shell and tube heat exchanger performance using $\mathrm{CuO} /$ water nanofluid. The experimental setup consisted of a shell and tube heat exchanger (STHX), two pumps, a nanofluid tank and a water tank, two flow meters, and two valves. The STHX (series: BCF/SSCF/SX2000/B300) was made of 28 carbon steel tubes and carbon steel shell. The nanofluids were used to flow through the tube side of the shell and tube heat exchanger. The heat transfer was measured for the nanofluids at different flow rates and different volume fractions of the nanoparticles. Both tanks were filled with the heat transfer fluids at the desired temperature and the pump were turned on. The valves were opened for shell and tube sides according to the desired flow rate. Two thermocouples were placed at the inlet and outlet of the heat exchanger. For each tank, two thermocouples were fixed on the inlet and outlet side to measure the fluid temperature. The data from the thermocouples for both sides (hot and cold) were recorded using the data logger acquisition device.

Results showed that the convective heat transfer was slightly higher using nanofluid instead of water for the same fluid inlet temperatures and mass flow rates. Overall heat transfer coefficient and the convective heat transfer coefficient increased by $7 \%$ and $11.39 \%$, respectively.

Ahmed et al. [64] studied the convective heat transfer properties of synthesized stable $\mathrm{ZnO}-\mathrm{Eg} /$ water nanofluid flow through a single tube heat exchanger under turbulent regime. The experimental setup consisted of a control panel, voltage regulator, electrical heater, inlet and outlet valves, main valves, flow meter, pressure meter, pump, tank, chiller, frequency control meter, and digital data logger. A circular closed single aluminum pipe with a length of $1.2 \mathrm{~m}$ and with a diameter of $0.01 \mathrm{~m}$ was used as heat exchanger. Five 
K-type thermocouples were placed along the surface of heat exchanger at equal distance of $0.2 \mathrm{~m}$ from the entry region. Two highly sensitive thermocouples were fixed at the inlet and outlet side of the tube to measure the fluid temperature. Different flow rates $(2.5,3$, $4,5,6,7,8$, and $9 \mathrm{~L} / \mathrm{min}$ ) and a constant heat flux were considered to study heat transfer improvement.

The experimental results showed that the average heat transfer increased with the enhancement of the Reynolds number. The enhancement of the average Nusselt number was $8-15,7-14,7-13$, and $6.5-12$ for nanofluid with a weight concentration of $0.1 \%, 0.075 \%$, $0.05 \%$, and $0.025 \%$, respectively.

Esmaeilzadeh et al. [65] carried out an experimental investigation on the characteristics of 1-pyrene carboxylic acid (PCA)-functionalized graphene nanofluid in a wick heat pipe.

The experimental setup consisted of a test section, cooling section, heating section, a movable table with adjustable angle, data logger and a computer unit. The test segment of the copper heating tube was composed of a sintered copper tube with a length of $300 \mathrm{~mm}$, an outlet diameter of $10 \mathrm{~mm}$, a wall thickness of $0.5 \mathrm{~mm}$, and a sintered wick thickness of $0.2 \mathrm{~mm}$. The test section was covered with numerous sheets of ceramic fiber to reduce the heat loss from the condenser and evaporator section. For each test, the heat pipe was loaded with the working fluid (equal to $40 \%$ of heat pipe volume) and subsequently discharged to reach the vacuum with the aid of a vacuum pump. In the condenser section, the inlet fluid temperature was $20^{\circ} \mathrm{C}$ with a flow rate of $400 \mathrm{~mL} / \mathrm{min}$. The DC power supply (KEYSIGHT Technologies) was used in the evaporator section to set the heat power input at 40,60, 80,100 , and $120 \mathrm{~W}$. A variable angle holder table was utilized to modify the heat pipe inclination angle from $0^{\circ}$ to $90^{\circ}$. Two K-type thermocouples (Omega) were mounted at the inlet and outlet side of the tube to measure the inlet/outlet fluid temperature. Five K-type thermocouples were placed along the surface of the heating tube at a distance of 50, 100, 150,200 , and $250 \mathrm{~mm}$ from the entry point of the evaporator section. All the data were recorded in Graphtec data logger (mini logger GL220).

In each test, the best thermal performance was achieved for an inclination angle of $90^{\circ}$ and the thermal efficiency increased by increasing heat input. For PCA functionalized graphene nanofluid with $0.06 \mathrm{wt} \%$, the maximum thermal performance improvement of $49.4 \%$ was found.

\section{Experimental Setups for Forced Convection under Laminar and Turbulent Regimes}

Kim et al. [66] investigated the effect of nanofluids on convective heat transfer in a circular straight tube with a constant heat flux condition, in the laminar and turbulent flow regimes. The transient-hot-wire method was used to measure the effective thermal conductivity of the nanofluids. The heat transfer test section is a straight seamless stainless tube of $4.57 \mathrm{~mm}$ diameter and $2 \mathrm{~m}$ long. Eleven T-type thermocouples were placed at different axial distances on the test section to measure the wall temperature, and two T-type thermocouples were inserted to measure the bulk temperature at the inlet and outlet of the test section. To minimize heat dissipation there was a thick thermal insulating layer surrounding the test section. To obtain a constant heat flux condition, the heat transfer section was heated electrically by a constant DC power supply. The inlet temperature for all the tests was $22{ }^{\circ} \mathrm{C}$. Alumina and amorphous carbonic nanofluids at 3 and $3.5 \mathrm{vol} \%$ were prepared by two- and one-step methods without any surfactant.

The thermal conductivity of alumina nanofluids compared with that of pure water increased from $8 \%$ to $11 \%$ as the temperature rose from 22 to $52{ }^{\circ} \mathrm{C}$, while for amorphous carbonic nanofluids there was only a slight increase at $52{ }^{\circ} \mathrm{C}$.

Ahmed et al. [67] experimentally studied convective heat transfer of $\mathrm{SiO}_{2}$ /water nanofluid flow in trapezoidal, sinusoidal and straight channels.

The experimental setup included a test section, thermocouples, plate heater, flowmeter, differential pressure transducer, data logger, power regulator, and multimeter and water chiller, which consisted of a pump, a condensing unit, and a tank. The test section consisted of the top and bottom walls and two sidewalls. The upper and lower (corrugated) walls of 
the test section were built with copper plates $8 \mathrm{~mm}$ thick, $50 \mathrm{~mm}$ wide, and $240 \mathrm{~mm}$ long. However, the shape of corrugations was achieved using wire electric discharge machining (WEDM). The sidewalls of the test section were made of acrylic, with a thickness of $8 \mathrm{~mm}$, to reduce heat losses to the environment. Each of them had two axial grooves (along the length of the sidewall) to prevent fluid from escaping from the test section. The test section was assembled and the corrugated wall-to-wall junction was sealed using thermal epoxy. In this study, three different channel shapes were built and tested such as trapezoidal, sinusoidal, and straight channels, as shown in Figure 15. The average distance $(\mathrm{H})$ between the upper and lower walls was $10 \mathrm{~mm}$, the channel width (W) was $50 \mathrm{~mm}$, the axial length of the test section was $240 \mathrm{~mm}$, the wavelength of the corrugated canal (L) was $20 \mathrm{~mm}$, and the width of the corrugated channel was $2.00 \mathrm{~mm}$. In order to create appropriate conditions for the inflow and outflow of the test section, two adiabatic rectilinear ducts, an upstream acrylic duct of $800 \mathrm{~mm}$ and a downstream acrylic duct of $200 \mathrm{~mm}$ in length, were used. A 0.4 HP pump was used to drive the working fluid from the eight-liter tank to flow through the test section. Two $320 \mathrm{~W}$ heater plates were placed to the rear faces of the top and bottom walls of the test section. To prevent heat loss to the surrounding, two layers of fiberglass insulation ( $5 \mathrm{~cm}$ thick) enveloped the test section. An AC power regulator unit, connected to the electrical heater (W5 SERIES, SPINE), was used to control the input voltage and current to the heaters. A digital multimeter (BK PRECISION, 2831 C) was connected to the circuit of the electrical heater to measure the current and the voltage. Six thermocouples were fixed at the rear face of the upper wall of the channel at 30, 70, $110,150,190$, and $230 \mathrm{~mm}$ from the inlet of the test section to measure wall and bulk fluid temperature. Furthermore, four thermocouples were installed to measure inlet and outlet fluid temperature. A bypass line with a valve was used to adjust the flow rate of the pump. A flowmeter (FC-SD70-R15, TOFCO) was connected between the pump and the inlet of the developing section to measure the flowrate of the fluid. A chiller, with $1 \mathrm{~kW}$ cooling capacity, was placed inside the tank to adjust the temperature of the working fluid before it entered the test section. In this study, the temperature of the working fluid considered was $25^{\circ} \mathrm{C}$. A differential pressure transducer (PX409-10WDWUI) with a panel meter (DP24-E-230) was used to measure the pressure drop across the test section. At a steady state condition, the pressure drop, the flowrate, the bulk fluid temperature at the inlet and the outlet of the test section, as well as the wall temperature of the test section were recorded. After each experiment, the system was cleaned with pure water.

Experimental results showed that the Nusselt number increased by increasing the Reynolds number and nanoparticle volume concentration for all the shapes considered. In particular, the highest Nusselt mean number and the greatest increase in heat transfer was obtained using the trapezoidal corrugated channel, followed by the sinusoidal and straight corrugated channel. For instance, the average Nusselt number enhancement for trapezoidal, sinusoidal, and straight channel, at $\operatorname{Re}=3000$ and $1 \mathrm{vol} \%$, was approximately $5.87,5.12$, and 1 , respectively.

Aghabozorg et al. [68] investigated the enhancement in heat transfer coefficient of $\mathrm{Fe}_{3} \mathrm{O}_{2}-\mathrm{CNT} /$ water nanofluid flow inside a horizontal shell and tube heat exchanger under laminar, transient and turbulent flow with three different heat fluxes.

The setup consisted of a pump, a test section, a tank, and a shell and tube heat exchanger. The test section consisted of a copper tube (11.42 mm inner diameter, $793 \mathrm{~mm}$ length) with the surface that was electrically heated by an AC power supply to yield three different heat flux with 3 voltage $(\mathrm{V}=80,120$ and $150 \mathrm{~V})$ and was insulated using a $150 \mathrm{~mm}$ thick blanket, to reduce the heat loss from the tube to the ambient. Five Ktype thermocouples were placed on the outer surface of the test section to measure the wall temperature of the tube. To measure the temperature of the nanofluids, two K-type thermocouples were fixed at the inlet and outlet of the test section. A pump (HV-77921-40) controlled the flow while a three-way valve regulated the flow rate. The heated fluids returned to the tank passing through a cooling unit (a shell and tube heat exchanger) to keep a constant temperature at the inlet of the test section. The three flow regimes were 
established by volumetric flow rates of $0.96,2.25$, and $3.43 \mathrm{~L} / \mathrm{min}$ and the temperatures during the experimental tests were recorded with a data acquisition system.

a)



b)

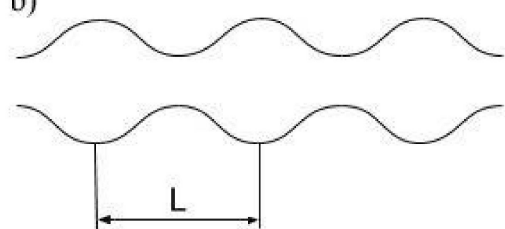

c)

$\mathrm{H}$

Figure 15. Representation of trapezoidal (a), sinusoidal (b), and straight (c) channel.

The results indicated that heat transfer coefficient increased with the voltage, weight concentration, and Reynolds number. For laminar, transient and turbulent flow, the maximum heat transfer coefficient of nanofluids with $0.2 \mathrm{wt} \%$ and a voltage of $150 \mathrm{~V}$ was equal to $3123.432,3777.923$, and $4272.850 \mathrm{~W} / \mathrm{m}^{2} \mathrm{~K}$, respectively.

Colangelo et al. [69] carried out an experimental investigation on the thermal performance of flat solar thermal collectors using $\mathrm{Al}_{2} \mathrm{O}_{3}$ / water nanofluid as heat transfer fluid. The experimental setup consisted of a flow loop, which contained a heating and a cooling unit, a pump, a reservoir tank, a reflux line and valves. The heating unit included a straight aluminum tube with a length of $2070 \mathrm{~mm}$, an inner diameter of $15 \mathrm{~mm}$, and an outer diameter of $45 \mathrm{~m}$, which was used as test section. Three grooves were made along the tube and three $8 \mathrm{~kW}$ cartridge heaters were placed to ensure a constant heat flux. The test section was thermally insulated by two $200 \mathrm{~mm}$ thick mineral wool panels. The flow rate was adjusted by a reflux line with a manual valve and a proportional solenoid valve (SV). After the test section, the heated fluid was cooled in the cooling unit, which included a chiller and a shell and tube heat exchanger. Fifteen K-type thermocouples were installed along the aluminum tube to measure the wall temperature and two T-type thermocouples were fixed at the inlet and outlet side of test section to measure the inlet/outlet fluid temperature. Finally, a thermocouple was installed before the reservoir tank to control fluid temperature. The experimental results showed that the convective heat transfer coefficient of nanofluid was higher than that of water in both laminar and turbulent regimes and increased with an increase in nanoparticle volume fraction, in any axial position. At $\operatorname{Re}=1381$, the enhancement in convective heat transfer was $12 \%$ and $26 \%$ for nanofluid with $1 \mathrm{vol} \%$ and $3 \mathrm{vol} \%$, respectively. At $\operatorname{Re}=5268$, the convective heat transfer increased from $7 \%$ and $25 \%$ for nanofluid with volume concentration of $1 \%$ and $3 \%$, respectively.

The works reported so far have been compared by means of Tables 4 and 5, where it is evident the diversity of investigations carried out and, above all, the dispersion of the results that often are very hard to compare. For this purpose, in the next section, a selection of comparable works is taken, to show, in graphical representations, the obtained results.

El-Kaddadi et al. [70] studied the characteristics of convective heat transfer using $\mathrm{TiO}_{2}$ water-based nanofluid for a heat storage cycle of charging and discharging in a vertical cylindrical system. 
The experimental setup included two reservoirs, a flowmeter (Tecfluid pt-11/PVC), a test section, a pump (Salmson NXL), an expansion tank, and a data logger system (OMBDAQ-2416). Two stainless-steel vertical concentric tubes with a length of $500 \mathrm{~mm}$, an inner diameter of $27.5 \mathrm{~mm}$, and an outer diameter of $102.5 \mathrm{~mm}$ were used as the test section. The thickness of the internal and external tubes was $2 \mathrm{~mm}$ and $4 \mathrm{~mm}$, respectively. The test section was insulated with $30 \mathrm{~mm}$ thick glass wool to prevent heat loss. A reservoir contained hot water at a constant temperature of $60^{\circ} \mathrm{C}$ using an electrical heating system and the other one was filled with cold water at a temperature of $18-20^{\circ} \mathrm{C}$. The nanofluid was contained in the annular space between the two concentric tubes; meanwhile, the pump pushed the hot/cold water through the test section in the upward direction. The flowmeter was mounted at the outlet section of the test section to measure the flow rate and to determine the laminar or turbulent nature of the flow. Fourteen K-type thermocouples were placed along the external tube surface and at the inlet/outlet section to measure the wall temperature in the longitudinal direction and the fluid temperature. Each heat storage cycle had a duration of 55 min that corresponded to the charging period and the time to reach the steady-state condition.

The experimental results showed that the convective heat transfer coefficient improved by increasing the weight fraction of the nanofluid. Higher values of the average heat transfer coefficient were observed in the discharging period. The maximum enhancement in convective heat transfer was $13.88 \%, 14.44 \%$, and $13.78 \%$ for nanofluid with $0.01 \mathrm{wt} \%$, in the discharging period, at a flow rate of 100, 200, and $300 \mathrm{~kg} / \mathrm{h}$, respectively. The increase of the average convective heat transfer during the cycle was approximately $30 \%$ compared to that of pure water.

Wen et al. [71] investigated the characteristics of heat transfer using $\mathrm{ZnO} /$ water-based nanofluid in two multiport mini-channels.

The experimental system included a gear pump, a reservoir, a chiller, and a test section. The working fluid was circulated from the reservoir into the flow loop with the aid of a pump. The flowmeter was located at the outlet section of the pump to measure the flow rate. The test section consisted of two multiport mini-channels, composed of 10 and 11 channels with hydraulic diameters of $1.22 \mathrm{~mm}$ and $1.42 \mathrm{~mm}$, respectively, and a length of $270 \mathrm{~mm}$. The test section was covered with a rectangular electric heating layer of polyimide supplied by a DC power and insulated with insulation heating foam to prevent heat loss. Before entering the test section, the fluid passed through a cold and a hot water bath to reach the desired temperature and then went into a flow distributor to obtain a uniform flow distribution. Five T-type thermocouples were placed along the surface of the tube with a distance of $40 \mathrm{~mm}$ to measure the wall temperature and two more were mounted at the inlet and outlet section to measure the fluid temperature.

It was found that the heat transfer coefficient and the Nusselt number increased by increasing the Reynolds number and volume nanoparticle concentration. Considering a mini channel with a hydraulic diameter of $1.42 \mathrm{~mm}$, the average enhancement in heat transfer coefficient was 3.6\% and $8.9 \%$ for nanofluid with $0.75 \mathrm{vol} \%$ and $1.5 \mathrm{vol} \%$ at $\operatorname{Re} 1680$. For the same nanofluids, but at a higher Reynolds number, the maximum increase in heat transfer coefficient was $14.8 \%$ and $33.5 \%$.

In the channel with a diameter of $1.22 \mathrm{~mm}$ using nanofluid with $0.75 \mathrm{vol} \%$ and $1.5 \mathrm{vol} \%$, the average increase in heat transfer coefficient was $5.8-10.7 \%$ at $\operatorname{Re} 1430$ and $10.5-29.5 \%$ at a higher Reynolds number. The Nusselt number increased by increasing the nanoparticle concentration and Reynolds number. The enhancement in the Nusselt number was 32.6\% and $28.9 \%$ for $1.5 \mathrm{vol} \%$ nanofluids at Re1600 in the channel with a hydraulic diameter of $1.42 \mathrm{~mm}$ and $1.22 \mathrm{~mm}$, respectively. 
Table 4. Summary of experimental studies on different types of nanofluid.

\begin{tabular}{|c|c|c|c|c|c|}
\hline & Nanofluid & Concentration & Flow Regime & Experimental Setup & Results \\
\hline [1] & $\mathrm{Al}_{2} \mathrm{O}_{3} /$ water & $\begin{array}{l}0.2 ; 0.5 ; 1 ; 1.5 \\
\quad 2.0 ; 2.5 \\
\quad(\text { vol } \%)\end{array}$ & $\begin{array}{c}\text { Laminar: } \\
700 \leq \operatorname{Re} \leq 2050\end{array}$ & Circular tube with constant wall temperature & $\begin{array}{l}\text { The heat transfer coefficient of nanofluid increases with Péclet } \\
\text { number as well as nanoparticles concentration. }\end{array}$ \\
\hline [3] & $\mathrm{Al}_{2} \mathrm{O}_{3} /$ water & $\begin{array}{c}1 ; 2 \\
(\mathrm{vol} \%)\end{array}$ & $\begin{array}{c}\text { Laminar: } \\
226 \leq \operatorname{Re} \leq 1676\end{array}$ & Microchannel heat sink & $\begin{array}{l}\text { For the nanofluid containing } 1 \text { vol } \% \text { alumina, the maximum } \\
\text { enhancement of about } 70 \% \text { in the average heat transfer } \\
\text { coefficient can be found at } \operatorname{Re}=1544 \text {. }\end{array}$ \\
\hline [4] & $\mathrm{Al}_{2} \mathrm{O}_{3} /$ water & $\begin{array}{c}0.1 ; 4 \\
(\mathrm{vol} \%)\end{array}$ & $\begin{array}{c}\text { Laminar: } \\
\text { Natural convection } \\
6.21 \times 10^{5} \leq \mathrm{Ra} \leq 2.56 \times 10^{8}\end{array}$ & Vertical square enclosures of different size & $\begin{array}{c}\text { For the nanofluids containing much lower particle fraction of } 0.1 \\
\mathrm{vol} \% \text {, a heat transfer enhancement of approximately } 18 \% \text { greater } \\
\text { than that of the base fluid for the largest enclosure at a high } \\
\text { Rayleigh number was found. }\end{array}$ \\
\hline [5] & $\mathrm{Al}_{2} \mathrm{O}_{3} /$ water & $\begin{array}{c}0.1 \\
(\mathrm{vol} \%)\end{array}$ & $\begin{array}{l}\text { Laminar: } \\
600 \leq \operatorname{Re} \leq 2275\end{array}$ & Circular pipe with coil inserts under constant heat flux & $\begin{array}{l}\text { An increase in the Nusselt number of } 15.91 \% \text { and } 21.53 \% \text { is } \\
\text { obtained at } \operatorname{Re}=2275 \text { for } 0.1 \text { vol } \% \text { of nanofluid using wire coil } \\
\text { inserts with a pitch ratio of } 2 \text { and 3, respectively. }\end{array}$ \\
\hline [6] & $\mathrm{Al}_{2} \mathrm{O}_{3} /$ water & $\begin{array}{c}0-4 \\
\text { vol } \%\end{array}$ & $\begin{array}{c}\text { Laminar } \\
300 \leq \text { Re } \leq 900 \\
\text { Mixed convection } \\
5 \times 10^{5} \leq \operatorname{Ra} \leq 9.6 \times 10^{5}\end{array}$ & Inclined copper tube with uniform wall heat flux & $\begin{array}{l}\text { An increase in the particle volume fraction from } 0 \% \text { to } 4 \% \text { leads } \\
\text { to a decrease in the Nusselt number for a horizontal tube. At Re } \\
=500 \text { a } 14 \% \text { decrease in the Nusselt number is observed. For the } \\
\text { vertical tube, the Nusselt number remains approximately } \\
\text { constant by increasing particle concentration, but it decreases } \\
\text { with the increase of the Reynolds number. }\end{array}$ \\
\hline [7] & $\mathrm{CuO} /$ base oil & $\begin{array}{l}0.07 ; 0.15 ; 0.3 \\
\quad(\text { vol } \%)\end{array}$ & $\begin{array}{l}\text { Laminar: } \\
10 \leq \operatorname{Re} \leq 120\end{array}$ & Horizontal coiled wire inserted tube under constant heat flux & $\begin{array}{l}\text { Nanofluid had better heat transfer performance when it flows } \\
\text { inside the tubes with wire coil inserts instead of flowing inside } \\
\text { the plain tube. The greatest heat transfer enhancement of } 40.2 \% \text {, } \\
\text { above the values for pure oil in the plain tube was obtained for } \\
0.3 \text { vol\% nanofluid inside the wire coil tube with the highest } \\
\text { wire diameter. }\end{array}$ \\
\hline [8] & $\begin{array}{l}\mathrm{Al}_{2} \mathrm{O}_{3-}^{-} \\
\mathrm{Cu} / \text { water }\end{array}$ & $\begin{array}{c}0.1 \\
(\mathrm{vol} \%)\end{array}$ & Laminar & Circular tube under constant heat flux & $\begin{array}{l}\text { The average increase in the Nusselt number for } \mathrm{Al}_{2} \mathrm{O}_{3}-\mathrm{Cu} / \text { water } \\
\text { hybrid nanofluid is } 10.94 \% \text {, when compared to pure water. The } \\
\text { maximum enhancement obtained is } 13.56 \% \text { at } \mathrm{Re}=1730 \text {. }\end{array}$ \\
\hline [9] & $\mathrm{Al}_{2} \mathrm{O}_{3} /$ water & $\begin{array}{c}0.1-2 \\
(\mathrm{vol} \%)\end{array}$ & Laminar & Horizontal tube & $\begin{array}{c}\text { At } \operatorname{Re}=330 \text {, the heat transfer enhancement is } 3 \% \text { for nanofluid } \\
\text { with } 0.001 \mathrm{vol} \% \text {. } \\
\text { At } \operatorname{Re}=2100 \text {, the heat transfer enhancement is } 32 \% \text { for nanofluid } \\
\text { with } 2 \text { vol } \% .\end{array}$ \\
\hline [10] & $\mathrm{CuO} /$ base oil & $\begin{array}{l}0.5 ; 1 ; 2 \\
(w t \%)\end{array}$ & $\begin{array}{l}\text { Laminar: } \\
\operatorname{Re} \leq 150\end{array}$ & Horizontal helically coiled tube under constant heat flux & $\begin{array}{c}\text { For nanofluids with } 2 \mathrm{wt} \% \text {, the maximum enhancement in heat } \\
\text { transfer coefficient of } 78.4 \% \text { is obtained for helical tube at } \\
\text { Reynolds number of } 82.2 \text {. }\end{array}$ \\
\hline
\end{tabular}


Table 4. Cont.

\section{Nanofluid} Concentration

Flow Regime
$[11]$

$\mathrm{Al}_{2} \mathrm{O}_{3} /$ water

$0.1 ; 0.2$

(vol\%)
Laminar

Laminar:

Natural convection

- $\mathrm{Ra}=30,855,746$ and $\mathrm{Ra}=63,943,592$

- $\mathrm{Ra}=38,801,494$ and $\mathrm{Ra}=67,175,834$

$-0.5 \mathrm{vol} \%$

$-0.77 \mathrm{vol} \%$
Experimental Setup

Wide rectangular microchannel heat sink
Square enclosure

\section{Results}

At $\operatorname{Re}=400$, the average Nusselt number for pure water and $3 \%$ nanofluid is 8432 and 19,408 , water and $3 \%$ nanoflid is 8432 and 19,408 , respectively. This corresponds to $130 \%$ thermal performance enhancent. average Nusselt number is achieved by using smaller sized nanoparticles.

The results show an enhancement of $57 \%$ in the heat transfer coefficient for nanofluid $10 \mathrm{wt} \%$ at $\operatorname{Re}=1515$.

Compared to pure water, the heat transfer of nanofluid shows an enhancement at a low nanoparticle mass fraction $(\mathrm{wt} \%=1 \%)$, it is almost the same at $\mathrm{wt} \%=2 \%$ and it is lower at a high nanoparticle mass fraction $(\mathrm{wt} \%=3 \%)$.

The Nusselt number depends on the volume concentration of nanofluid, Reynolds number and the inlet temperature. The highest Nusselt numb enter is $82 \%$ for $1 \mathrm{vol} \%$ nanofluid at $80^{\circ} \mathrm{C}$.

It was found that the Nusselt number increases by increasing particle weight concentration. The maximum enhancement is achieved in a horizontal microfin tube at $0.2 \mathrm{wt} \%, \mathrm{P}=600 \mathrm{~W}$ and $\mathrm{Ri}=10$.

Results indicate that the convective heat transfer coefficient increases with the increasing of the

Reynolds number, and at a certain Reynolds number

the convective heat coefficient increases by increasing nanoparticle weight fraction. The maximum enhancement of the convective heat transfer coefficient at $0.3 \%, 0.8 \%$, and $1.5 \mathrm{wt} \%$ are approximately $6.6 \%, 13.5 \%$, and $23.7 \%$, respectively. It is found that the convective heat transfer coefficient of nanofluids increases with the increase in the Reynolds number and particle volume fraction. The Reynolds number and particle volume fraction. The
maximum enhancement of $21 \%$ in the average heat maximum enhancement of $21 \%$ in the average heat
transfer coefficient is obtained with nanofluid of 2.3 $\mathrm{vol} \%$ at $\operatorname{Re}=940$.

Laminar:
$300 \leq \operatorname{Re} \leq 2100 \quad$ Solar heat exchangers

The maximum enhancement obtained is $12.75 \%$ corresponding to $100 \mathrm{~W}$ as heating power. Enhancement reduces to $3.51 \%$ and $2.51 \%$ for heating power of $125 \mathrm{~W}$ and $150 \mathrm{~W}$, respectively. 
Table 4. Cont.

\section{Nanofluid} Concentration

Flow Regime
Experimental Setup
Laminar:
$812 \leq \operatorname{Re} \leq 1896$
Vertical helical coiled heat exchanger
$0.1-0.5$

Heat sink with rectangular microchannel
$0.01 ; 0.0$

$(\mathrm{wt} \%)$

Laminar

$\mathrm{Ag} /$ water

ron Oxide

[21] (III)-Therminol 66/oil

based

$0-0.3$

$(\mathrm{wt} \%)$

$0.1 ; 0.25 ; 0.5$

(vol\%)

[22] $\mathrm{ZrO}_{2} /$ water

$600 \leq \operatorname{Re} \leq 2100$

Laminar

$0.003 \%$

( $\mathrm{vol} \%)$

$1350 \leq \operatorname{Re} \leq 2170$

[23] $\mathrm{CuO} /$ water
Circular copper tube

\section{Results}

The convective heat transfer coefficient increases by increasing the particle volume fraction of nanofluid and the Reynolds number. At $\operatorname{Re}=1625$, the improvement in convective heat transfer is approximately $10.5 \%$ and $70 \%$ using nanofluids with $0.1 \mathrm{vol} \%$ and $0.5 \mathrm{vol} \%$, respectively.

Results demonstrate that an increase in heat flux, fluid flow rate, Reynolds number, and the mass

concentration of nanofluid increases the heat transfer coefficient. In particular, at $0.1 \mathrm{wt} \%$ of $\mathrm{Ag} /$ water nanofluid the heat transfer coefficient enhancement is $45 \%$

The heat transfer coefficient increases with an increase in the Reynolds number. At the highest Reynolds number and nanofluid weight concentration, the radiator experiences a $46.3 \%$ increase in heat transfer compared to the base fluid.

The highest value in the Nusselt number enhancement is obtained for nanofluid with a volume concentration of $0.5 \%$ in the backward flow using conical strip inserts with a twist ratio of 2.5.

The convective heat transfer coefficient increases with Th increase in the Reynolds number and heas flux. It an increase in the Reynolds number and heat flux. It assumes greater values in the entrance area of the test section and decreases with the axial distance. It is obtained an enhancement of $8 \%$ in heat transfer
coefficient using nanofluid with $0.003 \mathrm{vol} \%$ at $\operatorname{Re}=1350$.

Experimental results show that the convective heat transfer coefficient increases by increasing the

Reynolds number and nanoparticle weight fraction. It also decreases with the axial distance so it assumes a maximum value at the entrance of the test section. The highest enhancement in heat transfer coefficient is observed for graphene nanofluid at $0.5 \mathrm{wt} \%$ at the

$$
\text { flow rate of } 50 \mathrm{~mL} / \mathrm{s} \text {. }
$$

It is found that the convective heat transfer coefficient of the nanofluid increases with the increase in the Reynolds number, nanoparticle concentration, and flow rate. The maximum enhancement in convective heat transfer is about $10 \%$ for nanofluid with $1.2 \mathrm{vol} \%$ and at a constant flow rate of $13 \mathrm{~L} / \mathrm{min}$. 
Table 4. Cont.

\section{Nanofluid}

Concentration

$\mathrm{ZnO} /$ water

$0.1 ; 0.2 ; 0.3$

Car radiator $(\mathrm{vol} \%)$

$(\mathrm{vol} \%)$

$186 \leq \operatorname{Re} \leq 112$

Flow Regime

\section{Experimental Setup}

\section{Results}

The experimental results show that therma performance of the automobile radiator improves using nanofluid instead of base fluid. The greatest improvement in heat transfer rate, overall heat transfer coefficient, and the Nusselt number is approximately $41 \%, 50 \%$, and $31 \%$ respectively for the nanofluid with a nanoparticle volume concentration of $0.2 \%$.

Experimental results showed that, at the same

Reynolds number and nanofluid inlet temperature, Reynolds number and nanofluid inlet temperature, the convective heat transfer coefficient increased by increasing volume concentration of nanoparticles an flow rate. For nanofluid with $2 \mathrm{vol} \%$, an inlet temperature of $20^{\circ}$, at a flow rate of $5 \mathrm{~L} / \mathrm{min}$ and heat flux input of $1100 \mathrm{~W}$ the maximum enhancement in convective heat transfer was approximately $49 \%$

$$
\text { compared to that of water. }
$$

The experimental results show that at constant Prandtl number, the heat transfer coefficient increase by increasing the Reynolds number and nanoparticle volume concentration. The same trend is observed when the Reynolds number is kept constant and Prandtl number increases.

It is found that the average Nusselt number and heat transfer increases with the increase of Rayleigh number, temperature difference, and volume concentration of nanoparticles up to $0.05 \mathrm{vol} \%$. For nanofluids with a higher volume fraction of nanoparticles, a worse thermal performance is observed. It is found that the convective heat transfer coefficient increases by increasing the Reynolds number, volume concentration of nanofluid and inlet temperature. The createst ear $0 x=1500$ and at an inlet temperature of $70^{\circ} \mathrm{C}$. $\operatorname{Re}=1500$ and at an inlet temperature of $70^{\circ} \mathrm{C}$.

The experimental results show that the convective heat transfer coefficient increases using $\mathrm{Al}_{2} \mathrm{O}_{3}-\mathrm{Cu}$ / oil-based nanofluid instead of pure oil and it reaches a higher value by increasing the Reynolds number. The maximum enhancement in the Nusselt number is $12.06 \%$ for nanofluid with $0.1 \mathrm{vol} \%$ at $\operatorname{Re}=1820$. 
Table 4. Cont.

Nanofluid Concentration

Flow Regime

\section{$0.025-0.2$}

$\mathrm{ZnO}$ oil

$(\mathrm{wt} \%)$

$1 ; 2 ; 5$

$(\operatorname{vol} \%)$

[33] $\mathrm{CuO}$ and $\mathrm{Al}_{2} \mathrm{O}_{3} /$ water

$\begin{array}{lc}\mathrm{Al}_{2} \mathrm{O}_{3} / \text { non- } & 1 ; 2 ; 3 ; 4 \\ \text { Newtonian } & \text { (vol\%) }\end{array}$

$1 ; 2 ; 3 ; 4$
(vol\%)

Turbulent

Helicoidal heat exchanger

\section{Flat-plate}

solar collector

Air conditione

The greatest enhancement in thermal performances for f-GNPs, $\mathrm{SiO}_{2}$, and $\mathrm{ZnO}$ nanofluid with a weight nanoparticle concentation of $0.1 \%$ at a mass flow rate of $1.6 \mathrm{~kg} / \mathrm{min}$ is $17.45 \%, 12.36 \%$, and $13.05 \%$, respectively.

It is noticed that the heat transfer increased by increasing the volume nanoparticle fraction from $1 \%$

to $5 \%$. The maximum enhancement in thermal performance of the air conditioning system using $\mathrm{Al}_{2} \mathrm{O}_{3}$ and $\mathrm{CuO}$ water based nanofluid is $21.9 \%$ and $29.5 \%$, respectively.

It was observed that the thermal performance of helical heat exchanger equipped with corrugated turbulators was $10 \%$ higher compared to that with turbulators was $10 \%$ higher compared to that with smooth channels using nanofluid with a volume concentration of $1 \%$. The heat transfer increased with the increase of the Reynolds number, nanoparticle volume fraction, and the diameter size of nanoparticle $(20-50 \mathrm{~nm})$. In particular, the maximum enhancement in thermal performance index was $15 \%$ using $4 \mathrm{vol} \%$ nanofluid at $\operatorname{Re}=5000$

Results show that the convective heat transfer coefficient increases by increasing Reynolds numbers and nanoparticle concentrations. The heat transfer coefficient enhancement is 40.26 and $22.79 \%$ for MWCNTs and Graphene nanofluids at $0.5 \mathrm{wt} \%$ and Reynolds number of 4448 .

It was found that by using ethylene glycol instead of water as base fluid the thermal performance improved by $10 \%$, considering the Nusselt number as a term of

comparison. In particular, at a flow rate of 0.15

$\mathrm{Al}_{2} \mathrm{O}_{3}$ and $\mathrm{TiO}_{2} /$ water

[36] and ethylene glycol
$0.05-0.5$

$(\mathrm{vol} \%)$
Porous media

USGPM, an inlet temperature of $20^{\circ} \mathrm{C}$ and a heat flux of $60,000 \mathrm{~W} / \mathrm{m}^{2}$ the Nusselt number was higher using titanium oxide ethylene glycol-based nanofluid in lieu of aluminum oxide ethylene glycol-based nanofluid.

For a mass flow rate of $0.0178 \mathrm{~kg} / \mathrm{s}$, the increase in

Turbulent

Electronic heat sink: a thin channeled copper heat sink $59 \times 59 \times 12.6 \mathrm{~mm}$
[37] $\mathrm{Al}_{2} \mathrm{O}_{3}-\mathrm{Cu} /$ wate (vol\%) nanofluid was used as coolant in the heat sink was $25.2 \%$ compared to that of deionized water. 
Table 4. Cont.

\section{Nanofluid} Concentration

Flow Regime

\section{Turbulent}

[38] $\mathrm{Al}_{2} \mathrm{O}_{3} /$ water

$0 ; 2.8 ; 6$

$(\mathrm{vol} \%)$
$3800 \leq \operatorname{Re} \leq 88,000$

$5 \leq \operatorname{Pr} \leq 10$

[39] $\mathrm{CuO} /$ water
$0.015 ; 0.031 ; 0.039 ; 0.78$
$0.0118 ; 0.157 ; 0.236$
( $\mathrm{vol} \%)$

Turbulent:

Turbulent:
$6000 \leq \operatorname{Re} \leq 31,000$

$0.1 ; 0.5 ; 1.0$
$(\mathrm{wt} \%)$

[40]

$\mathrm{Al}_{2} \mathrm{O}_{3} / \mathrm{EG}$

$\mathrm{CuO} / \mathrm{EG}$

$0.1 ; 0.3 ; 0.5 ; 0.7$;

$1.0(\mathrm{wt} \%)$

Turbulent

Confined and submerged impinging jet heat transfer
Double pipe and plate heat exchangers

Experimental Setup

Results

Highest surface heat transfer coefficients can be achieved using an intermediate distance nozzle-heated surface of $5 \mathrm{~mm}$ and $2.8 \mathrm{vol} \%$.

nozzle-heated surface of $5 \mathrm{~mm}$ and $2.8 \mathrm{vol} \%$.
Nanofluids with higher particle fraction appear to be

inappropriate for the purpose of enhancing heat transfer in the confined and submerged jet configuration.

The heat transfer coefficient increases about $25 \%$, but its enhancement is not affected by the increase of the nanoparticle concentration.

In both heat exchangers, heat transfer is considerably enhanced for nanofluids compared to the base fluid. In a double pipe heat exchanger it is $26 \%$ for $1.0 \mathrm{wt} \%$ In a doub 源 plate heat exchanger, these are $38 \%$ and $49 \%$, respectively.

The Nusselt number increases by about $19.49 \%$, $27.06 \%$, and $39.53 \%$ with the nanoparticles'

concentration under turbulent flow through the
dimple tube. concentration under turbulent flow through the
dimple tube.

Nusselt number increases by increasing the Reynolds number and volume concentration. The enhancement of heat transfer coefficient in a plain tube with $0.6 \%$ of heat transfer coefficient in a plain tube with $0.6 \%$ volume concentration of $\mathrm{Fe}_{3} \mathrm{O}_{4}$-water nanofluid is
$20.99 \%$ and $30.96 \%$ at $\mathrm{Re}=3000$ and $\mathrm{Re}=22.000$, respectively, compared to water.

The maximum increase in the convective heat exchange coefficient is $2 \%$ for $\mathrm{Al}_{2} \mathrm{O}_{3} /$ water nanofluid and it is higher than $11 \%$ of that of pure water. The rate of heat transfer decreases as the concentration of nanoparticles increases. Therefore, the use of nanofluids with a volume fraction greater than $2 \%$ should be avoided.

The convective heat transfer coefficient increases with the flow rate and volume fraction of the nanoparticles and the maximum increase in the convective heat transfer coefficient is $29.03 \%$ for $0.2 \%$ volume fraction

\begin{tabular}{|c|c|c|c|c|c|}
\hline$[44]$ & $\mathrm{CuO} /$ water & $\begin{array}{l}0.1 ; 0.2 \\
(\mathrm{vol} \%)\end{array}$ & $\begin{array}{c}\text { Turbulent: } \\
2985 \leq \operatorname{Re} \leq 9360\end{array}$ & Electronic heat sink. & $\begin{array}{l}\text { the flow rate and volume fraction of the nanoparticles } \\
\text { and the maximum increase in the convective heat } \\
\text { transfer coefficient is } 29.03 \% \text { for } 0.2 \% \text { volume fraction } \\
\text { compared to pure water. }\end{array}$ \\
\hline
\end{tabular}


Table 4. Cont.

\begin{tabular}{|c|c|c|c|c|c|}
\hline & Nanofluid & Concentration & Flow Regime & Experimental Setup & Results \\
\hline [45] & $\mathrm{CuO} /$ water & $\begin{array}{l}0.1 ; 0.2 \\
(\mathrm{vol} \%)\end{array}$ & $\begin{array}{c}\text { Turbulent: } \\
1600 \leq \text { De } \leq 4000 \\
\text { (horizontal position) } \\
1592 \leq \text { De } \leq 4020 \\
\text { (vertical position) }\end{array}$ & $\begin{array}{l}\text { Horizontal and vertical helical coiled heat } \\
\text { exchanger }\end{array}$ & $\begin{array}{l}\text { For horizontal helical coiled tube, the increase in the } \\
\text { Nusselt number for nanofluid of } 0.1 \% \text { and } 0.2 \% \\
\text { volume concentration compared to that of water is } \\
36 \% \text { and } 45 \% \text { respectively. For vertical helical coiled } \\
\text { tube, considering the same nanoparticle volume } \\
\text { concentrations, an increase in the Nusselt number of } \\
37 \% \text { and } 49 \% \text {, respectively, is obtained. }\end{array}$ \\
\hline [46] & $\mathrm{TiO}_{2} /$ water & $\begin{array}{l}\text { From } 0.002 \text { to } 0.2 \\
\quad(\mathrm{vol} \%)\end{array}$ & $\begin{array}{l}\text { Turbulent: } \\
8000 \leq \operatorname{Re} \leq 51,000\end{array}$ & $\begin{array}{l}\text { Horizontal double tube counter-flow heat } \\
\text { exchanger }\end{array}$ & $\begin{array}{l}\mathrm{TiO}_{2} \text { nanofluids of } 0.002 \text { and } 0.2 \mathrm{vol} \% \text { have convective } \\
\text { heat transfer coefficients that are } 15 \% \text { and } 75 \% \text {, } \\
\text { respectively, higher than those produced by the base fluid. }\end{array}$ \\
\hline [47] & Ag-DI water & $\begin{array}{l}50 ; 200 ; 600 \\
\quad(\mathrm{ppm})\end{array}$ & Turbulent & Medium-sized cylindrical meshed heat pipe & $\begin{array}{c}\text { By applying } 50 \mathrm{ppm} \text { of nanofluid, the thermal } \\
\text { resistance and the response time of the heat pipe } \\
\text { decreased by } 30 \% \text { and } 20 \% \text {, respectively, compared to } \\
\text { DI-water. }\end{array}$ \\
\hline [48] & $\mathrm{TiO}_{2} /$ water & $\begin{array}{l}1 ; 1.5 ; 2 \\
(\mathrm{vol} \%)\end{array}$ & $\begin{array}{l}\text { Turbulent: } \\
8000 \leq \operatorname{Re} \leq 55,000\end{array}$ & $\begin{array}{l}\text { Horizontal double tube counter flow heat } \\
\text { exchanger }\end{array}$ & $\begin{array}{l}\text { The Nusselt number increases by increasing the } \\
\text { Reynolds number and volume concentration. } \\
\text { Nanofluid with } 20 \mathrm{~nm} \text { particle size diameter shows } \\
\text { higher thermal performance than the other particle } \\
\text { size diameters. The value of the maximum increase in } \\
\text { the Nusselt number of } 98.87 \% \text { was obtained for } \\
\text { nanofluid with a nanoparticle diameter of } 20 \mathrm{~nm} \text { and } \\
\text { particle volume fraction of } 2 \% \text { at } \operatorname{Re}>26,000 \text {. }\end{array}$ \\
\hline [49] & $\mathrm{Al}_{2} \mathrm{O}_{3} /$ water & $\begin{array}{l}0.5 ; 1 ; 2 ; 5 \\
\quad(\mathrm{vol} \%)\end{array}$ & $\begin{array}{l}\text { Turbulent: } \\
4000 \leq \operatorname{Re} \leq 20,000\end{array}$ & Circular pipe & $\begin{array}{l}\text { The Nusselt number increases by adding } \\
\text { nanoparticles into pure water with particle volume } \\
\text { concentration lower than } 2 \text { vol } \% \text { and increasing the } \\
\text { Reynolds number. The greatest heat transfer } \\
\text { enhancement is obtained at } \operatorname{Re}=8000 \text { and } 0.5 \mathrm{vol} \% \text {. }\end{array}$ \\
\hline [50] & $\mathrm{SiO}_{2} /$ water & $\begin{array}{c}0.5 ; 4 \\
(\mathrm{vol} \%)\end{array}$ & $\begin{array}{c}\text { Turbulent: } \\
5000 \leq \operatorname{Re} \leq 27,000\end{array}$ & $\begin{array}{l}\text { Circular tube under constant heat flux } \\
\text { boundary condition }\end{array}$ & $\begin{array}{l}\text { The heat transfer coefficient increases for nanofluids } \\
\text { with a volume concentration up to 3\% and } \\
\text { subsequently decreases. }\end{array}$ \\
\hline [51] & $\mathrm{Al}_{2} \mathrm{O}_{3} /$ water & $\begin{array}{c}1 \\
(\mathrm{vol} \%)\end{array}$ & $\begin{array}{c}\text { Turbulent: } \\
5000 \leq \operatorname{Re} \leq 20,000\end{array}$ & Double tubes heat exchanger & $\begin{array}{l}\text { The maximum enhancement in the Nusselt number is } \\
\text { about } 20 \% \text { for } 1 \mathrm{vol} \% \text { of nanoparticle concentration. }\end{array}$ \\
\hline [52] & $\begin{array}{l}\text { MWCNT- } \\
\mathrm{Fe}_{3} \mathrm{O}_{4} / \text { water }\end{array}$ & $\begin{array}{l}0.1 ; 0.3 \\
(\mathrm{vol} \%)\end{array}$ & $\begin{array}{l}\text { Turbulent: } \\
3000 \leq \operatorname{Re} \leq 22,000\end{array}$ & $\begin{array}{l}\text { Uniformly heated at constant heat flux circular } \\
\text { tube }\end{array}$ & 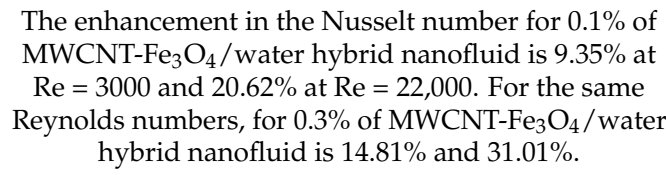 \\
\hline
\end{tabular}


Table 4. Cont.

\section{Nanofluid}

Concentration

Flow Regime

Turbulent:

$5400 \leq \operatorname{Re} \leq 15200$
Experimental Setup

Heat exchanger tube equipped with overlapped dual twisted-tapes
[53] $\mathrm{TiO}_{2} /$ water
( $\mathrm{vol} \%)$

$0.5 ; 1.0 ; 1.5 ; 2$

$(\mathrm{vol} \%)$
Turbulent:

$2500 \leq \operatorname{Re} \leq 26,000$
Straight pipe

\section{Results}

Overlapped swirling flows, obtained using O-DTs, improve fluid mixing and heat transfer enhancement. The Nusselt number increases with decreasing overlapped twist ratio and increasing $\mathrm{TiO}_{2}$ volume concentration.

The highest heat transfer coefficient and the Nusselt ninimum diamecite at a high

the Reyno ds nu the Reynolds number increases the impact of nanoparticle dimension on heat transfer coefficient and the Nusselt number increases.

Experimental results show that the maximum heat transfer enhancement of $46 \%$ is obtained at $0.2 \%$ nanofluid volume concentration. A decrease in heat transfer enhancement is found for $0.3 \%$ volume concentration compared to $0.2 \%$ volume concentration

The Nusselt number of GNP nanofluid is higher than that of base fluid by approximately $3-83 \%$ and increases as the flow rate and the heat flux increased.

The heat transfer coefficient of nanofluid is higher than that of pure water and it increases by increasing nanoparticle volume concentration and the Reynolds number. The heat transfer coefficient can enhance number. The heat transfer coefficient can enhance
about $57 \%$ by suspending $2 \%$ nanoparticle volume fraction and the maximum thermal performance factor is 1.266 for $2 \mathrm{vol} \%$ nanofluid at $\mathrm{Re}=3677$.

The addition of nanoparticles to the base fluid allows obtaining a higher convective heat exchange coefficient, which can reach a maximum increase of $40.3 \%$. Furthermore, an increase in the Nusselt number and the convective coefficient is obtained by increasing the Reynolds number.

The maximum enhancement in convective heat transfer coefficient at $1.0 \%$ volume concentration is $81.1 \%$ at $\operatorname{Re}=23,917$ for a flow in a tube with twisted tape inserts with a twist ratio of 5 .
Turbulent:
$8000 \leq \operatorname{Re} \leq 30,000$
Tube with twisted tape inserts 
Table 4. Cont.

\section{Nanofluid} Concentration

Flow Regime

Turbulent:

$1 ; 2 ; 3$
$(\mathrm{vol} \%)$

$000 \leq \operatorname{Re} \leq 13,000$
[60] $\mathrm{SiO}_{2} /$ wate
Experimental Setup

Free single jet impingement

\section{Results}

The results show that the convective heat transfer and Reynolds nut $3 \%$ nan $\mathrm{H} / \mathrm{D}=4$ the maximum increase of the heat transfer coefficient was $49 \%$

Results indicate that the performance evaluation parameter (PEC), which depends on the heat transfe coefficient, has a greater value at lower vapor qualities and for higher nanoparticle concentrations.

Convective heat transfer coefficient is improved up to $22.76 \%$ by using $\mathrm{TiO}_{2}$ nanofluid instead of base fluid. The maximum enthancement is found for nanoflid with a volume concentration of $0.2 \%$.

Results show that the overall heat transfer coefficient and convective heat transfer coefficient increase by $7 \%$ and $11.39 \%$, respectively

The average heat transfer increases with the enhancement of the Reynolds number. The nhancement of average Nusselt number is $8-15,7-14$,

7-13, and 6.5-12 for nanofluid with a weight concentration of $0.1 \%, 0.075 \%, 0.05 \%$, and $0.025 \%$, respectively.

[64] ZnO-Eg/water $\quad \begin{array}{cc}0.025 ; 0.05 ; 0.075 ; 0.1 & \text { Turbulent: } \\ (\text { vol } \%) & 5849 \leq \operatorname{Re} \leq 24,5\end{array}$

Horizontal circular tube

The best thermal performance is achieved for an inclination angle of $90^{\circ}$ and the thermal efficiency increases by increasing heat input. For PCA

\section{1-pyrene}

[65] carboxylic-acid

0.06

Turbulent

Heat Pipe

functionalized

$(w t \%)$

functionalized graphene nanofluid with $0.06 \mathrm{wt} \%$, the maximum thermal performance improvement is $49.4 \%$.

In laminar flow condition, the enhancement of the increases of $15 \%$ and $8 \%$, rective
Laminar:

Alumina nanofluids

[66] Amorphous carbonic

nanofluids
$3 ; 3.5$

$3 ; 3.5$
$(\mathrm{vol} \%)$

$\operatorname{Re}=1460$

Turbulent:

$\operatorname{Re}=6020$
Circular straight tube with constant heat flux.
In turbulent flow condition, the heat transfer coefficien

of alumina nanofluid ( $3 \mathrm{vol} \%$ ) increases to $20 \%$; however the enhancement of heat transfer of the amorphous carbonic nanofluid is similar to that of water. 
Table 4. Cont.

Nanofluid Concentration
Flow Regime
Laminar-Turbulent: $400 \leq \operatorname{Re} \leq 4000$
Experimental Setup

Trapezoidal, sinusoidal and straight channe
$\mathrm{SiO}_{2} /$ water

$(\mathrm{vol} \%)$

Laminar.

$\operatorname{Re}=3981.86$

Turbulent:

$(\mathrm{wt} \%)$

$\operatorname{Re}=6070.124$

[68] $\mathrm{Fe}_{3} \mathrm{O}_{2}-\mathrm{CNT} /$ water

$1 ; 2 ; 3$
$(\mathrm{vol} \%)$

Laminar

$\mathrm{Al}_{2} \mathrm{O}_{3} /$ water

(vol\%) (n)

Flat panel solar thermal collector

Horizontal shell and tube heat exchanger

\section{Results}

The Nusselt number increases with the increase of the

Reynolds number and particle volume fraction. The trapezoidal-corrugated channel is recommended as the best channel to achieve the highest thermal performance, followed by sinusoidal-corrugated and straight channel. At $\operatorname{Re}=3000$ the average Nusselt number enhancement is about 5.87 for $1 \mathrm{vol} \%$ nanofluid.

The heat transfer coefficient increases with increasing voltage, weight concentration, and Reynolds number. For laminar, transient and turbulent flow, the aximum heat transfer coefficient of nanofluids with $0.2 \%$ by weight and a voltage of $150 \mathrm{~V}$ is equal to $3123.432,3777.923$ and $4272.850 \mathrm{~W} / \mathrm{m}^{2} \mathrm{~K}$, respectively.

The convective heat transfer of nanofluid increases by increasing the nanofluid volume concentration. At $\operatorname{Re}=1381$, the enhancement in convective heat transfer is $12 \%$ and $26 \%$ for nanofluid with $1 \mathrm{vol} \%$ and $3 \mathrm{vol} \%$, respectively. At $\operatorname{Re}=5268$, the convective heat transfer increases from $7 \%$ and $25 \%$ for nanofluid with volume concentration of $1 \%$ and $3 \%$, respectively.

\section{Vertical cylindrical system}

The maximum enhancement in convective heat transfer is $13.88 \%, 14.44 \%$, and $13.78 \%$ for nanofluid with $0.01 \mathrm{wt} \%$, in the discharging period, at flow rates of 100,200 , and $300 \mathrm{~kg} / \mathrm{h}$, respectively. The increase of the average convective heat transfer during the cycle is approximately $30 \%$ compared to that of pure water.

The Nusselt number increases by increasing the nanoparticle concentration and the Reynolds number. The enhancement in the Nusselt number is $32.6 \%$ and $28.9 \%$ for $1.5 \mathrm{vol} \%$ nanofluids at Re1600 in the chanel $28.9 \%$ f $1.5 \mathrm{vo}$. respectively. 
Table 5. Uncertainty of experimental results for $\mathrm{Al}_{2} \mathrm{O}_{3}$ /water nanofluids.

\begin{tabular}{ll}
\hline & Flow Regime and Experimental Setup \\
\hline [1] Laminar flow in a circular tube \\
\hline [2] Laminar flow in a uniformly heated circular tube
\end{tabular}

Uncertainty Analysis

Uncertainty Analysis
Péclet number, Nusselt number, and Reynolds number are calculated to be $3 \%, 3 \%, 3 \%, 4 \%$, and $2.5 \%$, respectively. The experimental data are compared with the Shah equation and show good agreement within 3\% error.

[3] Laminar flow in a copper microchannel heat sink

The uncertainties for the experimental results are estimated to be $3.8-4 \%$ for the Reynolds number, $5.1-40.8 \%$ for the average heat transfer coefficient, and $4.7-41.0 \%$ for the average Nusselt number.

[4] Natural convection in vertical square enclosures

The uncertainty of the surface heat transfer coefficient, the average Nusselt number and Rayleigh numbers are 5.4-25.4\%, $7.0-26.9 \%$, and $5.7-23.4 \%$, respectively.

[6] Laminar flow inside an inclined tube Comparing the values of the Nusselt numbers calculated analytically and experimentally, it can be seen that the maximum and average errors were respectively $5 \%$ and $2 \%$.

[9] Laminar flow in a horizontal tube The uncertainty analysis is carried out using the theory of the propagation of error. It is found for the Nusselt number an uncertainty less than $\pm 6.0 \%$.

[11] Laminar flow inside a wide rectangular microchannel heat sink

The estimated errors for the average heat transfer coefficient, the average Nusselt number and Reynolds numbers are $5.97 \%, 6.21 \%$, and $4.7 \%$.

The uncertainties for the deducted experimental results are estimated to be 3.8-4.0\% for the Reynolds number, $4.7-16.4 \%$ for the average heat transfer coefficient, and $4.9-16.5 \%$ for the average Nusselt number.

[12] Laminar flow in a microchannel heat sink

The errors of the heat transfer coefficient and the Nusselt number are $5.65 \%$ and $8.275 \%$, respectively.

[13] Natural convection in a square enclosure

The estimated uncertainties are $4.1 \%$ for the heat transfer coefficient and $2.3 \%$ for the Reynolds number.

[21] Laminar flow in a convective radiator heating system The experimental uncertainties are $5.5 \%$ for the surface heat transfer coefficient and $10.5 \%$ for the computed values of the average Nusselt number.

[38] Turbulent flow in a confined and submerged impinging jet on a heated surface

The uncertainties in measurements of the related variables

[43] Turbulent flow in a corrugated plate heat exchanger resulted in the maximum error of $5.3 \%$ in the Reynolds number and $3.8 \%$ in the Prandtl number.

[51] Turbulent flow in a double heat exchanger Uncertainty of experimental heat transfer coefficient is about $3.4 \%$.

The transient-hot-wire method is used to measure the

[66] Laminar and turbulent flow through a circular straight tube effective thermal conductivity of the nanofluids and the measurement error is less than $1.5 \%$.

\section{Comparative Analysis of Experimental Results Carried Out in Different Campaigns}

A graphic comparison of the results of the increase in convective heat transfer coefficient, reported in several researches, has been reported in the next figures.

Figure 16 shows a comparison between the thermal performances achieved in different experimental investigations using nanofluids as working fluids, under turbulent regime, in particular for $\operatorname{Re}=8000$. The maximum enhancement in heat transfer was obtained by Arani et al. [33] using $\mathrm{TiO}_{2}$ / water nanofluid inside a horizontal double tube counterflow heat exchanger. The heated test section consisted of two concentric tubes: the inner copper tube and the outer stainless-steel tube. A straight plastic tube with the same 
internal diameter of the copper tube was used to reduce the axial heat transfer rate from the upstream and downstream test section. The test section was heated by hot water and insulated by glass wool to reduce heat loss to the ambient. The Nusselt number of nanofluid was higher than the one of the base fluid, because the nanoparticles lead to an increase of thermal conductivity and heat transfer. It increased by the increasing the Reynolds number and nanoparticle concentration in the nanofluid. The enhancement in heat transfer coefficient, achieved using $\mathrm{TiO}_{2}$ / water nanofluid, was higher than that obtained in the other experiments, with the jet impingement of $\mathrm{SiO}_{2}$ /water nanofluid [47] and graphene oxide/water nanofluid through an isothermal pipe [45]. Although, in the first case, a nanofluid with a much lower volumetric concentration than the others was used. For the particular experimental setup used by Lv et al. [47], the heat transfer coefficient increased with the increase of the jet-to-target distance, Reynolds number, and nanoparticle volume concentration, and decreased along the radial direction. It was also observed that the heat transfer coefficient enhanced with the impact angle, in fact, the highest value was obtained when the jet impinged vertically. Considering the jet-to-target distance (H/D) equal to 4 , the enhancement in convective heat transfer coefficient was approximately $15 \%$ at $\operatorname{Re}=8000$ and for nanofluid with volume concentration of $1 \%$. Both Ranjbarzadeh et al. [47] and Sahin et al. [36] investigated the characteristics of heat transfer inside a circular tube: the former using water/graphene oxide nanofluid and the latter $\mathrm{Al}_{2} \mathrm{O}_{3} /$ water nanofluid. For alumina nanofluid, the heat transfer coefficient increased by increasing the Reynolds number and the volume concentration of the nanoparticles up to $1 \%$, in fact for nanofluids with higher concentrations the heat transfer worsened. For water/graphene oxide nanofluid, a higher value of heat transfer coefficient was obtained at a lower Reynolds number and a higher particle volume concentration.

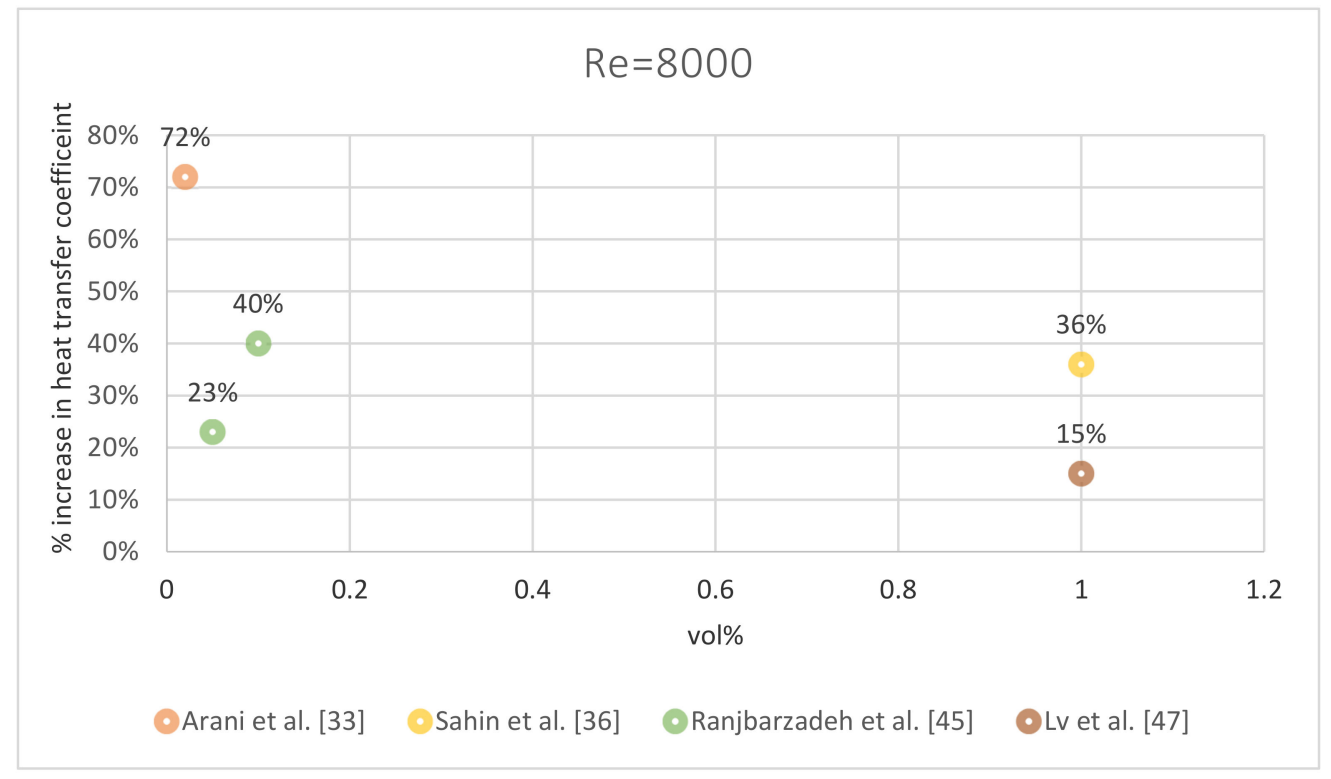

Figure 16. Graphic representation of the results obtained for nanofluids at $\operatorname{Re}=8000$.

A comparative overview of the thermal performance of the nanofluids used in various experiments showed that a greater increase in the convective heat transfer coefficient was not always obtained at high concentrations, as shown in Figure 17. Suresh et al. [41] investigated the thermal performance of $\mathrm{CuO}$ / water nanofluid inside helically dimpled tube. A straight copper tube was used as test section, which was first wounded with sun mica and then with ceramic beads coated electrical SWG nichrome heating wire. A thick insulation, consisting of layers of ceramic fiber, asbestos rope, glass wool, and another layer of asbestos rope, was provided above the electrical winding to prevent radial heat dispersion. Finally, the test section was insulated from its upstream and downstream 
sections by plastic bushings to minimize the heat loss from axial heat conduction. The enhancement in convective heat transfer coefficient of $19.49 \%, 27.06 \%$, and $39.53 \%$ for nanofluid with volume fraction concentration of $0.1 \%, 0.2 \%$, and $0.3 \%$, respectively, was obtained. A higher value was found by Zarringhalam et al. [57] using $\mathrm{CuO} /$ water nanofluid with $1 \mathrm{vol} \%$ inside a horizontal double-tube counter flow heat exchanger. The test section was heated by hot water and insulated by fiberglass. Moreover, in this case, two plastic fittings at the inlet and outlet side of test section were used to prevent the axial heat conduction. A good performance was also achieved by using $\mathrm{Fe}_{3} \mathrm{O}_{2}-\mathrm{CNT} /$ water magnetic nanofluids within a horizontal shell and tube heat exchanger, as demonstrated in the investigation by Aghaborzorg et al. [68]. On the other hand, the experimental study conducted by Kim et al. [53] showed that for higher volume concentration of alumina nanoparticles in water-based suspensions the increase in the heat transfer coefficient was lower than in previous cases. The test section was a straight seamless stainless-steel tube, which was electrically heated by a constant DC power supply to obtain a constant heat flux condition and insulated by a thick thermal insulating layer to reduce heat loss. It was found that the convective heat transfer coefficient enhanced with the increase of the Reynolds number and the nanoparticle concentration in each investigation considered.

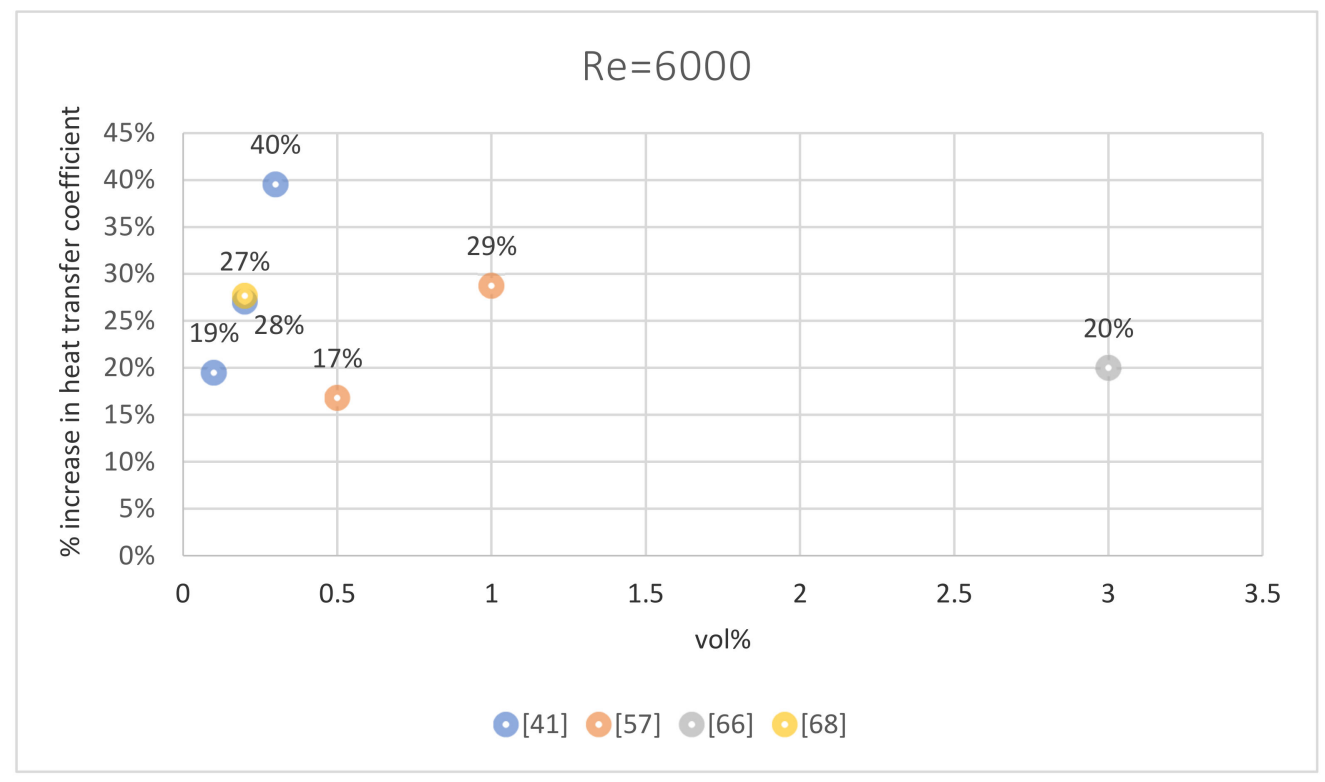

Figure 17. Graphic representation of the results obtained for nanofluids at $\operatorname{Re}=6000$.

Figure 18 shows a graphic comparison of the experimental results obtained using nanofluids inside microchannel heat sink. In this study, the characteristics of heat transfer using nanofluids in different types of experimental setups were analyzed and the thermal performances achieved were compared. The best thermal performance was achieved by Kaltel et al. [11] using $\mathrm{Al}_{2} \mathrm{O}_{3}$ /water nanofluid inside a wide rectangular microchannel heat sink made of silicon wafer with glass layers. A self-electrically insulated heater was attached to the bottom of the silicon wafer to simulate the heat flux and a thermal insulation layer. The whole system was placed in Teflon housing to insulate the test section. It was found that the average Nusselt number increased by increasing the Reynolds number and nanoparticle volume concentration due to higher convective effects. In particular, the enhancement in the Nusselt number was $130 \%$ for nanofluid with a nanoparticle volume concentration of $3 \%$ at $\mathrm{Re}=500$. Moreover, Ho et al. [3] used $\mathrm{Al}_{2} \mathrm{O}_{3} /$ water nanofluid as working fluid in a microchannel heat sink. In this case, twenty-four parallel rectangular mini-channels were machined into an oxygen-free copper block to form the heat sink. The heat input was provided by a plate heater, which was placed close to the test section. To prevent heat loss, a heater guard was installed parallel to the rear surface of the main heater. 
Results showed that the increase in the average Nusselt number was approximately $40 \%$ and $53 \%$ for nanofluids with a $1 \%$ nanoparticle volume concentration at $\operatorname{Re}=332$ and 1641 , respectively. For the nanofluid containing $2 \%$ alumina, there was a significant increase in the Nusselt number, only for the Reynolds number above 775 .

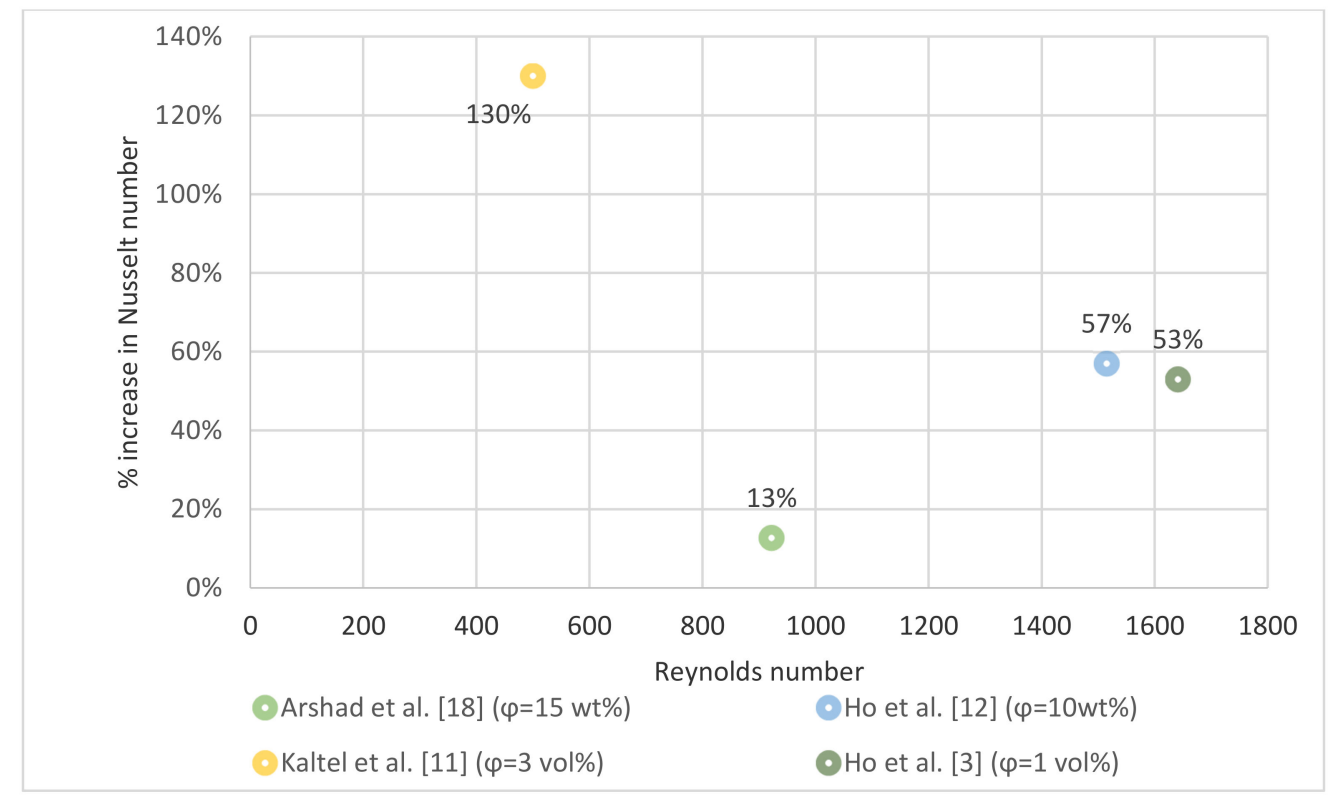

Figure 18. Graphic comparison of the experimental results obtained using nanofluids inside microchannel heat sink.

Another investigation was conducted by Ho et al. [12] using the same nanofluid in a similar experimental setup, that differed from the previous one as it consisted of ten parallel mini rectangular channels. Significant enhancements in the average Nusselt number using nanofluid as working fluid instead of pure water were found. The heat transfer coefficient increased by increasing the nanoparticle weight fraction, which reached a virtual maximum value of $6 \%$. Further increase in nanoparticle weight concentration did not affect the heat transfer. Arshad et al. [18] investigated the heat transfer effects of $\mathrm{TiO}_{2} /$ water nanofluid flow in a copper mini-channel heat sink, which was used as a simulated microprocessor. Three cartridge heaters, each of $200 \mathrm{~W}$ maximum power, were placed at the bottom of the heat sink to guarantee an equal distribution of heat. The results indicated that $\mathrm{TiO}_{2} /$ water nanofluid thermal performance was strongly dependent on heating power and the heat transfer coefficient had better value at lower heating power. The maximum enhancement in the Nusselt number of $12.75 \%$ was found for nanofluid with $15 \mathrm{wt} \%$ at heating power of $100 \mathrm{~W}$ and $\mathrm{Re}=922$. Furthermore, Sarafraz et al. [20] conducted an experimental study on the thermal performance of $\mathrm{AgO} /$ water nanofluid inside a copper heat sink with seven rectangular section microchannels as well. To supply the required heater, five cartridge heaters were placed inside the copper heater block, which contained the heat sink. In order to reduce heat loss, the heater block was wrapped with glass wool. Results showed that with an increase in the flow rate and mass concentration of nanofluid, the heat transfer coefficient increased. For nanofluid with particle weight fraction of $0.05 \%$ at $\operatorname{Re}=1400$, an enhancement in thermal performance of $37 \%$ was obtained. It was found that the highest value of the heat transfer coefficient was obtained for the entrance region and decreased along with the length, due to the viscous forces that occurred between the fluid layers and the wall surface, and between the adjacent layers of fluid. Overall, the synthesized silver/water nanofluid could be considered as a promising coolant to be used in a microchannel heat sink.

The results of several studies on the heat transfer characteristics of $\mathrm{Al}_{2} \mathrm{O}_{3}$ /water nanofluid in laminar regime are shown in Figure 19. The highest enhancement in convective 
heat transfer coefficient of $70 \%$ was found by Ho et al. [3] using $\mathrm{Al}_{2} \mathrm{O}_{3}$ /water nanofluid, with a volume concentration of $1 \%$ in microchannel heat sink. It was observed that, at the same volume concentration of nanoparticles, in solar thermal collectors, the increase in heat transfer improvement was $12 \%$. Generally, the heat transfer increased with the increases of the Reynolds number and volumetric nanoparticle concentration. Despite this, the increase in the heat exchange coefficient obtained by Heyat et al. [9] in a straight copper tube and Colangelo et al. [69] in solar systems, at a higher Reynolds number and nanoparticle volume concentration, was less than that achieved in the previous case and by Ho et al. [12]. The experimental systems studied by Ho et al. $[3,12]$ were also compared in Figure 16. Finally, Hwang et al. [2] demonstrated that, with a very low volume concentration of nanoparticles, a better thermal performance was obtained using alumina nanofluid compared to water.



Figure 19. Graphic comparison of the experimental results obtained using $\mathrm{Al}_{2} \mathrm{O}_{3}$ /water nanofluid in laminar regime.

\section{Conclusions}

Nanofluids are considered innovative heat transfer fluids that can be used in cooling and heating systems and have numerous applications in the automotive, manufacturing, microelectronics, energy, and industrial sectors due to their superior heat transfer characteristics. In this review study, a comparison of the results of different research studies was made. Here are some concluding remarks:

- Experimental findings demonstrate that the heat transfer enhancements of nanofluids are highly dependent on the volumetric concentration of nanoparticles. Only in some cases, an opposite trend was observed: a limit value of the Reynolds number or concentration is reached, beyond which the heat transport decreases or shows no improvement.

- The reason for the heat transfer enhancement of nanofluids included many issues, such as the mixing effects of nanoparticles near the wall, thermal conductivity enhancement, Brownian motion of particles, particle shape, and particle migration.

- The enhancement in heat transfer coefficient depends on the boundary conditions, fluid inlet temperature, and heating power. Considering certain setups, the heat transport also depends on the geometric configuration of the experimental system.

- The experimental setup configuration and boundary conditions of the test have a great influence on the experimental results with big data dispersion. 
Author Contributions: Conceptualization, G.C., M.M., A.d.R., G.S.; formal analysis, G.C., N.F.D. and M.M.; methodology, G.C., G.S.; resources, A.d.R., G.S.; supervision, G.C.; writing-original draft, G.C. and N.F.D.; writing-review and editing, G.C., N.F.D. and M.M. All authors have read and agreed to the published version of the manuscript.

Funding: This research received no external funding.

Institutional Review Board Statement: Not applicable.

Informed Consent Statement: Not applicable.

Data Availability Statement: Not applicable.

Conflicts of Interest: The authors declare no conflict of interest.

$\begin{array}{ll}\text { Nomenclature } \\ \text { BPHE } & \begin{array}{l}\text { brazed plate heat exchanger } \\ \text { diameter (mm) }\end{array} \\ \text { D } & \text { Deborah number } \\ \text { De } & \text { double-walled carbon nanotubes } \\ \text { DWCNT } & \text { graphene nanoplatelet } \\ \text { GNP } & \text { microchannel heat sink } \\ \text { MCHS } & \text { multi walled carbon nanotube } \\ \text { MWCNT } & \text { Nusselt number } \\ \text { Nu } & \text { propeller pitch } \\ \text { p } & \text { Péclet number } \\ \text { Pe } & \text { proportion integration derivative } \\ \text { PID } & \text { Prandtl number } \\ \text { Pr } & \text { Rayleigh number } \\ \text { Ra } & \text { Reynolds number } \\ \text { Re } & \text { resistance temperature detector } \\ \text { RTD } & \text { thickness (mm) } \\ \text { s } & \text { solenoid valve } \\ \text { SV } & \text { thermal interface material } \\ \text { TIM } & \text { volume fraction } \\ \text { vol } & \text { weight fraction } \\ \text { wt } & \end{array}$

\section{References}

1. Heris, S.Z.; Esfahany, M.N.; Etemad, S. Experimental investigation of convective heat transfer of $\mathrm{Al}_{2} \mathrm{O}_{3} /$ water nanofluid in circular tube. Int. J. Heat Fluid Flow 2007, 28, 203-210. [CrossRef]

2. Hwang, K.S.; Jang, S.P.; Choi, S.U. Flow and convective heat transfer characteristics of water-based $\mathrm{Al}_{2} \mathrm{O}_{3}$ nanofluids in fully developed laminar flow regime. Int. J. Heat Mass Transf. 2009, 52, 193-199. [CrossRef]

3. Ho, C.J.; Wei, L.; Li, Z. An experimental investigation of forced convective cooling performance of a microchannel heat sink with $\mathrm{Al}_{2} \mathrm{O}_{3}$ /water nanofluid. Appl. Therm. Eng. 2010, 30, 96-103. [CrossRef]

4. Ho, C.J.; Liu, W.; Chang, Y.; Lin, C. Natural convection heat transfer of alumina-water nanofluid in vertical square enclosures: An experimental study. Int. J. Therm. Sci. 2010, 49, 1345-1353. [CrossRef]

5. Chandrasekar, M.; Suresh, S.; Bose, A.C. Experimental studies on heat transfer and friction factor characteristics of $\mathrm{Al}_{2} \mathrm{O}_{3} / \mathrm{water}$ nanofluid in a circular pipe under laminar flow with wire coil inserts. Exp. Therm. Fluid Sci. 2010, 34, 122-130. [CrossRef]

6. Mansour, R.B.; Galanis, N.; Nguyen, C.T. Experimental study of mixed convection with water $\mathrm{Al}_{2} \mathrm{O}_{3}$ nanofluid in inclined tube with uniform wall heat flux. Int. J. Therm. Sci. 2011, 50, 403-410. [CrossRef]

7. Saeedinia, M.; Akhavan-Behabadi, M.; Nasr, M. Experimental study on heat transfer and pressure drop of nanofluid flow in a horizontal coiled wire inserted tube under constant heat flux. Exp. Therm. Fluid Sci. 2012, 36, 158-168. [CrossRef]

8. Suresh, S.; Venkitaraj, K.P.; Selvakumar, P.; Chandrasekar, M. Effect of $\mathrm{Al}_{2} \mathrm{O}_{3}-\mathrm{Cu}$ /water hybrid nanofluid in heat transfer. Exp. Therm. Fluid Sci. 2012, 38, 54-60. [CrossRef]

9. Heyhat, M.; Kowsary, F.; Rashidi, A.; Momenpour, M.; Amrollahi, A. Experimental investigation of laminar convective heat transfer and pressure drop of water-based $\mathrm{Al}_{2} \mathrm{O}_{3}$ nanofluids in fully developed flow regime. Exp. Therm. Fluid Sci. 2013, 44, 483-489. [CrossRef]

10. Hashemi, S.; Akhavan-Behabadi, M. An empirical study on heat transfer and pressure drop characteristics of CuO-base oil nanofluid flow in a horizontal helically coiled tube under constant heat flux. Int. Commun. Heat Mass Transf. 2012, 39, 144-151. [CrossRef] 
11. Kalteh, M.; Abbassi, A.; Saffar-Avval, M.; Frijns, A.J.; Darhuber, A.; Harting, J. Experimental and numerical investigation of nanofluid forced convection inside a wide microchannel heat sink. Appl. Therm. Eng. 2012, 36, 260-268. [CrossRef]

12. Ho, C.J.; Chen, W. An experimental study on thermal performance of $\mathrm{Al}_{2} \mathrm{O}_{3}$ /water nanofluid in a minichannel heat sink. Appl. Therm. Eng. 2013, 50, 516-522. [CrossRef]

13. Hu, Y.; He, Y.; Qi, C.; Jiang, B.; Schlaberg, H.I. Experimental and numerical study of natural convection in a square enclosure filled with nanofluid. Int. J. Heat Mass Transf. 2014, 78, 380-392. [CrossRef]

14. Hussein, A.M.; Bakar, R.; Kadirgama, K. Study of forced convection nanofluid heat transfer in the automotive cooling system. Case Stud. Therm. Eng. 2014, 2, 50-61. [CrossRef]

15. Derakhshan, M.; Akhavan-Behabadi, M.; Mohseni, S. Experiments on mixed convection heat transfer and performance evaluation of MWCNT-Oil nanofluid flow in horizontal and vertical microfin tubes. Exp. Therm. Fluid Sci. 2015, 61, 241-248. [CrossRef]

16. Barzegarian, R.; Moraveji, M.K.; Aloueyan, A. Experimental investigation on heat transfer characteristics and pressure drop of BPHE (brazed plate heat exchanger) using $\mathrm{TiO}_{2}$-water nanofluid. Exp. Therm. Fluid Sci. 2016, 74, 11-18. [CrossRef]

17. Ebrahimnia-Bajestan, E.; Moghadam, M.C.; Niazmand, H.; Daungthongsuk, W.; Wongwises, S. Experimental and numerical investigation of nanofluids heat transfer characteristics for application in solar heat exchangers. Int. J. Heat Mass Transf. 2016, 92, 1041-1052. [CrossRef]

18. Arshad, W.; Ali, H.M. Experimental investigation of heat transfer and pressure drop in a straight minichannel heat sink using $\mathrm{TiO}_{2}$ nanofluid. Int. J. Heat Mass Transf. 2017, 110, 248-256. [CrossRef]

19. Bhanvase, B.A.; Sayankar, S.D.; Kapre, A.; Fule, P.J.; Sonawane, S.H. Experimental investigation on intensified convective heat transfer coefficient of water based PANI fluid in vertical helical coiled heat exchanger. Appl. Therm. Eng. 2018, 128, 134-140. [CrossRef]

20. Sarafraz, M.; Nikkhah, V.; Nakhjavani, M.; Arya, A. Thermal performance of a heat sink microchannel working with biologically produced silver-water nanofluid: Experimental assessment. Exp. Therm. Fluid Sci. 2018, 91, 509-519. [CrossRef]

21. Sarafraz, M.M.; Baghi, A.D.; Safaei, M.R.; Leon, A.S.; Ghomashchi, R.; Goodarzi, M.; Lin, C.-X. Assessment of Iron Oxide (III)-Therminol 66 Nanofluid as a Novel Working Fluid in a Convective Radiator Heating System for Buildings. Energies 2019, 12, 4327. [CrossRef]

22. Shajahan, M.I.; Micheal, J.J.; Arulprakasajothi, M.; Suresh, S.; Nasr, E.A.; Hussein, H.M.A. Effect of conical strip inserts and $\mathrm{ZrO}_{2}$ /DI-water nanofluid on heat transfer augmentation: An experimental study. Energies 2020, 13, 4554. [CrossRef]

23. Asirvatham, L.G.; Vishal, N.; Gangatharan, S.K.; Lal, D.M. Experimental Study on Forced Convective Heat Transfer with Low Volume Fraction of CuO/Water Nanofluid. Energies 2009, 2, 97-119. [CrossRef]

24. Naddaf, A.; Heris, S.Z.; Pouladi, B. An experimental study on heat transfer performance and pressure drop of nanofluids using graphene and multi-walled carbon nanotubes based on diesel oil. Powder Technol. 2019, 352, 369-380. [CrossRef]

25. Sheikhadeh, G.A.; Fakaihari, M.M.; Khorasanizadeh, H. Experimental investigation of laminar convection heat transfer of $\mathrm{Al}_{2} \mathrm{O}_{3}$ -Ethylene Glycol-Water Nanofluid as a coolant in a Car radiator. J. Appl. Fluid Mech. 2017, 10, $209-219$.

26. Qasim, M.; Kamran, M.S.; Ammar, M.; Jamal, M.A.; Javaid, M.Y. Heat Transfer Enhancement of an Automobile Engine Radiator using ZnO Water Base Nanofluids. J. Therm. Sci. 2020, 29, 1010-1024. [CrossRef]

27. Yıldız, O.; Açıkgöz, Ö.; Yıldız, G.; Bayrak, M.; Dalkılıç, A.S.; Wongwises, S. Single phase flow of nanofluid including graphite and water in a microchannel. Heat Mass Transf. 2019, 56, 1-24. [CrossRef]

28. Baghban, A.; Sasanipour, J.; Pourfayaz, F.; Ahmadi, M.H.; Kasaeian, A.; Chamkha, A.J.; Oztop, H.F.; Chau, K.-W. Towards experimental and modeling study of heat transfer performance of water- $\mathrm{SiO}_{2}$ nanofluid in quadrangular cross-section channels. Eng. Appl. Comput. Fluid Mech. 2019, 13, 453-469. [CrossRef]

29. Rahimi, A.; Kasaeipoor, A.; Malekshah, E.H.; Kolsi, L. Experimental and numerical study on heat transfer performance of three-dimensional natural convection in an enclosure filled with DWCNTs-water nanofluid. Powder Technol. 2017, 322, 340-352. [CrossRef]

30. Sajedi, R.; Jafari, M.; Nasirivatan, S.; Osanloo, B. An experimental study on the proper criterion to judge the thermal performance of the nanofluids. Int. Commun. Heat Mass Transf. 2017, 82, 20-28. [CrossRef]

31. Phanindra, Y.; Kumar, S.D.; Pugazhendhi, S. Experimental Investigation on $\mathrm{Al}_{2} \mathrm{O}_{3}-\mathrm{Cu}$ /Oil Hybrid Nanofluid using Concentric Tube Heat Exchanger. Mater. Today Proc. 2018, 5, 12142-12150. [CrossRef]

32. Akram, N.; Montazer, E.; Kazi, S.; Soudagar, M.E.M.; Ahmed, W.; Zubir, M.N.M.; Afzal, A.; Muhammad, M.R.; Ali, H.M.; Márquez, F.P.G.; et al. Experimental investigations of the performance of a flat-plate solar collector using carbon and metal oxides based nanofluids. Energy 2021, 227, 120452. [CrossRef]

33. Ahmed, F.; Khan, W.A. Efficiency enhancement of an air-conditioner utilizing nanofluids: An experimental study. Energy Rep. 2021, 7, 575-583. [CrossRef]

34. Ibrahim, M.; Algehyne, E.A.; Saeed, T.; Berrouk, A.S.; Chu, Y.-M.; Cheraghian, G. Assessment of economic, thermal and hydraulic performances a corrugated helical heat exchanger filled with non-Newtonian nanofluid. Sci. Rep. 2021, 11, 11568. [CrossRef]

35. Askari, S.; Rashidi, A.; Koolivand, H. Experimental investigation on the thermal performance of ultra-stable kerosene-based MWCNTs and Graphene nanofluids. Int. Commun. Heat Mass Transf. 2019, 108, 104334. [CrossRef]

36. Saghir, M.Z.; Welsford, C. Forced Convection in Porous Media Using $\mathrm{Al}_{2} \mathrm{O}_{3}$ and $\mathrm{TiO}_{2}$ Nanofluids in Differing Base Fluids. Energies 2020, 13, 2665. [CrossRef] 
37. Selvakumar, P.; Suresh, S. Use of $\mathrm{Al}_{2} \mathrm{O}_{3}-\mathrm{Cu}$ water hybrid nanofluid in an electronic heat sink. IEEE Trans. Compon. Packag. Manuf. Technol. 2012, 2, 1600-1607. [CrossRef]

38. Nguyen, C.T.; Galanis, N.; Polidori, G.; Fohanno, S.; Popa, C.V.; Le Bechec, A. An experimental study of a confined and submerged impinging jet heat transfer using $\mathrm{Al}_{2} \mathrm{O}_{3}$-water nanofluid. Int. J. Therm. Sci. 2009, 48, 401-411. [CrossRef]

39. Fotukian, S.; Esfahany, M.N. Experimental study of turbulent convective heat transfer and pressure drop of dilute CuO/water nanofluid inside a circular tube. Int. Commun. Heat Mass Transf. 2010, 37, 214-219. [CrossRef]

40. Zamzamian, A.; Oskouie, S.N.; Doosthoseini, A.; Joneidi, A.; Pazouki, M. Experimental investigation of forced convective heat transfer coefficient in nanofluids of $\mathrm{Al}_{2} \mathrm{O}_{3} / \mathrm{EG}$ and $\mathrm{CuO} / \mathrm{EG}$ in a double pipe and plate heat exchangers under turbulent flow. Exp. Therm. Fluid Sci. 2011, 35, 495-502. [CrossRef]

41. Suresh, S.; Chandrasekar, M.; Sekhar, S.C. Experimental studies on heat transfer and friction factor characteristics of CuO/water nanofluid under turbulent flow in a helically dimpled tube. Exp. Therm. Fluid Sci. 2011, 35, 542-549. [CrossRef]

42. Sundar, L.S.; Naik, M.; Sharma, K.V.; Singh, M.; Reddy, T.S. Experimental investigation of forced convection heat transfer and friction factor in a tube with $\mathrm{Fe}_{3} \mathrm{O}_{4}$ magnetic nanofluid. Exp. Therm. Fluid Sci. 2012, 37, 65-71. [CrossRef]

43. Pandey, S.D.; Nema, V.K. Experimental analysis of heat transfer and friction factor of nanofluid as a coolant in a corrugated plate heat exchanger. Exp. Therm. Fluid Sci. 2012, 38, 248-256. [CrossRef]

44. Selvakumar, P.; Suresh, S. Convective performance of $\mathrm{CuO} /$ water nanofluid in an electronic heat sink. Exp. Therm. Fluid Sci. 2012, 40, 57-63. [CrossRef]

45. Kannadasan, N.; Ramanathan, K.; Suresh, S. Comparison of heat transfer and pressure drop in horizontal and vertical helically coiled heat exchanger with $\mathrm{CuO}$ /water based nanofluid. Exp. Therm. Fluid Sci. 2012, 42, 64-70. [CrossRef]

46. Arani, A.A.A.; Amani, J. Experimental study on the effect of $\mathrm{TiO}_{2}$-water nanofluid on heat transfer and pressure drop. Exp. Therm. Fluid Sci. 2012, 42, 107-115. [CrossRef]

47. Hajian, R.; Layeghi, M.; Sani, K.A. Experimental study of nanofluid effects on the thermal performance with response time of heat pipe. Energy Convers. Manag. 2012, 56, 63-68. [CrossRef]

48. Arani, A.A.A.; Amani, J. Experimental investigation of diameter effect on heat transfer performance and pressure drop of $\mathrm{TiO}_{2}$-water nanofluid. Exp. Therm. Fluid Sci. 2013, 44, 520-533. [CrossRef]

49. Sahin, B.; Gültekin, G.G.; Manay, E.; Karagoz, S. Experimental investigation of heat transfer and pressure drop characteristics of $\mathrm{Al}_{2} \mathrm{O}_{3}$-water nanofluid. Exp. Therm. Fluid Sci. 2013, 50, 21-28. [CrossRef]

50. Azmi, W.; Sharma, K.V.; Sarma, P.; Mamat, R.; Anuar, S.; Rao, V.D. Experimental determination of turbulent forced convection heat transfer and friction factor with $\mathrm{SiO}_{2}$ nanofluid. Exp. Therm. Fluid Sci. 2013, 51, 103-111. [CrossRef]

51. Darzi, A.R.; Farhadi, M.; Sedighi, K. Heat transfer and flow characteristics of $\mathrm{AL}_{2} \mathrm{O}_{3}-$ water nanofluid in a double tube heat exchanger. Int. Commun. Heat Mass Transf. 2013, 47, 105-112. [CrossRef]

52. Sundar, L.S.; Singh, M.K.; Sousa, A. Enhanced heat transfer and friction factor of $\mathrm{MWCNT}-\mathrm{Fe}_{3} \mathrm{O}_{4} /$ water hybrid nanofluids. Int. Commun. Heat Mass Transf. 2014, 52, 73-83. [CrossRef]

53. Eiamsa-Ard, S.; Kiatkittipong, K.; Jedsadaratanachai, W. Heat transfer enhancement of $\mathrm{TiO}_{2} /$ water nanofluid in a heat exchanger tube equipped with overlapped dual twisted-tapes. Eng. Sci. Technol. Int. J. 2015, 18, 336-350. [CrossRef]

54. Esfe, M.H.; Saedodin, S. Turbulent forced convection heat transfer and thermophysical properties of Mgo-water nanofluid with consideration of different nanoparticles diameter, an empirical study. J. Therm. Anal. Calorim. 2015, 119, 1205-1213. [CrossRef]

55. Ali, H.M.; Ali, H.; Liaquat, H.; Maqsood, H.T.B.; Nadir, M.A. Experimental investigation of convective heat transfer augmentation for car radiator using ZnO-water nanofluids. Energy 2015, 84, 317-324. [CrossRef]

56. Sadeghinezhad, E.; Togun, H.; Mehrali, M.; Nejad, P.S.; Latibari, S.T.; Abdulrazzaq, T.; Kazi, S.; Metselaar, H.S.C. An experimental and numerical investigation of heat transfer enhancement for graphene nanoplatelets nanofluids in turbulent flow conditions. Int. J. Heat Mass Transf. 2015, 81, 41-51. [CrossRef]

57. Zarringhalam, M.; Karimipour, A.; Toghraie, D. Experimental study of the effect of solid volume fraction and Reynolds number on heat transfer coefficient and pressure drop of CuO-water nanofluid. Exp. Therm. Fluid Sci. 2016, 76, 342-351. [CrossRef]

58. Ranjbarzadeh, R.; Karimipour, A.; Afrand, M.; Isfahani, A.H.M.; Shirneshan, A. Empirical analysis of heat transfer and friction factor of water/graphene oxide nanofluid flow in turbulent regime through an isothermal pipe. Appl. Therm. Eng. 2017, 126, 538-547. [CrossRef]

59. Azmi, W.; Sharma, K.V.; Sarma, P.; Mamat, R.; Anuar, S. Comparison of convective heat transfer coefficient and friction factor of $\mathrm{TiO}_{2}$ nanofluid flow in a tube with twisted tape inserts. Int. J. Therm. Sci. 2014, 81, 84-93. [CrossRef]

60. Lv, J.; Hu, C.; Bai, M.; Zeng, K.; Chang, S.; Gao, D. Experimental investigation of free single jet impingement using $\mathrm{SiO}_{2}$-water nanofluid. Exp. Therm. Fluid Sci. 2017, 84, 39-46. [CrossRef]

61. Sheikholeslami, M.; Darzi, M.; Sadoughi, M. Heat transfer improvement and pressure drop during condensation of refrigerantbased nanofluid; an experimental procedure. Int. J. Heat Mass Transf. 2018, 122, 643-650. [CrossRef]

62. Subramani, J.; Nagarajan, P.; Mahian, O.; Sathyamurthy, R. Efficiency and heat transfer improvements in a parabolic trough solar collector using $\mathrm{TiO}_{2}$ nanofluids under turbulent flow regime. Renew. Energy 2018, 119, 19-31. [CrossRef]

63. Said, Z.; Rahman, S.; Assad, M.E.H.; Alami, A.H. Heat transfer enhancement and life cycle analysis of a Shell-and-Tube Heat Exchanger using stable CuO/water nanofluid. Sustain. Energy Technol. Assess. 2019, 31, 306-317. [CrossRef] 
64. Ahmed, W.; Chowdhury, Z.Z.; Kazi, S.; Johan, M.; Badruddin, I.; Soudagar, M.; Kamangar, S.; Mujtaba, M.; Gul, M.; Khan, T. Evaluation on Enhanced Heat Transfer Using Sonochemically Synthesized Stable Zno-Eg@Dw Nanofluids in Horizontal Calibrated Circular Flow Passage. Energies 2021, 14, 2400. [CrossRef]

65. Esmaeilzadeh, A.; Silakhori, M.; Ghazali, N.N.N.; Metselaar, H.S.C.; Bin Mamat, A.; Sanjani, M.S.N.; Iranmanesh, S. Thermal Performance and Numerical Simulation of the 1-Pyrene Carboxylic-Acid Functionalized Graphene Nanofluids in a Sintered Wick Heat Pipe. Energies 2020, 13, 6542. [CrossRef]

66. Kim, D.; Kwon, Y.; Cho, Y.; Li, C.; Cheong, S.; Hwang, Y.; Lee, J.; Hong, D.; Moon, S. Convective heat transfer characteristics of nanofluids under laminar and turbulent flow conditions. Curr. Appl. Phys. 2009, 9, e119-e123. [CrossRef]

67. Ahmed, M.; Yusoff, M.; Ng, K.C.; Shuaib, N. Numerical and experimental investigations on the heat transfer enhancement in corrugated channels using $\mathrm{SiO}_{2}$-water nanofluid. Case Stud. Therm. Eng. 2015, 6, 77-92. [CrossRef]

68. Aghabozorg, M.H.; Rashidi, A.; Mohammadi, S. Experimental investigation of heat transfer enhancement of $\mathrm{Fe}_{2} \mathrm{O}_{3}-$ $\mathrm{CNT}$ / water magnetic nanofluids under laminar, transient and turbulent flow inside a horizontal shell and tube heat exchanger. Exp. Therm. Fluid Sci. 2016, 72, 182-189. [CrossRef]

69. Colangelo, G.; Favale, E.; de Risi, A.; Laforgia, D. A new solution for reduced sedimentation flat panel solar thermal collector using nanofluids. Appl. Energy 2013, 111, 80-93. [CrossRef]

70. El-Kaddadi, L.; Asbik, M.; Zari, N.; Zeghmati, B. Experimental study of the sensible heat storage in the water/TiO 2 nanofluid enclosed in annular space. Appl. Therm. Eng. 2017, 122, 673-684. [CrossRef]

71. Wen, T.; Zhu, G.; Jiao, K.; Lu, L. Experimental study on the thermal and flow characteristics of ZnO/water nanofluid in mini-channels integrated with GA-optimized ANN prediction and CFD simulation. Int. J. Heat Mass Transf. 2021, 178, 121617. [CrossRef] 